University of Arkansas, Fayetteville

ScholarWorks@UARK

Graduate Theses and Dissertations

$12-2014$

\title{
Antibacterial Activity of Commercially Available Plant Extracts on Selected Campylobacter jejuni Strains
}

Divya Oppath Sivasankaran

University of Arkansas, Fayetteville

Follow this and additional works at: https://scholarworks.uark.edu/etd

Part of the Bacteriology Commons, and the Food Microbiology Commons

\section{Citation}

Sivasankaran, D. O. (2014). Antibacterial Activity of Commercially Available Plant Extracts on Selected Campylobacter jejuni Strains. Graduate Theses and Dissertations Retrieved from https://scholarworks.uark.edu/etd/2115

This Thesis is brought to you for free and open access by ScholarWorks@UARK. It has been accepted for inclusion in Graduate Theses and Dissertations by an authorized administrator of ScholarWorks@UARK. For more information, please contact scholar@uark.edu. 
Antibacterial Activity of Commercially Available Plant Extracts on Selected Campylobacter jejuni Strains 
Antibacterial Activity of Commercially Available Plant Extracts on Selected Campylobacter jejuni Strains

A thesis submitted in partial fulfillment of the requirements for the degree of Master of Science in Poultry Science

\section{By}

Divya Oppath Sivasankaran Visvesvaraya Technological University Bachelor of Technology in Biotechnology, 2007 Anna University Master of Technology in Biotechnology, 2010

December 2014

University of Arkansas

This thesis is approved for recommendation to the Graduate Council

Dr. Michael F. Slavik

Thesis Director

Dr. John Marcy

Committee Member
Dr. Narayan C. Rath

Committee Member 


\begin{abstract}
Campylobacter jejuni is recognized as a leading cause of foodborne illness worldwide with approximately 850,000 cases per year in the United Sates. A total of 18 species of Campylobacter have been identified worldwide to date. Foodborne transmission of C. jejuni is mainly through the consumption of unpasteurized milk, contaminated poultry meat and water. $C$. jejuni can survive in very diverse environments under stressful conditions in human and animals which is different from the specific conditions and media required in laboratory experiments. There has been increased research in recent years to identify naturally occurring antibacterial agents to control and eliminate $C$. jejuni on poultry. This study involves the evaluation of commercially available plant extracts of oregano, green tea and hawthorn to reduce /eliminate $C$. jejuni on poultry. Four isolates of $C$. jejuni, one human and three poultry isolates were used in this study. Research was done in broth culture to determine the effects of these extracts at different concentrations on the 4 isolates using cell counts at regular intervals of 0, 1, 2, 4 and 24 hours post-treatment. Results indicated that oregano and green tea were the most antibacterial and killed all the bacteria in broth culture in 24 hours at all concentrations tested. No significant differences were observed on the action of each of these plant extracts on the different isolates. Hawthorn was not successful in killing any of the strains of $C$. jejuni in 24 hours and no significant difference in cell counts post-treatment was observed compared to the control. The effects of these plant extracts then were tested as marinades on chicken breast fillets. The results showed that higher concentrations were required in the meat model study as compared to broth studies to completely kill all the bacteria. In the marinade studies, oregano was found to be the most effective, killing all 81176 and PRCC isolates in 2 hours and all the POCC and RECC C. jejuni isolates in 6 hours. The extracts of green tea and hawthorn tested were unsuccessful in
\end{abstract}


killing the $C$. jejuni isolates within 24 hours at all tested concentrations. The results of this study indicate the potential of using oregano extracts as antimicrobial against $C$. jejuni on poultry. 


\section{ACKNOWLEDGEMENTS}

I am pleased to thank and express my sincere gratitude to my supervisor, Dr. Michael. F. Slavik for his guidance, patience, encouragement during the entire graduate program. I am also grateful to my committee members Dr. Narayan C. Rath and Dr. John Marcy for their valuable comments and inputs during the completion of this research.

I would like to specially thank Dr. Geetha Kumar-Phillips for supporting, teaching and helping me with ideas without which this thesis would not have taken shape. I would also like to thank Dr. Komala Arsi and Ann Wooming for their kind support during my research work.

Last, but definitely not least, I would like to thank my parents and my husband who encouraged and believed in me throughout this endeavor. 


\section{DEDICATION}

I would like to dedicate this work to my husband, Dr. Pradeep Nambiath for believing in me constantly motivating my journey towards the completion of this thesis. 


\section{TABLE OF CONTENTS}

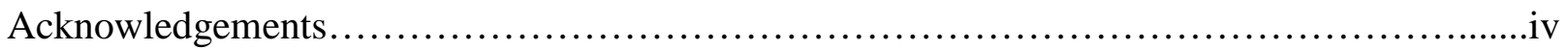

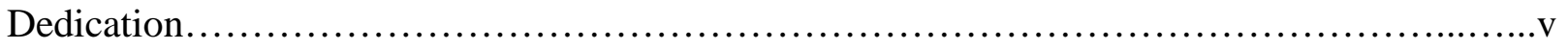

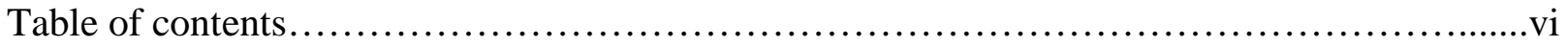

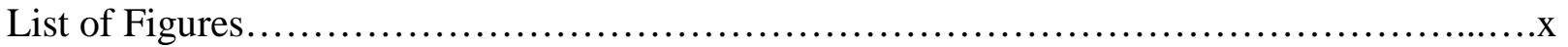

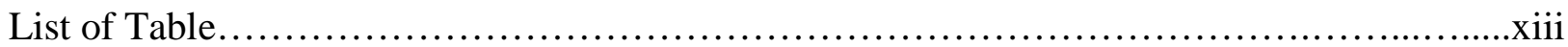

\section{CHAPTER 1}

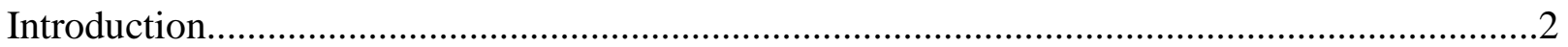

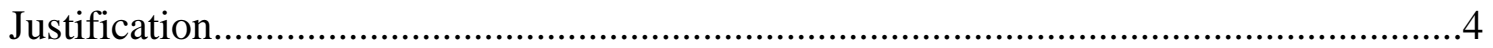

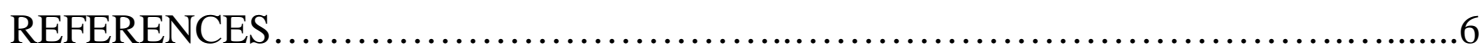

\section{CHAPTER 2}

Literature review

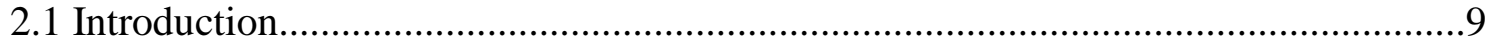

2.2 History and Taxonomy of Campylobacter.......................................................9

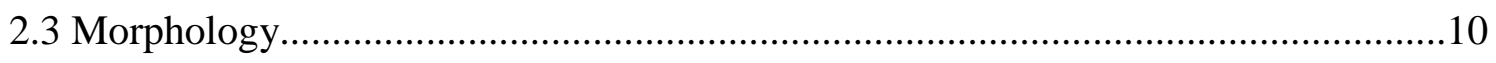

2.4 Pathogenesis...........................................................

2.4.1. Mechanism of pathogenesis......................................11

2.4.2. Toxin production by Campylobacter...............................12

2.4.3. Clinical manifestation....................................................................13

2.4.3.1. Gullian-Barré syndrome.....................................................13 


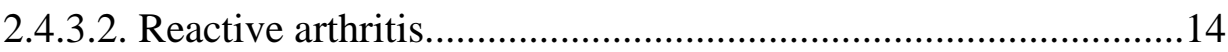

2.4.3.3. Campylobacter resistance mechanism..........................................14

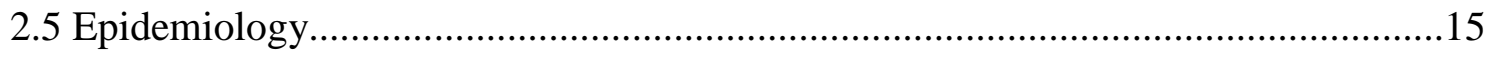

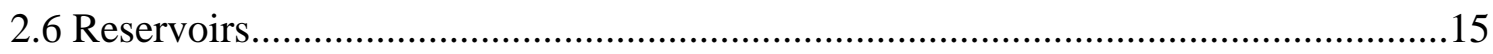

2.7 Growth conditions for Campylobacter ...................................................................16

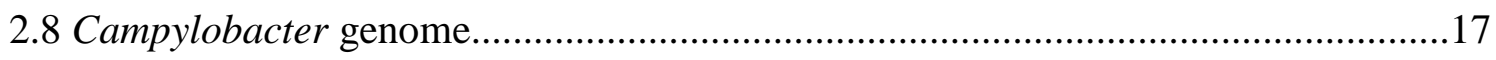

2.9 Prevention and control of Campylobacter in poultry................................................17

2.9.1. Pre-harvest control..................................................................................17

2.9.1.1. Biosecurity................................................................................18

2.9.1.2. Water treatment...........................................................................19

2.9.1.3. Vaccination..................................................................................19

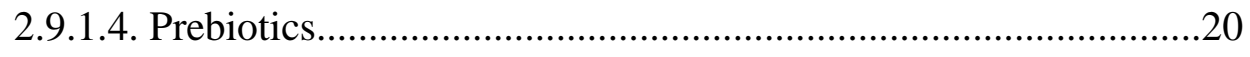

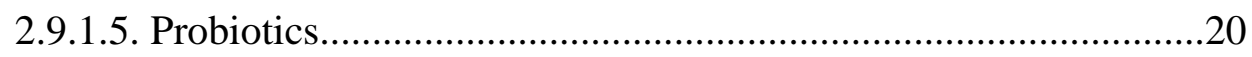

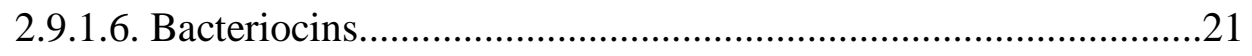

2.9.1.7. Bacteriophage...............................................................................21

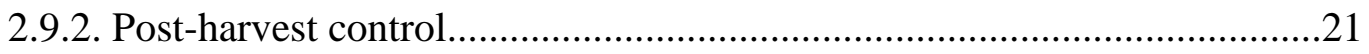

2.9.2.1. Preservation of fresh meat...........................................................21

2.9.2.2. Natural antimicrobials for the control of Campylobacter in

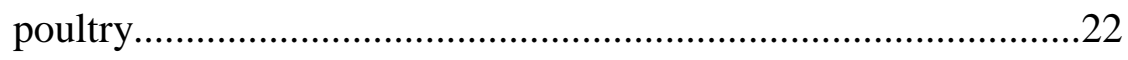

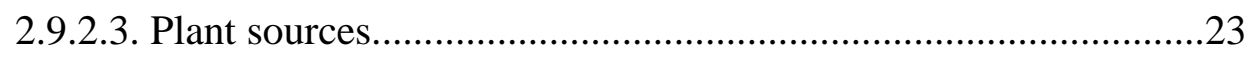

2.9.2.4. Spices and Essential Oils...............................................................23

Mechanism of antimicrobial action.....................................24

2.9.2.5. Essential Oil in Hurdle technology..............................................25

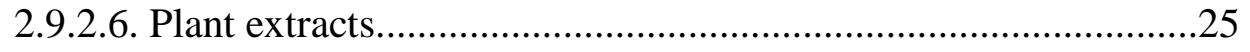

Oregano................................................................ . 25 
Hawthorn.................................................................30

Curcumin..................................................................32

2.9.2.7. Effect of plant antimicrobial marinade on survival of

Campylobacter in meat.........................................................33

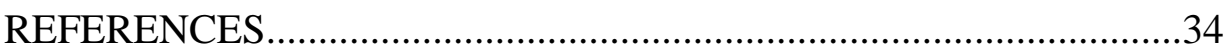

\section{CHAPTER 3}

Antibacterial activity of commercially available plant extracts on selected Campylobacter

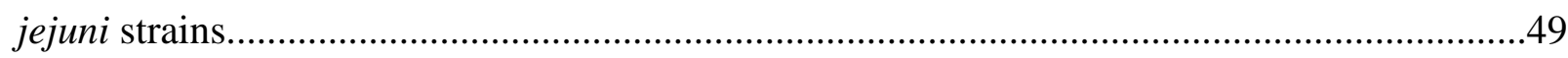

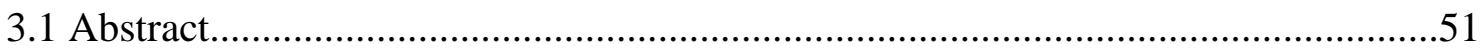

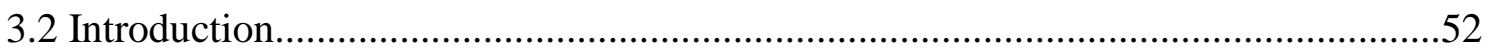

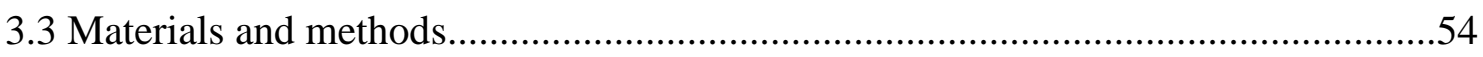

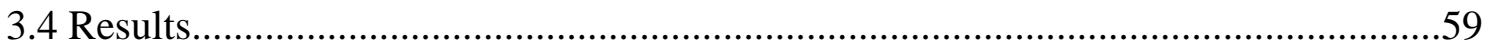

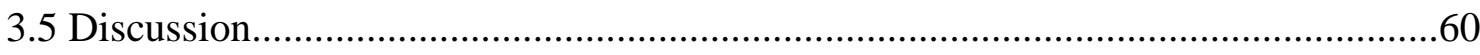

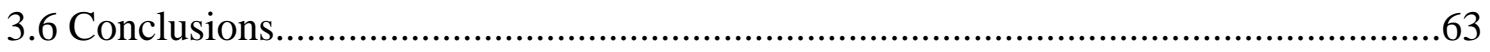

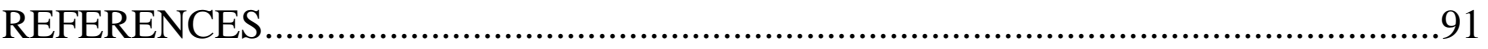

\section{CHAPTER 4}

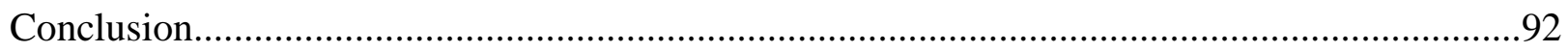

\section{APPENDIX A1}

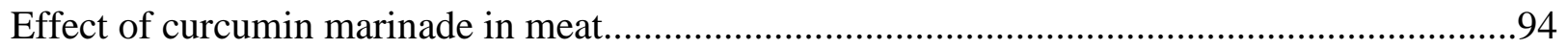




\section{APPENDIX A2}

Commercially available extracts production process..........................................................99 


\section{LIST OF FIGURES}

Fig 2.1. Chemical structure of polyphenol classes and the microorganisms sensitive to them (Source: Daglia / Current opinion in biotechnology, 23(2), 174-181)..

Fig 3.1. Fig 3.1. Log CFU vs Time of green tea extract at 3 different concentrations against C.jejuni 81176. Green tea was effective at killing bacteria within 24 hours of incubation. There was a 7-log decrease in growth in 24 hours for all 3 concentration levels $(\mathrm{P}<0.05)$

Fig 3.2. Log CFU vs Time of green tea extract at 3 different concentrations against C.jejuni PRCC. For all 3 concentration levels, green tea showed a 7-log reduction from the control in 24 hours. Although green tea at 1\% concentration showed a 1-log decrease in growth in 4 hours, it killed all the bacteria in 24 hours $(\mathrm{P}<0.05)$. . .68

Fig 3.3. Log CFU vs Time of green tea extract at 3 different concentrations against C.jejuni POCC. Green tea showed a 7- $\log$ reduction from the control in 24 hours $(\mathrm{P}<0.05)$. There was no significant difference in the action of $0.25 \%$ and $0.5 \%$ concentrations against the isolate.

Fig 3.4. Log CFU vs Time of green tea extract at 3 different concentrations against C.jejuni RECC. All three concentrations of green tea showed a 7-log reduction from the control in 24 hours $(\mathrm{P}<0.05)$. Green tea at $1 \%$ showed a 1 -log reduction in 4 hours, but there was a steady decline in count after that. .70

Fig 3.5. Log CFU vs Time of oregano extract at 3 different concentrations against C.jejuni 81176. Oregano was effective at killing bacteria within 24 hours, showing a 7- log reduction $(\mathrm{P}<0.05)$. Although oregano $1 \%$ showed a 1 - $\log$ reduction in 4 hours, there was a steep decline in growth after that. . .71

Fig 3.6. Log CFU vs Time of oregano extract at 3 different concentrations against C.jejuni PRCC. All concentrations of oregano were effective in killing bacteria within 24 hours $(\mathrm{P}<$ $0.05)$. .72

Fig 3.7. Log CFU vs Time of oregano extract at 3 different concentrations against C.jejuni POCC. For all 3 concentrations of oregano, there was an 8- $\log$ decrease $(\mathrm{P}<0.05)$ killing all the bacteria in 24 hours. Oregano 1\% showed a 1 - log decrease in 4 hours with a steady decline after that.

Fig 3.8. Log CFU vs Time of oregano extract at 3 different concentrations against C.jejuni RECC. Oregano was found to be effective in killing bacteria within 24 hours of incubation $(\mathrm{P}<0.05)$. There was a $1-\log$ decrease for oregano $1 \%$ in 4 hours of incubation. 
Fig 3.9. Log CFU vs Time of hawthorn extract at 3 different concentrations against C.jejuni 81176. All the 3 concentrations did not show significant difference in their action against the isolate for all time points. Also, hawthorn at all concentrations failed to kill the bacteria within

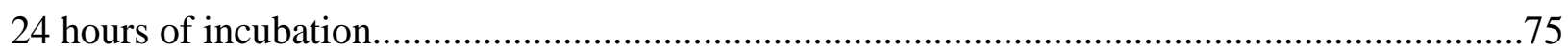

Fig 3.10. . Log CFU vs Time of hawthorn extract at 3 different concentrations against C.jejuni PRCC. Hawthorn 1\% showed more than 1- log reduction in growth at 24 hours. ......................76

Fig 3.11. Log CFU vs Time of hawthorn extract at 3 different concentrations against C.jejuni POCC. Hawthorn 1\% showed a 1- log difference in 24 hours. There was no significant difference observed between the concentrations at 24 hour time point. . .77

Fig 3.12. Log CFU vs Time of hawthorn extract at 3 different concentrations against C.jejuni RECC. Although a slight decrease was seen from the control in 24 hours for all the three concentrations, there was no significant difference in its action between the concentrations against the isolate. .78

Fig 3.13. Log CFU vs Time of curcumin extract at 3 different concentrations against C.jejuni 81176. Curcumin 1\% showed more than 2- log reduction in 24 hours whereas $0.25 \%$ and $0.5 \%$ showed less than 1- log reduction with no significant difference in its action between the two concentrations. .79

Fig 3.14. Log CFU vs Time of curcumin extract at 3 different concentrations against C.jejuni PRCC. Curcumin 1\% was found to be effective among the three concentrations and showed a 3$\log$ reduction in 24 hours of incubation whereas $0.25 \%$ and $0.5 \%$ concentrations showed a 2 log decrease in growth.

Fig 3.15. Log CFU vs Time of curcumin extract at 3 different concentrations against C.jejuni POCC. Curcumin 1\% showed a $2-\log$ reduction in 24 hours of incubation. .81

Fig 3.16. Log CFU vs Time of curcumin extract at 3 different concentrations against C.jejuni RECC. Curcumin 1\% showed a 3- log decrease in 24 hours of incubation. Curcumin $0.25 \%$ and $0.5 \%$ concentrations showed more than 2 - log reduction, in 24 hours.

Fig 3.17. Log CFU vs Time of oregano, green tea and hawthorn extract marinated on chicken breast pieces at 2 different concentration levels against C.jejuni 81176. Oregano at 50\% succeeded in killing all bacteria within 2 hours of incubation resulting in a 6- log reduction (P $<0.05$ ) whereas oregano 30\% showed a 2 - log decrease in 24 hours. Green tea $100 \%$ showed 2$\log$ reduction whereas green tea 50\% and hawthorn 100\% showed a 1 - log reduction in 2 hours of incubation. .83 
Fig 3.18. Log CFU vs Time of oregano, green tea and hawthorn extract on chicken breast pieces at 2 different concentration levels against C.jejuni PRCC. Oregano at 50\% was the most effective of the extracts which succeeded in killing all bacteria within 2 hours of incubation $(\mathrm{P}<0.05)$.

Fig 3.19. Log CFU vs Time of oregano, green tea and hawthorn extract on chicken breast pieces at 2 different concentrations against C.jejuni POCC. Oregano at 30\% and 50\% succeeded in killing all bacteria within 6 hours of incubation $(\mathrm{P}<0.05)$. .85

Fig 3.20. Log CFU vs Time of oregano, green tea and hawthorn extract on chicken breast pieces at 2 different concentrations against C.jejuni RECC. Oregano at 30\% and 50\% succeeded in killing all bacteria within 6 hours of incubation $(\mathrm{P}<0.05)$. . .86

Figure A1.1. Log CFU vs Time of curcumin at 2 different concentrations against C.jejuni 81176. Curcumin was not effective at reducing or killing the bacteria within 24 hours. .92

Figure A1.2. Log CFU vs Time of curcumin at 2 different concentrations against C.jejuni PRCC. Curcumin was not effective at reducing or killing the bacteria within 24 hours.

Figure A1.3. Log CFU vs Time of curcumin at 2 different concentrations against C.jejuni POCC. Curcumin was not effective at reducing or killing the bacteria within 24 hours. .94

Figure A1.4. Log CFU vs Time of curcumin at 2 different concentrations against C.jejuni RECC. Curcumin was not effective at reducing or killing the bacteria within 24 hours. .95

Figure A2.1 Curcumin commercial extraction process (Source: G.Harris, personal communication, April 16, 2014). 


\section{LIST OF TABLES}

Table 3.1. Log CFU at 2 hour and 24 hour time point for oregano and green tea to determine concentrations that reduced bacteria over a 2 hour period in chicken breast fillet compared to in vitro studies. The maximum concentration that effectively killed bacteria within 24 hours in all strains tested was the starting point for meat model study. 
CHAPTER 1

INTRODUCTION 
Campylobacter are gram-negative spiral shaped bacteria known for causing diseases in humans and animals (CDC 2014). These gram-negative bacteria are resistant to multiple drugs and are increasingly resistant to available antibiotics (CDC 2014). Campylobacteriosis is the most common disease caused by Campylobacter. Infection with Campylobacter produces antibodies that protect the individual against a second infection.

C. jejuni is one of the species of Campylobacter that is isolated from humans (Konkel et al, 2001) and is one of the most common causes of bacterial induced diarrheal disease worldwide (Zilbauer et al, 2008). The Center for Disease control and Prevention reports the occurrence of one case of Campylobacter in the United States for approximately 7000 persons in population (CDC 2014). There is active surveillance of such cases in the United Sates through Foodnet (CDC 2014). Symptoms of affected patients include diarrhea, fever and abdominal cramping with bacteremia and septic arthritis (Altekruse et al, 1999). C. jejuni infections are usually confined to the intestine, but a complication from this infection usually observed in a small percentage of cases is Guillain-Barré syndrome (GBS), a condition that can affect peripheral nerves (Zilbauer et al, 2008). Fluid and electrolyte replacement are regularly prescribed treatments for patients infected with campylobacteriosis (Altekruse et al, 1999). Treatment with antibiotics is recommended for patients with high fever and bloody diarrhea (Altekruse et al, 1999). A new trend being observed is the antibiotic resistant strains of $C$. jejuni that have been identified (Young et al, 2007). The United States Food and Drug Administration (FDA) has recently approved a conjugate vaccine for human trials that contain a polysaccharides from $C$. jejuni joined to a protein (Zuraw, 2014). Attempts similar to this underline the importance attached to the elimination of $C$. jejuni from food. 
Human infection by C. jejuni can occur through a variety of routes with commercial food production being a primary source. Poultry is thought to account for $50-70 \%$ of $C$. jejuni infections (Epps et al, 2013) in humans also possibly through contaminated water and the formation of biofilms (Young et al, 2007). Poultry meat induced human infection can be controlled or prevented by a variety of methods which center around safe drinking water supply, biosecurity procedures and safe handling of poultry meat.

Campylobacter can potentially be controlled by the use of natural plant antimicrobials that are generally recognized as safe (Klančnik et al, 2012). Plant derived antimicrobials have also been investigated as components of hurdle technology as an alternative to synthetic antimicrobials. Compounds from plant sources such as essential oils, spices, plant extracts and their active components have shown their effectiveness against antibiotic resistant bacteria (Ravishankar et al, 2008). Plant based antimicrobials are effective because of certain key components such as phenolics like terpenes, aliphatic alcohols, aldehydes, ketones, acids and isoflavonoids (Tiwari et al, 2009; Hayek et al, 2013). Researchers have indicated that gram-negative bacteria are more resistant than gram-positive bacteria to natural antimicrobials (Davidson et al., 2013). Some nonphenolic constituents of essential oils are more effective against gram-negative bacteria (Hayek et al., 2013).

The main emphasis of this study is to determine the efficacy of commercially available oregano, green tea, hawthorn and curcumin plant extracts on reducing/eliminating 4 different strains of Campylobacter jejuni from poultry meat. Tea has been shown to inhibit the growth of $C$. jejuni strains within 4 hours (Diker et al, 1991) emphasizing their antimicrobial properties. Green tea composition is complex and consists of catechins, flavonoids, alkaloids, volatile oils, polysaccharides, amino acids, lipids, minerals and other compounds (Perumalla et al, 2011). 
Comparing the antibacterial activities of different plant extracts on gram-positive and gramnegative bacteria, Campylobacter spp. was found to be more sensitive than other gram-negative bacteria to plant extracts (Klančnik et al, 2010).

Oregano essential oils have been shown to possess antimicrobial properties. However, this property of oregano differs with composition and is linked to geographical location, species and development stage of the plant (Falco et al, 2013). Oregano and some of its extracts have shown the ability to suppress the growth of gram-negative bacteria, gram-positive bacteria, yeast and fungi in in vitro models (Singletary, 2010). Oregano oil has been investigated in combination with vacuum packing and research has shown effectiveness against gram-negative bacteria and extended shelf life of chicken breast fillets by 8-9 days (Pavelkova et al, 2013).

Herbal medicine utilizes all components of the hawthorn plant (Chau, 2014). Hawthorn has shown strong inhibitory effect on Staphylococcus aureus and Klebsiella pnuemoniae with ethanol extract showing stronger antibacterial activity as compared to water extract (Niu et al, 2013). There is not a significant amount of literature on the effects of hawthorn extracts or its components on gram-negative and specifically Campylobacter spp. This study is aimed at learning more about the effect of hawthorn extract on C. jejuni.

\section{JUSTIFICATION}

In recent years there has been a strong consumer demand for quality meat products because of increased awareness and availability of information. C. jejuni is a gram-negative bacterium which is a leading cause of gastroenteritis from food. Poultry and other meat products are primary sources for this infection along with unpasteurized milk and contaminated water. According to official monitoring by the European Food Safety Authority in 2009, 90-100\% of 
raw chicken in retail market may be contaminated by Campylobacter (Piskernik et al, 2011). This study focuses on the use of commercially available plant antimicrobial extracts on the reduction/elimination of $C$. jejuni. 


\section{REFERENCES}

Altekruse, S. F., Stern, N. J., Fields, P. I., \& Swerdlow, D. L. (1999). Campylobacter jejuni--an emerging foodborne pathogen. Emerging infectious diseases, 5(1), 28.

CDC 2014. Center for Disease Control and Prevention. 2014. Campylobacter General Information. http://www.cdc.gov/nczved/divisions/dfbmd/diseases/Campylobacter/. Accessed August 2014.

Chau, B., "Hawthorn, A Medicinal Plant”, http://mason.gmu.edu/ bchau1/Chem350/projects/plant/plant.html. Acessed Aug. 2014.

Davidson, P. M., Critzer, F. J., \& Taylor, T. M. (2013). Naturally occurring antimicrobials for minimally processed foods. Annual review of food science and technology, 4, 163-190.

De Falco, E., Mancini, E., Roscigno, G., Mignola, E., Taglialatela-Scafati, O., \& Senatore, F. (2013). Chemical Composition and Biological Activity of Essential Oils of Origanum vulgare L. subsp. vulgare L. under Different Growth Conditions. Molecules, 18(12), 14948-14960.

Diker, K. S., Akan, M., Hascelik, G., \& Yurdakök, M. (1991). The bactericidal activity of tea against Campylobacter jejuni and Campylobacter coli. Letters in Applied microbiology, 12(2), 34-35.

Epps, S. V., Harvey, R. B., Hume, M. E., Phillips, T. D., Anderson, R. C., \& Nisbet, D. J. (2013). Foodborne Campylobacter: Infections, Metabolism, Pathogenesis and Reservoirs. International journal of environmental research and public health, 10(12), 62926304.

Hayek, S. A., Gyawali, R., \& Ibrahim, S. A. (2013). Antimicrobial Natural Products.

Klančnik, A., Piskernik, S., Jeršek, B., \& Možina, S. S. (2010). Evaluation of diffusion and dilution methods to determine the antibacterial activity of plant extracts. Journal of microbiological methods, 81(2), 121-126.

Klančnik, A., Možina, S. S., \& Zhang, Q. (2012). Anti-Campylobacter activities and resistance mechanisms of natural phenolic compounds in Campylobacter.PloS one, 7(12), e51800.

Konkel, M. E., Monteville, M. R., Rivera-Amill, V., \& Joens, L. A. (2001). The pathogenesis of Campylobacter jejuni-mediated enteritis. Current issues in intestinal microbiology, 2(2), 55-71.

Niu, Y., Nan, Y., Yuan, L., \& Wang, R. (2013). Study on Antibacterial Effect of Medlar and Hawthorn Compound Extract In Vitro. African Journal of Traditional, Complementary, and Alternative Medicines, 10(3), 567. 
Pavelková, A., Kačániová, M., Horská, E., Rovná, K., Hleba, L., \& Petrová, J. (2013). The effect of vacuum packaging, EDTA, oregano and thyme oils on the microbiological quality of chicken's breast. Anaerobe.

Perumalla, A. V. S., \& Hettiarachchy, N. S. (2011). Green tea and grape seed extracts—Potential applications in food safety and quality. Food Research International, 44(4), 827-839.

Piskernik, S., Klančnik, A., Riedel, C. T., Brøndsted, L., \& Možina, S. S. (2011). Reduction of Campylobacter jejuni by natural antimicrobials in chicken meat-related conditions. Food Control, 22(5), 718-724.

Ravishankar, S., Zhu, L., Law, B., Joens, L., \& Friedman, M. (2008). Plant-derived compounds inactivate antibiotic-resistant Campylobacter jejuni strains. Journal of Food Protection, 71(6), 1145-1149.

Singletary, K. (2010). Oregano: overview of the literature on health benefits. Nutrition Today, 45(3), 129-138.

Tiwari, B. K., Valdramidis, V. P., O’Donnell, C. P., Muthukumarappan, K., Bourke, P., \& Cullen, P. J. (2009). Application of natural antimicrobials for food preservation. Journal of agricultural and food chemistry, 57(14), 5987-6000.

Young, K. T., Davis, L. M., \& DiRita, V. J. (2007). Campylobacter jejuni: molecular biology and pathogenesis. Nature Reviews Microbiology, 5(9), 665-679.

Zilbauer, M., Dorrell, N., Wren, B. W., \& Bajaj-Elliott, M. (2008). Campylobacter jejunimediated disease pathogenesis: an update. Transactions of the Royal Society of Tropical Medicine and Hygiene, 102(2), 123-129.

Zuraw, L. (2014, May 19). FDA Approves Campylobacter Vaccine for Human Trials | Food Safety News. Retrieved from http://www.foodsafetynews.com/2014/05/campylobacter-vaccinein-human-trials. 
CHAPTER 2

LITERATURE REVIEW 


\subsection{Introduction}

Campylobacter jejuni is one of the most common bacterial causes of foodborne illnesses worldwide. Campylobacteriosis caused by Campylobacter is estimated to affect over 1.3 million people/ year with higher incidence in the summer months (CDC, 2014). In the United States over 99\% of the infections associated with Campylobacter spp. are with Campylobacter jejuni (Friedman et al., 2000). It is estimated that 76 people die from the disease every year (CDC, 2014). Severe diarrhea with stool specimens containing blood is associated with Campylobacter infections. These illnesses often are resolved without medication and the incubation period of Campylobacter in humans is usually between two to seven days. Deaths associated with the disease are rare and usually occur in very young or old people suffering from other diseases like AIDS (WHO, 2014). Treatment is not required except rehydration and electrolyte replacement (WHO, 2014; CDC, 2014). Guillain-Barré Syndrome (GBS), defined as an acute neuro-muscular paralysis, is a complication associated with C. jejuni infections (Altekruse et al., 1999). C. jejuni is microaerophilic $\left(5 \% \mathrm{O}_{2}, 10 \% \mathrm{CO}_{2}\right.$ and $\left.85 \% \mathrm{~N}_{2}\right)$, thermophilic, with an optimum growth temperature between $37^{\circ} \mathrm{C}$ and $42^{\circ} \mathrm{C}$ (Davis \& DiRita, 2008).

\subsection{History and Taxonomy of Campylobacter}

The genus Campylobacter was suggested by Sebald and Veron for a "vibrio" which had been thought to be the cause for abortion in cattle by McFaydean and Stockman in 1913 (Veron and Chatelain, 1973). In 1886, Theodor Escherich recorded his observations of "spiral bacteria" diarrhea infected children (Altekruse et al., 1999) in "Münchener Medizinische Wochenschrift" (Butzler, 2004). The human strain V. fetus was isolated from patients as well as other "related vibrios” and their symptoms and infections were studied (King et al., 1957). A common 
symptom observed was the diarrheal symptoms in infected patients (Skirrow, et al., 1977). The first major isolation techniques was reported in 1973 by Butzler which paved the way for successful characterization of the bacteria (Butzler, 2004). The "Vibrio like" bacteria were divided into four distinct species in the genus Campylobacter in work published by Veron and Chatelain in 1973. They were C.fetus, Campylobacter coli, Campylobacter jejuni and Campylobacter sputorum (Debruyne et al., 2008). There are 18 species of Campylobacter identified as - C.fetus, C.hyointestinalis, C.lanienae, C.sputorum, C.mucosalis, C.concisus, C.curvus, C.rectus, C.gracilis, C.showae, C.hominis, C.jejuni, C.coli, C.lari, C.insulaenigrae, C. canadensis, C.upsaliensis and C.helveticus (Debruyne et al., 2008). There are two subspecies within C.jejuni, C.jejuni subspecies jejuni and C.jejuni subspecies doylei (Epps et al., 2013).

\subsection{Morphology}

Campylobacter are gram-negative, slender, spirally curved and non-spore forming rods with a single flagelllum at one or both ends of the cell responsible for its corkscrew like motion. The spiral form is usually observed in active cultures and indicates that the bacteria are actively

growing (Svensson et al., 2008). The coccoid form has been shown to be inactive and classified as old (NG et al., 1985). The transition from spiral curved to the coccoid form is through the intermediate forms and can be identified via a double staining method (Alonso et al., 2002). Scanning electron microscope images have shown the existence of both types within a single colony with the active spiral form on the outside because of nutrient availability and coccoid in the middle (NG et al., 1985). The transitional phase in between the two forms has been described as many researchers as being donut or spiral shaped possibly as a result of cell wall degeneration (Alonso et al., 2002; NG et al., 1985; Svensson et al., 2008). 
The transition to coccoid form is normally as a result of stress conditions, environmental conditions and lack of nutrients (Ikeda et al., 2012). The coccoid form has characteristics similar to a viable but non-culturable (VBNC), state but researchers have accepted these to be separate phenomenon (Svensson et al., 2008). The success of Campylobcater existing in harsh environments can possibly be attributed to its dormant coccoid state although C. jejuni in VBNC state has been shown to be unable to return to a culturable state (Svensson et al., 2008).

\subsection{Pathogenesis}

\subsubsection{Mechanism of pathogenesis}

Diarrheal symptom is more prevalent in human infections as opposed to poultry infection (Young et al., 2007). This behavior is very similar to that of Escherichia coli and control in the host is the most effective measure against the pathogen (Young et al., 2007).The key to understanding the pathogenicity of $C$. jejuni is the understanding of the routes of entry into the host, the number of bacteria required to cause infection and the defense mechanism of the host once infection has been detected (Duan et al., 2013). The pathogenesis factors can, therefore, be divided into host and pathogen dependent. Low doses of the organism have shown to cause illness (Black et al., 1988) in experiments on humans. The symptoms of Campylobacter infection are inflammation, abdominal pain fever and diarrhea with an incubation period of 2-5 days (Blaser, et al., 1983). C. jejuni is able to achieve penetration of the mucus layer by virtue of its motility and unique morphology (Young et al., 2007). This penetration was studied in humans (Van Spreeuwel et al., 1985) and animals (Yao et al., 1997) as well as in vitro experiments. The intestinal cells respond by initiating an inflammatory response (Epps et al., 2013) which is not common for all strains of C. jejuni (Young et al., 2007). This can possibly be explained by how 
different strains of C. jejuni access the epithelial cells differently (Nachamkin et al., 2008). A model of pathogenesis proposed by Konkel et al., 2001, suggests protein synthesis through flagella as a means to interact with the host epithelial cells. It has been suggested that targeting adhesins specific to chicken epithelial cells may assist in the development of anti-Campylobacter drugs (Rubinchik et al., 2012).

According to Epps et al., 2013, "The virulence of the pathogen is governed by motility, drug resistance, host cell adherence, host cell invasion, alteration of the host cell signaling pathways, induction of the host cell death, evasion of the host, immune system defenses and acquisition of iron , a micronutrient for growth”. Additional determinant factors stated by Ketley et al., 1997, are active secretion and epithelial disruption with leakage of serosal fluid and toxin production. Attachment and colonization requirements are chemotaxis, motility (Carrillo et al.,, 2004; Golden et al., 2002; Grant et al., 1993) and flagellar proteins secreted through flagella components (Konkel et al., 2004; Song et al., 2004). An important observation made by Ketley et al., 1997 was that the different mechanisms are not necessarily operating in isolation but very dependent on the host and strain of infecting C. jejuni. After the onset of infection, severity, length and complications from the infection are a function of the age of the host and the immunity derived from previous $C$. jejuni infections (Altekruse et al., 1999). The survival of $C$. jejuni in harsh environments points to the ability to adapt cell functions making it difficult to isolate its bacterial determinants (Nachamkin et al., 2008).

\subsubsection{Toxin production by Campylobacter}

Cytolethal distending toxin (CDT) which causes "arrest at the G/S or G/M transition of the cell cycle” (Young et al., 2007) is the only identified toxin produced by Campylobcater (Dasti et al., 
2010). This toxin is encoded by three genes $c d t A, c d t B$ and $c d t C$ (Miller, 2008) with the A and C responsible for the pathogen binding to the host cell (Dasti et al., 2010). Previously reported enterotoxin (Ketley, 1997; Ruiz-Palacios et al., 1983) has not been clearly identified from recent genome analysis (Hu \& Kopecko, 2008). A summary is provided by Picket, 2000 describing CHO/HeLa cell cytotoxins, Vero-Active and Shiga-Like Toxins, hepatoxins, hemoslysins, CLRT, CLDT/CLRT and porin-lipopolysaccharide toxins.

\subsubsection{Clinical manifestation}

Campylobacter infections can occur without symptoms to severe and life threatening and are often self-limiting. C. jejuni and C. coli are the strains of Campylobacter spp. that cause infection in humans. In some cases complications can arise resulting in life threatening conditions (Zilbauer et al., 2008). C. jejuni infections are exhibited in humans through severe gastroenteritis (Zilbauer et al., 2008) with blood in the stool along with leukocytes (Epps et al., 2013). In certain cases fever and abdominal cramping are also reported (Altekruse et al., 1999). Genetic variations that exist between C. jejuni strains is an explanation offered for different symptoms seen in human infection (Dasti et al., 2010). In severe case C. jejuni infections can cause reactive arthritis and an autoimmune disease Guillain-Barré syndrome (GBS) (Dasti et al., 2010; Peterson et al., 1994).

\subsubsection{Gullian-Barré syndrome}

Gullian-Barré syndrome (GBS) is a complication of a C. jejuni infection and presents as damage to the peripheral nervous system resulting in paralysis and in certain extreme cases death (Konkel et al., 2001; Epps et.al., 2013) which can develop 1-3 weeks after C. jejuni infection. Gullian-Barré syndrome has been established as a mechanism where antibodies are the 
pathogenic component that trigger Gullian-Barré syndrome (Shahrizaila et al., 2010). Miller Fischer Syndrome is a subform of Gullian-Barré syndrome characterized by absent reflexes, inability to control muscle movements, and eye control problems (Epps et al., 2013). Two other forms are "acute inflammatory demyelinating neuropathy" and "acute motor axonal neuropathy" (Shahrizaila et al., 2010). There had been concerns relating increased risk of GBS after vaccinations since 1976 when a 7-8 fold increased risk for GBS was observed in the 6 weeks after swine flu vaccination (Salmon et al., 2013). This risk of GBS after administration of vaccines was not found to exist after an extensive study was conducted at the Northern California Kaiser Permanente site (Salmon et al., 2013).

\subsubsection{Reactive arthritis}

Campylobacter induced intestinal infection can sometimes result in reactive arthritis (ReA) which can result in patients developing inflammation in the joints (Hannu et al., 2002). This condition usually develops within four weeks of an infection with conditions lasting more than 6 months, a sign of severe infection (Pope et al., 2007). Patients with HLA-B27 (human leukocyte antigen) positive condition is believed to interact with bacteria like Salmonella and Campylobacter causing this condition with reoccurrence reported as late as 7 years after the initial condition (Pope et al., 2007). In a study in Finland, it was found that ReA had an annual incidence of around 4.3 per 100,000 with acute ReA at reduced levels with a higher percentage in adults (Hannu et al., 2002). According to Townes, 2010; "Reactive arthritis is a concept, not a well-defined disease" with further study required to understand its prevalence in populations.

\subsubsection{Campylobacter resistance mechanism}


Campylobacter infections are usually self-limiting and rarely require treatment except in extreme cases and in patients whose immune systems are compromised. Typical antimicrobials like fluoroquinolones, macrolides, aminoglycosides and beta lactams have been noticed to be ineffective against many strains of Campylobacter (Iovine et al., 2013). The similarity of $C$. jejuni infection symptoms with those caused by other bacterial infections results in treatments with fluoroquinolones (Iovine et al., 2013). The resistance of Campylobacter can be related to the ability to mutate and acquire resistance by natural transformation, transduction or conjugation (Koluman et al., 2012; Wieczorek et al., 2013; Iovine et al., 2013).

\subsection{Epidemiology}

In the early years of 1980's Campylobacter enteritis emerged as the most frequent form of bacterial diarrhea exceeding Salmonella infections (Skirrow, 1982). In studies in Norway published by Lassen \& Kapperud in 1984; 3\% of all severe intestinal illnesses were attributed to Campylobacter with infection isolated to travelers returning from abroad. A more recent study was carried out in England and Wales over 20 years showed a seasonal increase between May and June with increased incidence in areas with lower population density and lower percentage of native population (Nichols et al., 2012). In the United States Campylobacter caused foodborne infection resulting in a total of 9135 illnesses from 262 outbreaks and three deaths in the period between 1997 to 2008 (Taylor et al., 2013).

\subsection{Reservoirs}

There has been an increase in the number of outbreaks associated with Campylobacter but a decrease in Campylobacter infections was seen from 1997-1998 baseline (Taylor et al., 2013). The transmission cycle of the bacteria from animals to humans is usually through the food chain. 
Consumption, handling and cross-contamination of chicken meat are identified as the major contributors to $C$. jejuni infections along with drinking unpasteurized milk and contaminated water (Friedman et al., 2000). C. jejuni mainly colonizes the cecum and colon of poultry with the colonization in broiler chicks causing transmission of the infection (Hermans et al., 2011;

Hermans et al., 2012a; Epps et al., 2013). Colonization of flock can take several weeks with cage free chickens taking 0-8 days (Horrocks et al., 2009). Although poultry has been identified as the major animal reservoir for $C$. jejuni, cattle and other swine are known to carry the infection (Jensen et al., 2006). Studies have suggested that $C$. jejuni and C. coli co-exist in pigs with C.jejuni always being in lower numbers (Jensen et al., 2006; Madden et al., 2000). Human infections can occur as a result of contaminated surface water with human to human transmission of infection not thought to be significant (Dasti et al., 2010).

\subsection{Growth conditions for Campylobacter}

The inability of $C$. jejuni to survive and multiply outside of the host in normal atmospheric conditions was observed by to Park, 2002 (Murphy et al., 2006). The bacterium grows best in low oxygen and is sensitive to harsh cold, dry and acidic environments (Altekruse et al., 1999) and requires a microaerophilic growth environment (5\% O2, 10\% CO2, 85\% N2) (Davis \& DiRita, 2008). C. jejuni grows at a specific temperature range of $37^{\circ} \mathrm{C}$ and $42^{\circ} \mathrm{C}$ in select media (Davis \& DiRita, 2008). The time required for growth of $C$. jejuni is also longer compared to other gram-negative bacteria like E. coli (Davis \& DiRita, 2008). This growth outside of this temperature range can go down to zero within a few degrees (Hazeleger et al., 1998) although survival at $7^{\circ} \mathrm{C}$ has been recorded (Davis \& DiRita, 2008). Another factor influencing its survival is the limited capability to utilize energy for survival and growth via carbohydrate fermentation, and adaptability is important for its survival in environment before host entry (Epps et al., 2013). 
A method of survival for C. jejuni is possibly with the formation of biofilms (Joshua et al., 2006).

\subsection{Campylobacter genome}

The first Campylobacter jejuni strain (NCTC11168) was sequenced by Parkhill et al., 2000 and since then 34 more have been completed (Zhou et al., 2013). The genome of Campylobacter jejuni according to Gundogdu et al., 2007 is “1,641,481 bp long with 25 polymorphic regions” (Epps et al., 2013). Strain variations and the work by Gundogdu et al., 2006 on NCTC11168 revealed "new information for 1450 of the original 1654 coding sequences" (Epps et al., 2013). Stahl and Stintzi in 2011, identified one hundred ninety-five genes, essential to cell processes and core functions with genes grouped into categories based on function (Stahl et al., 2011).

\subsection{Prevention and control of Campylobacter in poultry}

Prevention measures and reduction in colonization are different based on the stage of intervention in the colonization process. Prevention measures are responsible for reducing probability of poultry being colonized by Campylobacter, while the control of C.jejuni refers to the steps taken to reduce the presence of the pathogen prior to slaughter (Hermans et al., 2011). Many studies to date suffer as a result of "poor design, sampling and statistical analysis" (Newell et al., 2011). The control of Campylobacter in poultry can be divided into pre-harvest and postharvest control strategies.

\subsubsection{Pre-harvest control}

Broiler chickens are the most common source for Campylobacter infection, so measures are needed to control pathogen colonization and spread of Campylobacter spp. in the flock. Studies 
have shown that the spread of the pathogen can occur in the flock within three days of contact with the infected bird (Shanker et al., 1990). Horizontal transmission of Campylobacter spp. can be controlled by "identifying the pathogen sources and farm management practices that result in exposure to the pathogen" (Doyle \& Erickson, 2012). The important factors that influence the ability to control the colonization and spread of Campylobacter spp. in the flock are explained.

\subsubsection{Biosecurity}

The term "Biosecurity" can be broadly defined as steps or components of a program that prevent the entry of pathogens into the production site (Bagust et al., 2013). Before explaining various steps required to achieve a biosecure environment, two terms require definition; vertical transmission and horizontal transmission. The term vertical transmission is used to define contamination of the egg within the hen prior to completion of the shell (Newell et al., 2011). Horizontal transmission is the most widespread mode of spreading pathogen within the flock via chicks (Newell et al., 2011). The most basic procedures include limited access to sites where poultry is stored, single point of entry and good hygiene (Bagust et al., 2013). The presence of “hygiene barriers" has been shown to reduce risk of flock infection by 50\% (Newell et al., 2011). Important measures include washing hands, wearing protective clothing, disinfected boots and disinfection protocols (Ghareeb et al., 2013). Implementation of biosecurity measures in Denmark decreased the Campylobacter recolonized flock, from 43\% to 27\% accompanied by a 12\% reduction in human Campylobacter cases during the same period (Rosenquist et al., 2009). Special attention has to be given to "environmental exposure" as increased levels can nullify biosecurity measures with delayed onset of flock colonization by Campylobcater (Ghareeb et al., 2013). 


\subsubsection{Water treatment}

Water being one of the reservoirs of Campylobacter, the proper treatment of drinking water can prevent the transmission of the pathogen to the flock. Campylobacter spp. can maintain long term contamination of water sources with survival time based on the state of the bacteria (Whiley et al., 2013). There have been studies reporting efficiency of standard treatment processes successful in Campylobcater elimination although more resistant $C$. jejuni will require complicated treatment processes (Whiley et al., 2013). Chlorination of water reduces the risk for Campylobacter colonization (Ellis-Iverson et al., 2009). Ground water and drinking water are not considered to be major reservoirs for the pathogen although outbreaks in poultry and humans have been associated with these water supplies in the past (Whiley et al., 2013).

\subsubsection{Vaccination}

The protective nature of “Campylobacter-specific antibodies” visible in young broilers during the initial weeks after hatch (Sahin et al., 2003) suggests an effect of associated antibodies (Lin et al., 2009). This supports the feasibility of vaccines for control of Campylobacter in poultry (Sahin et al., 2003). This protection does not extend beyond the initial days and efforts to use purified and concentrated egg yolk antibodies from C. jejuni vaccinated hens has shown no significant reduction in C. jejuni colonies in poultry gut (Ghareeb et al.,2013). In spite of the improved protection offered by live vaccines, safety concerns have limited their use (Doyle \& Erickson, 2012). The challenges faced by vaccine efficacy are strain, dose, age, breed, and administration (Barrow et al., 2007; Doyle \& Erickson, 2012). Campylobacter colonization reduction in hosts is through "muscoal immunity" stimulation and to achieve this, "recombinant vaccines using attenuated live vaccines” can be administered (Kuttappan et al., 2013). In 
addition, subunit vaccines have shown promise whereas heterologous vaccines for Campylobacter have shown reduction in bacterial counts but not protection (Hermans et al., 2012b). The diverse strains of Campylobacter limits the range of protection of standard vaccines (Kuttappan et al., 2013) and, hence, no effective vaccine against Campylobacter is currently available (Hermans et al., 2012b).

\subsubsection{Prebiotics}

According to Jordan et al., 2014, "Prebiotics are defined as indigestible carbohydrates mostly with a relatively short chain length that can be fermented in the digestive tract”. The principle involves using "live microbial feed" by which the harmless or good bacteria are encouraged to grow and control harmful pathogenic bacteria thereby improving intestinal health in poultry (Jordan et al., 2014). In this method, individual strains are added or mixed with other strains which are cultivated separately (Ghareeb et al., 2013; Doyle \& Erickson, 2012). Currently, “mannanoligosaccharides” is only the organism based prebiotic in use (Ghareeb et al., 2013; Jordan et al., 2014).

\subsubsection{Probiotics}

Probiotic uses the technique where non-pathogenic pathogens are introduced into the animals and colonize the gastrointestinal tract of the animal and creating an inhospitable condition for foodborne pathogens (Doyle \& Erickson, 2012; Ghareeb et al., 2013; Jordan et al., 2014). Bacterial strains of Lactobaccilus, Enterococcus, Pediococcus and Bacillus have shown promise in this application (Gaggia et al., 2010). The addition of probiotics and prebiotics, referred to as synbiotics, have shown to offer greater benefit together than when used individually (Awad et al., 2009). 


\subsubsection{Bacteriocins}

Bacteriocins are "ribosomal antimicrobial small peptides" generated by bacteria to inhibit other bacteria (Doyle \& Erickson et al., 2012; Lin et al., 2009). They have been proposed as solutions to the antibiotic resistance of bacterial strains (Lin et al., 2009). They have effects similar to antibiotics but differ in their synthesis, mode of action and resistance mechanism (Jordan et al., 2014; Lin et al., 2009; Doyle \& Erickson et al., 2012). These differences should make it safe to use in food applications (Cleveland et al., 2001). Lactic Acid Bacteria (LAB) and nisin are the two widely used bacteriocins in food applications (Cleveland et al., 2001). BACTIBASE is an online database which is dedicated to bacteriocin research (Jordan et al., 2014).

\subsubsection{Bacteriophage}

Bacteriophages are viral parasites that are function against pathogenic bacteria and can have a prolonged survival in host gut without negative effects (Jordan et al., 2014). The bacteriophages function by reducing pathogen number and as a result multiply with researchers suggesting a minimum number of pathogens below which the bacteriophage will not function in this way (Doyle \& Erickson, 2012; Jordan et al., 2014). It is preferred to introduce bacteriophage into poultry before slaughter to prevent survival of bacteriophage resistant Campylobacter in flock (Ghareeb et al., 2013). Research is required into the most effective ratio of bacteriophage to pathogen or the most effective mix of bacteriophage against the specific pathogen (Doyle \& Erickson, 2012).

\subsubsection{Post-harvest control}

\subsubsection{Preservation of fresh meat}


The term fresh meat is used to describe freshly processed meat, vacuum sealed meat or atmosphere controlled meat. Meat is rich in nutrients that promote the growth of foodborne pathogens (Zhou et al., 2010). Therefore, the primary purpose of preservation is to prevent the growth of pathogens and spoilage organisms that degrade the quality of meat (Zhou et al., 2010). The most common preservation techniques are refrigeration, ionizing radiation, chemical preservation and preservation resulting from packaging (Zhou et al., 2010). Moisture, another significant cause for pathogenic activity in meat needs to be controlled by drying or additive means to inhibit bacterial cell growth (Dave et al., 2011).

\subsubsection{Natural antimicrobials for control of Campylobacter in poultry}

The health impacts of using synthetic food additives that have long term side effects to reduce the activity of pathogens has been under significant review in the last decade (Witkowska et al., 2013). The importance of natural and organic ingredients that do not trigger food allergies and the information on negative side effects of increased sodium intake has also increased interest (Davidson et al., 2013 ; Tajkarimi et al., 2010 ; Burt et al., 2004 ; Jayasena et al., 2013;

Witkowska et al., 2013). Consumers across the world have indicated a preference for "natural food additives" with the ability to act against a wider range of pathogens (Jayasena et al., 2013). Natural antimicrobials from plant or animal sources have to meet the conditions of non-toxicity, affordability, low concentration inhibition and neutral to taste and smell (Davidson et al., 2013). Naturally occurring additives that have been investigated for antimicrobial properties include essential oils, nisin, chitosan and lysozyme (Zhou et al., 2010). The preservation ability of chitosan through penetration of the outer cell membrane of microbes has been investigated (Siripatrawan et al., 2012). 


\subsubsection{Plant sources}

Phenolic compounds, known for their antimicrobial effects are the main antimicrobial agents in plants (Hayek et al., 2013). Steam distillation, hydro distillation and supercritical fluid extraction are the most common extraction methods for large scale plant antimicrobial production (Tajkarimi et al., 2010). Commercial products have also been produced using bioengineering (Burt et al., 2004). According to Tiwari et al., 2009, "the antimicrobial compounds in plant materials are usually found in essential oil fraction of the leaves, flowers, bulbs, seeds, fruits and other parts of the plant”. The constituents of these plant components that are used to fight microbes are polyphenols, quinones and alkaloids (Lorenzo et al., 2014).

Phenols are classified into three groups: simple phenols, phenolic acids, hydroxycinnamic acid derivatives with the latter group consisting of catechins, proanthocyanins, anthocyanidins, flavons, flavonols and their glycosides (Smid et al., 1999). The role of phenols in plant defense is still unclear with the phenolic compounds thought to affect the cytoplasmic membrane of pathogens changing its structure and function (Witkowska et al., 2013; Holley et al., 2005). The presence of multiple phenolic compounds in extracts would involve multiple modes of action against the bacteria (Witkowska et al., 2013; Holley et al., 2005). The effect of phenols vary with concentration; lower concentrations affecting the activity of enzymes and higher concentration causing protein denaturation (Tiwari et al., 2009).

\subsubsection{Spices and essential oils (EO)}

Research has identified plants with different antimicrobial action depending on the type and strain of bacteria but the mechanism of action of only a small fraction of the essential oils (EO) is well documented (Burt, 2004). Gram-positive bacteria are generally more sensitive to essential 
oils than gram-negative bacteria because of the outer membrane present in gram-negative bacteria though Campylobacter spp. is a more sensitive gram-negative bacterium (Burt et al., 2004; Holley et al., 2005; Klančnik et al., 2010). The possibility of this defense mechanism in gram-negative bacteria just delaying the action of EO’s has been studied by researchers (Fischer et al., 2008). Essential oil compounds are classified into a group containing terpenes and trepenoids and a group containing aromatic compounds (Jayasena et al., 2013). The EO’s from clove, thyme, rosemary, ginger and oregano on meat and meat products have been summarized by Jayasena et al., 2013 showing significant inhibition of bacterial pathogens. The antibacterial activity of essential oils is attributed to the presence of phenols like carvacrol, eugenol and thymol (Akthar et al., 2014; Oussalah et al., 2006).

\section{Mechanism of antimicrobial action}

The major antimicrobial action of EO is attributed to its "hydrophobic” nature of certain compounds which penetrate through the outer membrane (Krisch et al., 2008). The research into EO components has identified the action of the components on the cytoplasmic membrane of the pathogen (Burt et al., 2004; Davidson et al., 2013; Lv et al., 2011). According to Davidson et al., 2013, "increased membrane permeability, dissipation of proton motive force, inhibition of ATP synthesis and enzyme inhibition” are factors in the inhibitory mechanism of EO (Tajkarimi et al., 2010; Akthar et al., 2014). Terpenoids which are modifications of terpenes have shown antibacterial activity over a wide range of pathogens (Hyldgaard et al., 2012).

However, the effectiveness of antimicrobials has been shown to decrease in the food model as compared to in vitro (Lv et al., 2011). Research has revealed that a combination of different natural antimicrobials against pathogenic bacteria has an additive and combined effect 
preventing the pathogens from building resistance (Škrinjar et al., 2009; Bassole et al., 2012; Techathuvanan et al., 2014). This combination effect can be between molecules, sections of plant or different plant varieties (Vuuren et al., 2011).

\subsubsection{Essential oils in hurdle technology}

According to Leistner et al., 2000, "hurdle technology is used in industrialized as well as developing countries for the gentle, but effective preservation of food", the most important of which are temperature, water activity, acidity, redox potential, preservatives and competitive microorganism (Leistner et al., 2000). Essential oil added to edible films and coating is an example of the role plant based antimicrobials could play in hurdle technology (Jayasena et al., 2013).

\subsubsection{Plant extracts}

\section{Oregano}

Oregano is a common name for a plant genera usually used to reference Origanum and there are at least "61 species of 17 genera that belong to six families" under the name oregano (Kintzios S, 2003). The volatile oils are the most important group of chemicals isolated form oregano with composition of oils varying significantly among different types of oregano with phenolic monoterpenoids such as carvacol and thymol being significant components of oregano (Kintzios S, 2003). The composition of carvacol and thymol, two major antibacterial components of oregano can vary depending on the region where it is grown as well as the time the crop is picked (Burt, 2004). There have been differences observed in the antibacterial activities of EO’s between studies on the same bacteria. Studies on the effect of oregano oil against S.Typhimurium in tests by Mith et al., 2014 was found to be approx. 2-10 times that observed by Hammer $e t$ al., 
1999. The inhibitory effect under "modified atmospheric packaging" containing oregano on the same bacteria was observed by Sakandamis et al., (2002) in "sterile and naturally contaminated beef fillets" (Akthar et al., 2014). During an analysis of the different tests using essential oils, Hood et al., (2003) observed the uneven distribution of essential oils in the medium could possibly lead to higher concentration zones and possibly inaccurate results. Antimicrobial activity of oregano is primarily against bacteria and fungus (Kintzios S, 2003). O. vulgare was shown to yield one of the most effective oils among the 52 investigated EO's according to Hammer et al., 1999 with Biondi et al., 1993 and Izzo et al., 1995 reporting strong inhibitory action gram-positive and gram-negative bacteria. This action has been attributed to the effect of thymol and carvacol (Kintzios S, 2003). In context of determining antibacterial activity, the definition of the term minimum inhibitory concentration (MIC) is very important. MIC according to Cosentino et al., 1999 can be defined as the lowest concentration resulting in a significant decrease in inoculum viability (Burt, 2004). The MIC values of thymol and carvacol has been reported by researchers against a variety of gram-positive and gram-negative bacteria (Cosentino et al., 1999, Kim et al., 1995; Lambert et al., 2001; Pol et al., 1999). Thymol and carvacrol, constituents of oregano are believed to show antibacterial effects because of the ability to penetrate the cell and interfere with cellular functions according to Lambert et al., (2001), Marino et al., (2001) and Karami-Osboo et al., (2010) and "disturb the active site of enzymes” (Kotan et al., 2013).

Oregano has shown to delay the start of spoilage by Chouliara et al., 2007 used with "modified atmospheric packaging” (Tajkarimi et al., 2010). Oregano essential oil enriched chotisan films have shown strong inhibitory effect against gram-positive Listeria monocytogenes and gramnegative Escherichia coli (Zivanovic et al., 2005). The difference in effectiveness against gram- 
positive and negative bacteria is due to their "hydrophobic nature" of the essential oil (Dussault et al., 2014) with the lipopolysaccharide component of the outer membrane of gram-negative bacteria (Dussault et al., 2014; Du et al., 2009). The formation of biofilms in bacteria has been shown to be influenced by carvacrol interfering with bacterial quorum sensing ability (Burt et al., 2014).

\section{Green tea}

Tea can be classified into three types on the basis of their fermentation process; green tea, oolong tea and black tea (Wang et al., 2000). Green tea is made from the leaves of Camellia sinensis and is prepared by preventing the "enzymatic oxidation of catechins" by firing or by steaming (Wang et al., 2000). The major constituent of green tea is polyphenols of which flavonoids is believed to have health benefits (Taylor et al., 2005). Polyphenols like flavan-3-ols, flavonols and tannins have shown higher antimicrobial activity as compared to others and also work well with antibiotics, Figure 1 (Daglia, 2012).

Phenolic acids, flavonoids and lignans are the classification of polyphenols occurring in plants with structural binding and phenol rings being the major difference between them (Gharras et al., 2009). The major benefit of polyphenols is their antioxidant activity with genetic and environmental factors affecting the amount of polyphenols present in fruits and vegetables (Gharras et al., 2009). Polyphenols account for a third of composition of green tea (An et al., 2004). The major polyphenols found in green tea are epicatechin (EC), gallocatechin (GC), gallocatechin gallate (GCG), epigallocatechin (EGC), epicatechin gallate (ECG) and epigallocatechin gallate (EGCg) (Cooper et al., 2005). 


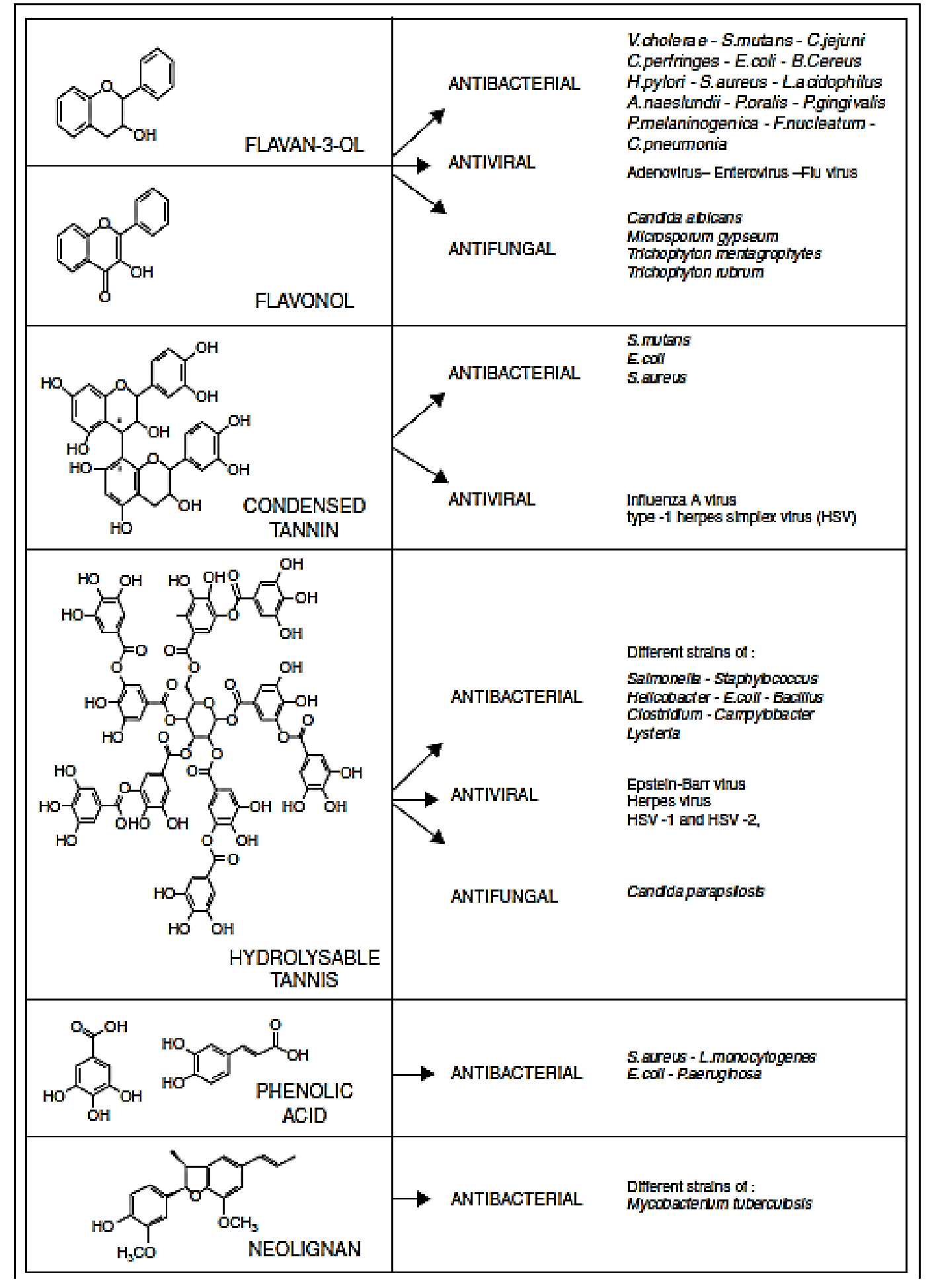

Figure 2.1: Chemical structure of polyphenol classes and the microorganisms sensitive to them (Source: Daglia / Current opinion in biotechnology, 23(2), 174-181). 
In studies by Yam et al., 1997, showed that "gallocatechins and their gallates” are the main components that are responsible for its antibacterial activity. The plant kingdom has flavonoids that help in fighting fungal microbes and protect against radiation (Harborne et al., 2000; Middleton et al., 1994; Cushnie \& Lamb, 2005). The major functions of this class of compounds are related to energy acquisition from the environment, basic growth and energy transfer (Harborne et al., 2000; Middleton et al., 1994; Cushnie \& Lamb, 2005). Flavonoids can be divided into flavones, flavanones, catechins and anthocyanins on the basis of molecular structure (Nijveldt et al., 2001). The flavonoids in their common forms are "water-soluble” and "less reactive towards free radicals” (Rice-Evans et al., 1997). In a study of antibacterial activity of flavonoids against methicillin-resistant $S$. aureus strains, it was found that an increase in flavonoid concentration resulted in decreased bacterial count and the structure of flavonoids affected the activity against $S$. aureus (Alcaraz et al., 2000).

Flavan-3-ols are shown to be the most significant phenolics in green tea accounting for over two thirds of its antioxidant activity (Stewart et al., 2005). Ethanol has shown to be a more effective extraction medium as compared to water for antioxidative research in studies related to green tea with higher polyphenol content (Gramza et al., 2006). This effect was also seen in antibacterial studies of green tea extract against Listeria monocytogenes in methanol and aqueous extract where methanol showed increased antibacterial activity (Mbata et al., 2008).

According to Shimamura et al., 2007, "The antibacterial activity of catechins is considered nonspecific with limited species selectivity”. Research by Hammilton-Miller (1997) and Yoda (2004) have revealed mode of interaction to EGCg by gram-negative bacteria like E.coli and gram-positive bacteria like S.aureus (Shimamura et al., 2007) and also observed antibacterial activity of ECG and EGCg (Miller, 1995). The antimicrobial action of tea extracts were shown to 
be different between gram-negative and gram-positive bacteria in a study against different pathogenic bacteria where Staphylococci and Y. enterocolitica were the most sensitive grampositive and gram-negative bacteria respectively (Yam et al., 1997). Tests that were conducted to compare the antibacterial activity of Chinese green tea crude extracts against different bacteria showed more potency against S.aureus and L.monocytogenes than Salmonella and E.coli (Si et al., 2006). In studies conducted on Mongolian gerbils, the catechin ECG was shown to eradicate 10-36\% (depending on the diet combination fed to the animals) of the treated gerbils (Mabe et al., 1999). According to Mabe et al., 1999, "EGC has demonstrated ability to inhibit the urease activity and motility of H.pylori”. Research conducted by Friedman et al., 2006 involving evaluation of antimicrobial activity of green tea catechins against Bacillus cereus revealed that "most compounds were more active than were medicinal antibiotics such as tetracycline and vancomycin at comparable concentrations”. Other applications of green tea extracts include antiseptic creams, mouthwashes (Taylor et al., 2005) and introduction to vacuum cleaner filters to reduce airborne contaminations (Hara, 2001).

\section{Hawthorn}

Hawthorn has been extensively used as medicinal material for their health effects and antioxidant activity in parts of Europe and China for hundreds of years (Liu, 2012). The Crataegus species commonly referred to as hawthorn has over 1000 species native to Asia, Europe and North America (Zhao and Tian, 1996). Hawthorn plants have been shown to contain procyanidins, flavanols, flavonols. C-glycosyl flavones, phenolic acids, anthocyanins and lignans (Liu, 2012) having astringent, antispasmodic, cardiotonic, diuretic, hypotensive and antiatherosclerotic properties (Tadić et al., 2008). Hawthorn extracts are consumed as tea, tinctures or fruits in Europe at upto $720 \mathrm{mg}$ /day (Benli et al., 2008). 
In a study conducted on rats using hawthorn extract against Micrococcus flavus, Bacillus subtilis and Lysteria monocytogenes showed "moderate bacterial acivity" and no effect against Candida albicans (Tadić et al., 2008). Antibacterial activity of ethanol extracts of Crataegus monogyna (Hawthorn) against S.aureus and E.coli and P.aeruginosa was observed using disk agar diffusion method (Ignat et al., 2013). A similar difference in antibacterial activity between ethanolic and water extracts of hawthorn on S.aureus and Klebsiella pneumonia was also observed (Niu et al., 2013). An observation by Niu et al., 2013, was that the higher percentage of gallic acid content present in the ethanol extract over water extract might explain the difference in antibacterial activity.

In studies using C. tanacetifolia, a Carataegusi species from Turkey, antibacterial effects were observed against Bacillus subtilis, Shigella, S.aureus and L.monocytogenes (Benli et al., 2008). Ethanol extracts of Crataegus oxyacantha, another variant of hawthorn, was investigated and shown ineffective against B.subtilis and S.aureus but effective against E.coli, P.aeruginosa and S.albony (Kostić et al., 2012). The “flavonoid structure” was found to influence effectivity against different bacteria (Kostic et al., 2012). The antibacterial activity of C.azarolus variety against S.aureus, E.faecalis, E.coli, S.enteritidis and S.typhimurium bacteria showed varying degrees of inhibition (Nadia et al., 2014). However, it was reported that C.monogyna and C.oxycantha berries in equal ratio in ethanol, similar to the mix found in commercially available extracts, showed moderate antibacterial activity against M.flavis, B.subtilis and L.monocytogenes and no effect against C.albicans (Tadic et al., 2008). In studies on the effect of Crataegus monogyna on C.jejuni (clinical isolate), the extract did not totally inhibit the growth of the bacterium but less than $25 \%$ growth was observed and the results were consistent for both water 
and methanol extracts (Galgóczy et al., 2009). Cartaegus pinnatifada, a species found in China has been used in native medicine and also combined with other herbs (Wu et al., 2014).

\section{Curcumin}

Curcumin is responsible for the yellow color of turmeric (Chattopadhyay et al., 2004). In 1815, Vogel and Pelletier isolated curcumin (Roughley et al., 1973). Its chemical structure was explained in 1973 (Roughley et al., 1973). In 1995, Ruby et al., stated curcumin to consist of 94\% curcumin I and 6\% of curcumon II and 0.3\% of curcumin III (Chattopadhyay et al., 2004). Human clinical trials have shown that curcumin has no toxicity at doses of 1-10 grams/day (Wu, 2003). The geographical source of curcumin has shown to play an important role in resistance to growth of bacteria (Naz et al., 2010). In studies involving comparison of antibacterial effects of microcapsule curcumin against S.aureus, B.subtilis, B.cereus, E.coli and Y.enterocolitica, results were comparable to free curcumin (Wang et al., 2009).

Curcumin has been found to help in control of E.coli, P.aeruginosa, Proteus mirabilis and Serratia marcescens by limiting the ability of these pathogens to form biofilms via quorum sensing (Packiavathy et al., 2014). The negative influence of curcumin on H.pylori biofilm formation was verified in studies by Pattiyathanee et al., 2009. This antimicrobial ability of curcumin against H.pylori was seen in infected mice and not dependent on the strain that caused the infection (De et al., 2009). Curcumin was found to control cell division in Bacillus subtilis, via filamentation (Rai et al., 2008).

Aqueous extracts of Curcuma longa from the Zingineraceae family had shown activity against E. coli, S. aureus, K. pneumoniae and S. epidermidis at low concentrations (Niamsa and Sittiwet, 2009). In a study of the effect of C.longa extracts against methicillin-resistant $S$. aureus, ethyl 
acetate extract of C.longa showed greater antibacterial action as compared to methanol or aqueous extracts (Kim et al., 2005). This is in agreement with other studies that showed the increased antibacterial activity of ethanolic extracts of Curcuma longa over aqueous extracts (Harit et al., 2013).

Synthetic modifications of curcumin like indium curcumin have shown antibacterial effects superior to curcumin in in vitro studies (Tajbakhsh et al., 2008). Bioconjugate and metalconjugate analogues have also been synthesized to improve the antibacterial activity of curcumin (Marathe et al., 2011).

\subsubsection{Effect of plant antimicrobial marinade on survival of Campylobacter in meat}

There is a significant increase in requirement of marinated broiler meat in some countries with taste and ease of cooking driving this need (Birk et al., 2010). The antibacterial effect of such marinades is an added benefit (Birk et al., 2010). Recent studies on the effect of thyme orange essential oil combination showed approx. $3 \log \mathrm{cfu} / \mathrm{ml}$ reduction in C. coli on the surface of breast fillets as compared to controls (Thanissery et al., 2014). A reduction of C. jejuni was observed over 35 days when using 3\% cultured sugar/vinegar blend on precooked chicken (Park et al., 2014). 


\section{REFERENCES}

Akthar, M. S., Degaga, B., \& Azam, T. (2014). Antimicrobial activity of essential oils extracted from medicinal plants against the pathogenic microorganisms: A review. Issues in Biological Sciences and Pharmaceutical Research, 2(1), 001-007.

An, B. J., Kwak, J. H., Son, J. H., Park, J. M., Lee, J. Y., Jo, C., \& Byun, M. W. (2004). Biological and anti-microbial activity of irradiated green tea polyphenols. Food Chemistry, 88(4), 549-555.

Alcaraz, L. E., Blanco, S. E., Puig, O. N., Tomas, F., \& Ferretti, F. H. (2000). Antibacterial Activity of Flavonoids Against Methicillin-resistant Staphylococcus aureus strains. Journal of theoretical biology, 205(2), 231-240.

Alonso, J. L., Mascellaro, S., Moreno, Y., Ferrús, M. A., \& Hernández, J. (2002). Doublestaining method for differentiation of morphological changes and membrane integrity of Campylobacter coli cells. Applied and environmental microbiology, 68(10), 5151-5154.

Altekruse, S. F., Stern, N. J., Fields, P. I., \& Swerdlow, D. L. (1999). Campylobacter jejuni--an emerging foodborne pathogen. Emerging infectious diseases, 5(1), 28.

Awad, W. A., K. Ghareeb, S. Abdel-Raheem, and J. Böhm. "Effects of dietary inclusion of probiotic and synbiotic on growth performance, organ weights, and intestinal histomorphology of broiler chickens." Poultry Science 88, no. 1 (2009): 49-56.

Bagust, T. J. (2013). Poultry health and disease control in developing countries.the role of poultry in human nutrition, 96.

Barrow, E. W., Dreier, J., Reinelt, S., Bourne, P. C., \& Barrow, W. W. (2007). In vitro efficacy of new antifolates against trimethoprim-resistant Bacillus anthracis. Antimicrobial agents and chemotherapy, 51(12), 4447-4452.

Bassolé, I. H. N., \& Juliani, H. R. (2012). Essential oils in combination and their antimicrobial properties. Molecules, 17(4), 3989-4006.

Benli, M., Yiğit, N., Geven, F., Güney, K., \& Bingöl, Ü. (2008). Antimicrobial activity of endemic Crataegus tanacetifolia (Lam.) Pers and observation of the inhibition effect on bacterial cells. Cell biochemistry and function, 26(8), 844-851.

Biondi, D., Cianci, P., Geraci, C., Ruberto, G., \& Piattelli, M. (1993). Antimicrobial activity and chemical composition of essential oils from Sicilian aromatic plants. Flavour and fragrance journal, 8(6), 331-337. 
Birk, T., Grønlund, A. C., Christensen, B. B., Knøchel, S., Lohse, K., \& Rosenquist, H. (2010). Effect of organic acids and marination ingredients on the survival of Campylobacter jejuni on meat. Journal of Food Protection ${ }^{\circledR}, 73(2), 258-265$.

Black, R. E., Levine, M. M., Clements, M. L., Hughes, T. P., \& Blaser, M. J. (1988). Experimental Campylobacter jejuni infection in humans. Journal of infectious diseases, 157(3), 472-479.

Blaser, M. J., Taylor, D. N., \& Feldman, R. A. (1983). Epidemiology of Campylobacter jejuni infections. Epidemiologic reviews, 5(1), 157-176.

Burt, Sara. "Essential oils: their antibacterial properties and potential applications in foods-a review." International journal of food microbiology 94.3 (2004): 223-253.

Burt, S. A., Ojo-Fakunle, V. T., Woertman, J., \& Veldhuizen, E. J. (2014). The Natural Antimicrobial Carvacrol Inhibits Quorum Sensing in Chromobacterium violaceum and Reduces Bacterial Biofilm Formation at Sub-Lethal Concentrations. PloS one, 9(4), e93414

Butzler, J. P. (2004). Campylobacter, from obscurity to celebrity. Clinical microbiology and infection, 10(10), 868-876.

Carrillo, C. D., Taboada, E., Nash, J. H., Lanthier, P., Kelly, J., Lau, P. C R Verhulp, 0. Mykytczuk, J. Sy, W. A. Findlay, K. Amoako, S. Gomis, P. Willson, J. W. Austin, A. Potter, L. Babiuk, B. Allan, and C. M. Szymanski. (2004). Genome-wide expression analyses of Campylobacter jejuni NCTC11168 reveals coordinate regulation of motility and virulence by flhA. Journal of Biological Chemistry, 279(19), 20327-20338.

CDC 2014. Center for Disease Control and Prevention. 2014. Campylobacter General Information. http://www.cdc.gov/nczved/divisions/dfbmd/diseases/Campylobacter/. Accessed August 2014.

Chattopadhyay, I., Biswas, K., Bandyopadhyay, U., \& Banerjee, R. K. (2004). Turmeric and curcumin: Biological actions and medicinal applications. Current science, 87(1), 44-53.

Chau, B., "Hawthorn, A Medicinal Plant”, http://mason.gmu.edu/ bchau1/Chem350/projects/plant/plant.html. Acessed Aug. 2014.

Chouliara, E., Karatapanis, A., Savvaidis, I. N., \& Kontominas, M. G. (2007). Combined effect of oregano essential oil and modified atmosphere packaging on shelf-life extension of fresh chicken breast meat, stored at 4 C. Food Microbiology, 24(6), 607-617.

Cleveland, J., Montville, T. J., Nes, I. F., \& Chikindas, M. L. (2001). Bacteriocins: safe, natural antimicrobials for food preservation. International journal of food microbiology, 71(1), 1-20. 
Cooper, R., Morré, D. J., \& Morré, D. M. (2005). Medicinal benefits of green tea: Part I. Review of noncancer health benefits. Journal of Alternative \& Complementary Medicine, 11(3), 521528.

Cosentino, S., Tuberoso, C. I. G., Pisano, B., Satta, M., Mascia, V., Arzedi, E., \& Palmas, F. (1999). In-vitro antimicrobial activity and chemical composition of Sardinian thymus essential oils. Letters in applied microbiology, 29(2), 130-135.

Cushnie, T. P., \& Lamb, A. J. (2005). Antimicrobial activity of flavonoids. International journal of antimicrobial agents, 26(5), 343-356.

Daglia, M. (2012). Polyphenols as antimicrobial agents. Current opinion in biotechnology, 23(2), 174-181.

Dasti, J. I., Tareen, A. M., Lugert, R., Zautner, A. E., \& Groß, U. (2010). Campylobacter jejuni: A brief overview on pathogenicity-associated factors and disease-mediating mechanisms. International Journal of Medical Microbiology, 300(4), 205-211.

Dave, D., \& Ghaly, A. E. (2011). Meat spoilage mechanisms and preservation techniques: A critical review. American Journal of Agricultural and Biological Sciences, 6(4), 486.

Davidson, P. M., Critzer, F. J., \& Taylor, T. M. (2013). Naturally occurring antimicrobials for minimally processed foods. Annual review of food science and technology, 4, 163-190.

Davis, L., \& DiRita, V. (2008). Growth and laboratory maintenance of Campylobacter jejuni. Current protocols in microbiology, 8A-1.

De, R., Kundu, P., Swarnakar, S., Ramamurthy, T., Chowdhury, A., Nair, G. B., \& Mukhopadhyay, A. K. (2009). Antimicrobial activity of curcumin against Helicobacter pylori isolates from India and during infections in mice. Antimicrobial agents and chemotherapy, 53(4), 1592-1597.

Debruyne, L., Gevers, D., \& Vandamme, P. (2008). Taxonomy of the family Campylobacteraceae. Campylobacter, 3-25.

Doyle, M. P., \& Erickson, M. C. (2012). Opportunities for mitigating pathogen contamination during on-farm food production. International journal of food microbiology, 152(3), 54-74.

Du, W. X., Olsen, C. W., Avena-Bustillos, R. J., McHugh, T. H., Levin, C. E., Mandrell, R., \& Friedman, M. (2009). Antibacterial Effects of Allspice, Garlic, and Oregano Essential Oils in Tomato Films Determined by Overlay and Vapor-Phase Methods. Journal of food science, 74(7), M390-M397.

Duan, Q., Zhou, M., Zhu, L., \& Zhu, G. (2013). Flagella and bacterial pathogenicity. Journal of basic microbiology, 53(1), 1-8. 
Dussault, D., Vu, K. D., \& Lacroix, M. (2014). In vitro evaluation of antimicrobial activities of various commercial essential oils, oleoresin and pure compounds against food pathogens and application in ham. Meat science,96(1), 514-520.

Ellis-Iversen, J., Jorgensen, F., Bull, S., Powell, L., Cook, A. J., \& Humphrey, T. J. (2009). Risk factors for Campylobacter colonisation during rearing of broiler flocks in Great Britain.

Preventive veterinary medicine, 89(3), 178-184.

El Gharras, H. (2009). Polyphenols: food sources, properties and applications-a

review. International journal of food science \& technology, 44(12), 2512-2518.

Epps, S. V., Harvey, R. B., Hume, M. E., Phillips, T. D., Anderson, R. C., \& Nisbet, D. J. (2013). Foodborne Campylobacter: Infections, Metabolism, Pathogenesis and

Reservoirs. International journal of environmental research and public health, 10(12), 62926304.

Escherich, T. (1886). Über das Vorkommen von Vibrionen im Darmkanal und den Stuhlgängen der Säuglinge. Münch Med Wochenschr, 33, 815-817.

Friedman, C. R. (2000). Epidemiology of Campylobacter jejuni infections in the United States and other industrialized nations. Campylobacter, 121-138.

Friedman, M., Henika, P. R., Levin, C. E., Mandrell, R. E., \& Kozukue, N. (2006).

Antimicrobial activities of tea catechins and theaflavins and tea extracts against Bacillus cereus. Journal of Food Protection, 69(2), 354-361.

Fisher, K., \& Phillips, C. (2008). Potential antimicrobial uses of essential oils in food: is citrus the answer? Trends in food science \& technology, 19(3), 156-164.

Gaggìa, F., Mattarelli, P., \& Biavati, B. (2010). Probiotics and prebiotics in animal feeding for safe food production. International Journal of Food Microbiology, 141, S15-S28.

Galgóczy, L., Hevér, T., Orosz, L., Krisch, J., Vágvölgyi, C., Tölgyesi, M., \& Papp, T. (2009).

Growth inhibition effect of fruit juices and pomace extracts on the enteric pathogens

Campylobacter jejuni and -Salmonella ser. Typhimurium. The Internet Journal of Microbiology, 7.

Ghareeb, K., Awad, W. A., Mohnl, M., Schatzmayr, G., \& Boehm, J. (2013). Control strategies for Campylobacter infection in poultry production. World's Poultry Science Journal, 69(01), 5776.

Golden, N. J., \& Acheson, D. W. (2002). Identification of motility and autoagglutination Campylobacter jejuni mutants by random transposon mutagenesis. Infection and immunity, 70(4), 1761-1771. 
Gramza, A., Khokhar, S., Yoko, S., Gliszczynska-Swiglo, A., Hes, M., \& Korczak, J. (2006). Antioxidant activity of tea extracts in lipids and correlation with polyphenol content. European journal of lipid science and technology, 108(4), 351-362.

Grant, C. C., Konkel, M. E., Cieplak, W., \& Tompkins, L. S. (1993). Role of flagella in adherence, internalization, and translocation of Campylobacter jejuni in nonpolarized and polarized epithelial cell cultures. Infection and immunity,61(5), 1764-1771.

Gundogdu, O., Bentley, S. D., Holden, M. T., Parkhill, J., Dorrell, N., \& Wren, B. W. (2007). Re-annotation and re-analysis of the Campylobacter jejuni NCTC11168 genome sequence. BMC genomics, 8(1), 162.

Hamilton-Miller, J. M. (1995). Antimicrobial properties of tea (Camellia sinensis L.). Antimicrobial agents and chemotherapy, 39(11), 2375.

Hamilton-Miller, J. M. T. (1997). Microbial properties of tea infusions. Chemical and biological properties of tea infusions. Frankfurt, Germany: $U$ \& M, 63-74.

Hammer, K. A., Carson, C. F., \& Riley, T. V. (1999). Antimicrobial activity of essential oils and other plant extracts. Journal of applied microbiology, 86(6), 985-990.

Hannu, T., Mattila, L., Rautelin, H., Pelkonen, P., Lahdenne, P., Siitonen, A., \& Leirisalo-Repo, M. (2002). Campylobacter-triggered reactive arthritis: a population-based

study. Rheumatology, 41(3), 312-318.

Hara, Y. (2001). Green tea: health benefits and applications. CRC Press.

Harborne, J. B., \& Williams, C. A. (2000). Advances in flavonoid research since 1992. Phytochemistry, 55(6), 481-504.

Harit, J., Barapatre, A., Prajapati, M., Aadil, K. R., \& Senapati, S. (2013). Antimicrobial Activity of Rhizome of Selected Curcuma Variety. International Journal of Life Sciences Biotechnology and Pharma Research, 2, 183-189.

Hayek, S. A., Gyawali, R., \& Ibrahim, S. A. (2013). Antimicrobial Natural Products.

Hazeleger, W. C., Wouters, J. A., Rombouts, F. M., \& Abee, T. (1998). Physiological activity of Campylobacter jejuni far below the minimal growth temperature. Applied and Environmental Microbiology, 64(10), 3917-3922.

Hermans, D., Van Deun, K., Martel, A., Van Immerseel, F., Messens, W., Heyndrickx, M., ... \& Pasmans, F. (2011). Colonization factors of Campylobacter jejuni in the chicken gut. Vet Res, 42(82), 10-1186. 
Hermans, D., Pasmans, F., Messens, W., Martel, A., Van Immerseel, F., Rasschaert, G., ... \& Haesebrouck, F. (2012a). Poultry as a host for the zoonotic pathogen Campylobacter jejuni. Vector-Borne and Zoonotic Diseases, 12(2), 89-98.

Hermans, D., Pasmans, F., Heyndrickx, M., Van Immerseel, F., Martel, A., Van Deun, K., \& Haesebrouck, F. (2012b). A tolerogenic mucosal immune response leads to persistent Campylobacter jejuni colonization in the chicken gut. Critical reviews in microbiology, 38(1), 17-29.

Holley, R. A., \& Patel, D. (2005). Improvement in shelf-life and safety of perishable foods by plant essential oils and smoke antimicrobials. Food Microbiology, 22(4), 273-292.

Hood, J. R., Wilkinson, J. M., \& Cavanagh, H. M. (2003). Evaluation of common antibacterial screening methods utilized in essential oil research. Journal of Essential Oil Research, 15(6), 428-433.

Horrocks, S. M., Anderson, R. C., Nisbet, D. J., \& Ricke, S. C. (2009). Incidence and ecology of Campylobacter jejuni and coli in animals. Anaerobe, 15(1), 18-25.

Hu, L., \& Kopecko, D. J. (2008). Cell biology of human host cell entry by Campylobacter jejuni. Campylobacter, 3, 297-313.

Hyldgaard, M., Mygind, T., \& Meyer, R. L. (2012). Essential oils in food preservation: mode of action, synergies, and interactions with food matrix components. Frontiers in microbiology, 3.

Ignat, I., Radu, D. G., Volf, I., Pag, A. I., \& Popa, V. I. (2013). Antioxidant and antibacterial activities of some natural polyphenols. cytokines, 4, 5 .

Ikeda, N., \& Karlyshev, A. V. (2012). Putative mechanisms and biological role of coccoid form formation in Campylobacter jejuni. European Journal of Microbiology and Immunology, 2(1), 41-49.

Iovine, N. M. (2013). Resistance mechanisms in Campylobacter jejuni. Virulence, 4(3), 230-240. Izzo, A. A., Di Carlo, G., Biscardi, D., De Fusco, R., Mascolo, N., Borrelli, F., ... \& Fasulo, M. P. (1995). Biological screening of Italian medicinal plants for antibacterial activity. Phytotherapy research, 9(4), 281-286.

Jayasena, D.D. and Jo, C., “ Essential oils as potential antimicrobial agents in meat and meat products: A Review”, Trends in Food Science and Technology, 34(2) December 2013, Pages 96108.

Jensen, A.N., Dalsgard, A., Anderson, Baggesen, D.I. and R., Nibet, D., “ The occurrence and characterization of Campylobacter jejuni and C.coli in organic pigs and their outdoor environment”, Vet Microbiology, 2006, 116,96-105. 
Jordan, K., Dalmasso, M., Zentek, J., Mader, A., Bruggeman, G., Wallace, J., ... \& Malakauskas, M. (2014). Microbes versus microbes: control of pathogens in the food chain. Journal of the Science of Food and Agriculture.

Joshua, G. P., Guthrie-Irons, C., Karlyshev, A. V., \& Wren, B. W. (2006). Biofilm formation in Campylobacter jejuni. Microbiology, 152(2), 387-396.

Karami-Osboo, R., Khodaverdi, M., \& Ali-Akbari, F. (2010). Antibacterial effect of effective compounds of Satureja hortensis and Thymus vulgaris essential oils against Erwinia amylovora. Journal of Agricultural Science and Technology, 12, 35-45.

Ketley, J. M. (1997). Pathogenesis of enteric infection by Campylobacter.Microbiology, 143(1), 5-21.

Kim, J., Marshall, M. R., \& Wei, C. I. (1995). Antibacterial activity of some essential oil components against five foodborne pathogens. Journal of Agricultural and Food Chemistry, 43(11), 2839-2845.

Kim, K. J., Yu, H. H., Cha, J. D., Seo, S. J., Choi, N. Y., \& You, Y. O. (2005). Antibacterial activity of Curcuma longa L. against methicillin-resistant Staphylococcus aureus. Phytotherapy Research, 19(7), 599-604

King, E. O. (1957). Human infections with Vibrio fetus and a closely related vibrio. Journal of Infectious Diseases, 101(2), 119-128.

Kintzios S (2003) Oregano. In: Handbook of Herbs and Spices Volume 2 (Ed. Peter K.V.) Woodhead, Amsterdam , pp.115-129.

Klančnik, A., Piskernik, S., Jeršek, B., \& Možina, S. S. (2010). Evaluation of diffusion and dilution methods to determine the antibacterial activity of plant extracts. Journal of microbiological methods, 81(2), 121-126.

Klančnik, A., Možina, S. S., \& Zhang, Q. (2012). Anti-Campylobacter activities and resistance mechanisms of natural phenolic compounds in Campylobacter.PloS one, 7(12), e51800.

Koluman, A., \& Dikici, A. (2013). Antimicrobial resistance of emerging foodborne pathogens: status quo and global trends. Critical reviews in microbiology, 39(1), 57-69.

Konkel, M. E., Monteville, M. R., Rivera-Amill, V., \& Joens, L. A. (2001). The pathogenesis of Campylobacter jejuni-mediated enteritis. Current issues in intestinal microbiology, 2(2), 55-71.

Konkel, M. E., Klena, J. D., Rivera-Amill, V., Monteville, M. R., Biswas, D., Raphael, B., \& Mickelson, J. (2004). Secretion of virulence proteins from Campylobacter jejuni is dependent on a functional flagellar export apparatus.Journal of bacteriology, 186(11), 3296-3303. 
Kostić, D. A., Velicković, J. M., Mitić, S. S., Mitić, M. N., \& Randelović, S. S. (2012). Phenolic content, and antioxidant and antimicrobial activities of Crataegus oxyacantha $L$ (Rosaceae) fruit extract from Southeast Serbia. Tropical Journal of Pharmaceutical Research, 11(1), 117-124.

Kotan, R., Dadasoğlu, F., Karagoz, K., Cakir, A., Ozer, H., Kordali, S., ... \& Dikbas, N. (2013). Antibacterial activity of the essential oil and extracts of Satureja hortensis against plant pathogenic bacteria and their potential use as seed disinfectants. Scientia Horticulturae, 153, 3441.

Krisch, J., Galgóczy, L., Tölgyesi, M., Papp, T., \& Vágvölgyi, C. (2008). Effect of fruit juices and pomace extracts on the growth of Gram-positive and Gram-negative bacteria. Acta Biol Szeged, 52(2), 267-270.

Kuttappan, V. A., Faulkner, O. T., Wolfenden, A. D., Tellez, G., Hargis, B. M., \& Bielke, L. R. (2013). Novel Recombinant Food Safety Vaccines against Salmonella and Campylobacter in Broiler Chickens. International Journal of Biotechnology and Bioengineering Research. Volume 4(6), 589-596

Lambert, R. J. W., Skandamis, P. N., Coote, P. J., \& Nychas, G. J. (2001). A study of the minimum inhibitory concentration and mode of action of oregano essential oil, thymol and carvacrol. Journal of applied microbiology, 91(3), 453-462.

Lassen, J., \& Kapperud, G. (1984). Epidemiological aspects of enteritis due to Campylobacter spp. in Norway. Journal of clinical microbiology, 19(2), 153-156.

Leistner, Lothar. "Basic aspects of food preservation by hurdle technology."International Journal of Food Microbiology 55, no. 1 (2000): 181-186.

Lin, J. (2009). Novel approaches for Campylobacter control in poultry.Foodborne pathogens and disease, 6(7), 755-765.

Liu, P. (2012, May). Composition of Hawthorn (Crataegus spp.) Fruits and Leaves and emblic Leafflower (Phyllanthus emblica) Fruits. Turku, University of Turku. Department of Biochemistry and Food Chemistry and Functional Foods Forum.

Lorenzo, José M., et al. "Influence of natural extracts on the shelf life of modified atmospherepackaged pork patties." Meat science 96.1 (2014): 526-534.

Lv, F., Liang, H., Yuan, Q., \& Li, C. (2011). In vitro antimicrobial effects and mechanism of action of selected plant essential oil combinations against four food-related microorganisms. Food Research International, 44(9), 3057-3064.

Mabe, K., Yamada, M., Oguni, I., \& Takahashi, T. (1999). In vitro and in vivo activities of tea catechins against Helicobacter pylori. Antimicrobial agents and chemotherapy, 43(7), 17881791. 
Madden, R.H., Moran, L. and Scates, P., “ Optimising recovery of Campylobacter spp. from the lower oricine gastrointestinal tract”, Journal of Microbiol. Meth., 2000, 42, 115-119.

Marathe, S. A., Dasgupta, I., Gnanadhas, D. P., \& Chakravortty, D. (2011). Multifaceted roles of curcumin: two sides of a coin!. Expert opinion on biological therapy, 11(11), 1485-1499.

Marino, M., Bersani, C., \& Comi, G. (2001). Impedance measurements to study the antimicrobial activity of essential oils from Lamiaceae and Compositae . International Journal of Food Microbiology, 67(3), 187-195..

Mbata, T. I., Debiao, L. U., \& Saikia, A. (2008). Antibacterial activity of the crude extract of Chinese green tea (Camellia sinensis) on Listeria monocytogenes. African Journal of Biotechnology, 7(10).

Middleton Jr, E., \& Kandaswami, C. (1994). The impact of plant flavonoids on mammalian biology: implications for immunity, inflammation and cancer. In The flavonoids (pp. 619-652). Springer US.

Miller, William G.. 2008. Comparative Genomics of Campylobacter Species Other than Campylobacter jejuni, p 73-95. In Nachamkin, Irving and Szymanski, Christine M. and Blaser, Martin J.(ed), Campylobacter , Third Edition. doi:10.1128/9781555815554.ch5

Mith, H., Duré, R., Delcenserie, V., Zhiri, A., Daube, G., \& Clinquart, A. (2014). Antimicrobial activities of commercial essential oils and their components against foodborne pathogens and food spoilage bacteria. Food Science \& Nutrition.

Možina, S. S., Kurinčič, M., Klančnik, A., \& Mavri, A. (2011).Campylobacter and its multiresistance in the food chain. Trends in Food Science \& Technology, 22(2), 91-98.

Murphy, C., Carroll, C., \& Jordan, K. N. (2006). Environmental survival mechanisms of the foodborne pathogen Campylobacter jejuni. Journal of applied microbiology, 100(4), 623-632.

Nachamkin, I., Szymanski, C. M., \& Blaser, M. J. (2008). Campylobacter (No. Ed. 3). ASM Press.

Nadia, M., Imen, M., Mounira, K., Fadwa, C., Zied, G., Kamel, G., ... \& Leila, C. G. (2014). Antibacterial activity and modulation of antibiotic resistance by Crataegus azarolus extracts. Journal of Natural Products, 7.

Naz, S., Jabeen, S., Ilyas, S., Manzoor, F., Aslam, F., \& Ali, A. (2010). Antibacterial activity of Curcuma longa varieties against different strains of bacteria. Pak. J. Bot, 42(1), 455-462.

Newell, D. G., Elvers, K. T., Dopfer, D., Hansson, I., Jones, P., James, S., ... \& Allen, V. M. (2011). Biosecurity-based interventions and strategies to reduce Campylobacter spp. on poultry farms. Applied and environmental microbiology,77(24), 8605-8614. 
Ng, L. K., Sherburne, R., Taylor, D. E., \& Stiles, M. E. (1985). Morphological forms and viability of Campylobacter species studied by electron microscopy.Journal of bacteriology, 164(1), 338-343.

Niamsa, N., \& Sittiwet, C. (2009). Antimicrobial activity of Curcuma longa aqueous extract. Journal of Pharmacology and Toxicology, 4(4), 173-177.

Nichols, G. L., Richardson, J. F., Sheppard, S. K., Lane, C., \& Sarran, C. (2012). Campylobacter epidemiology: a descriptive study reviewing 1 million cases in England and Wales between 1989 and 2011. BMJ open, 2(4).

Nijveldt, R. J., Van Nood, E. L. S., Van Hoorn, D. E., Boelens, P. G., Van Norren, K., \& Van Leeuwen, P. A. (2001). Flavonoids: a review of probable mechanisms of action and potential applications. The American journal of clinical nutrition, 74(4), 418-425.

Niu, Y., Nan, Y., Yuan, L., \& Wang, R. (2013). Study on Antibacterial Effect of Medlar and Hawthorn Compound Extract In Vitro. African Journal of Traditional, Complementary, and Alternative Medicines, 10(3), 567.

Oussalah, M., Caillet, S., Saucier, L., \& Lacroix, M. (2006). Antimicrobial effects of selected plant essential oils on the growth of a Pseudomonas putida strain isolated from meat. Meat science, 73(2), 236-244.

Packiavathy, I. A. S. V., Priya, S., Pandian, S. K., \& Ravi, A. V. (2014). Inhibition of biofilm development of uropathogens by curcumin-An anti-quorum sensing agent from Curcuma longa. Food chemistry, 148, 453-460.

Park, N. Y., Hong, S. H., \& Yoon, K. S. (2014). Effects of commercial marinade seasoning and a natural blend of cultured sugar and vinegar on Campylobacter jejuni and Salmonella Typhimurium and the texture of chicken breasts. Poultry science, 93(3), 719-727.

Parkhill, J., Wren, B. W., Mungall, K., Ketley, J. M., Churcher, C., Basham, D., Chillingworth, T., Davies, R.M., Feltwell, T., Holroyd, S., Jagels, K., Karlyshev, A.V., Moule, S., Pallen, M.J., Pennl, C.W., Quail, M.A., Rajandream, M-A., Rutherford, K.M., van Villet, A.H.M., Whithead, M.A. \& Barrell, B. G. (2000). The genome sequence of the food-borne pathogen Campylobacter jejuni reveals hypervariable sequences. Nature, 403(6770), 665-668.

Pattiyathanee, P., Vilaichone, R. K., \& Chaichanawongsaroj, N. (2009). Effect of curcumin on Helicobacter pylori biofilm formation. African Journal of Biotechnology, 8(19).

Peterson, M. C. (1994). Clinical aspects of Campylobacter jejuni infections in adults. Western journal of medicine, 161(2), 148.

Pickett, C. L. (2000). Campylobacter toxins and their role in pathogenesis.Campylobacter, 2nd ed. ASM Press, Washington, DC, 179-190. 
Pol, I. E., \& Smid, E. J. (1999). Combined action of nisin and carvacrol on Bacillus cereus and Listeria monocytogenes. Letters in Applied Microbiology,29(3), 166-170.

Pope, J. E., Krizova, A., Garg, A. X., Thiessen-Philbrook, H., \& Ouimet, J. M. (2007, August). Campylobacter reactive arthritis: a systematic review. InSeminars in arthritis and rheumatism (Vol. 37, No. 1, pp. 48-55). WB Saunders.

Rai, D., Singh, J., Roy, N., \& Panda, D. (2008). Curcumin inhibits FtsZ assembly: an attractive mechanism for its antibacterial activity. Biochem. J,410, 147-155.

Rice-Evans, C., Miller, N., \& Paganga, G. (1997). Antioxidant properties of phenolic compounds. Trends in plant science, 2(4), 152-159.

Rosenquist, H., Boysen, L., Galliano, C., Nordentoft, S., Ethelberg, S., \& Borck, B. (2009). Danish strategies to control Campylobacter in broilers and broiler meat: facts and effects. Epidemiology and infection, 137(12), 1742-1750.

Roughley, P. J., \& Whiting, D. A. (1973). Experiments in the biosynthesis of curcumin. Journal of the Chemical Society, Perkin Transactions 1, 2379-2388.

Rubinchik, S., Seddon, A., \& Karlyshev, A. V. (2012). Molecular mechanisms and biological role of Campylobacter jejuni attachment to host cells. European Journal of Microbiology and Immunology, 2(1), 32-40.

Ruby, A. J., Kuttan, G., Dinesh Babu, K., Rajasekharan, K. N., \& Kuttan, R. (1995). Antitumour and antioxidant activity of natural curcuminoids. Cancer letters, 94(1), 79-83.

Ruiz-Palacios, G., Torres, N., Ruiz-Palacios, B., Torres, J., Escamilla, E., \& Tamayo, J. (1983). Cholera-like enterotoxin produced by Campylobacter jejuni: characterisation and clinical significance. The Lancet, 322(8344), 250-253.

Sahin, O., Luo, N., Huang, S., \& Zhang, Q. (2003). Effect of Campylobacter-specific maternal antibodies on Campylobacter jejuni colonization in young chickens. Applied and environmental microbiology, 69(9), 5372-5379.

Skandamis, P., Tsigarida, E., \& Nychas, G. J. (2002). The effect of oregano essential oil on survival/death of Salmonella typhimurium in meat stored at $5^{\circ} \mathrm{C}$ under aerobic, VP/MAP conditions. Food Microbiology, 19(1), 97-103.

Salmon, D. A., \& Halsey, N. A. (2013). Guillain-Barré syndrome and vaccinations. Clinical infectious diseases, cit218.

Shanker, S., Lee, A., \& Sorrell, T. C. (1990). Horizontal transmission of Campylobacter jejuni amongst broiler chicks: experimental studies. Epidemiology and Infection, 104(01), 101-110. 
Shahrizaila, N., \& Yuki, N. (2010). Guillain-Barré syndrome animal model: the first proof of molecular mimicry in human autoimmune disorder. BioMed Research International, 2011.

Shimamura, T., Zhao, W. H., \& Hu, Z. Q. (2007). Mechanism of action and potential for use of tea catechin as an antiinfective agent. Anti-Infective Agents in Medicinal Chemistry (Formerly Current Medicinal Chemistry-Anti-Infective Agents), 6(1), 57-62.

Si, W., Gong, J., Tsao, R., Kalab, M., Yang, R., \& Yin, Y. (2006). Bioassay-guided purification and identification of antimicrobial components in Chinese green tea extract. Journal of Chromatography A, 1125(2), 204-210.

Siripatrawan, U., \& Noipha, S. (2012). Active film from chitosan incorporating green tea extract for shelf life extension of pork sausages. Food Hydrocolloids,27(1), 102-108.

Skirrow, M. B. (1977). Campylobacter enteritis: a" new" disease. British medical journal, 2(6078), 9.

Skirrow, M. B. (1982). Campylobacter enteritis-the first five years. Journal of Hygiene, 89(02), 175-184.

Škrinjar, M. M., \& Nemet, N. T. (2009). Antimicrobial effects of spices and herbs essential oils. Acta periodica technologica, (40), 195-209.

Smid, E. J., \& Gorris, L. G. (1999). Natural antimicrobials for food preservation. FOOD SCIENCE AND TECHNOLOGY-NEW YORK-MARCEL DEKKER-, 285-308.

Song, Y. C., Jin, S., Louie, H., Ng, D., Lau, R., Zhang, Y ., Weerasekera, S. Al Rashid, L. A. Ward, S. D. Der, and V. L. Chan. (2004). FlaC, a protein of Campylobacter jejuni TGH9011 (ATCC43431) secreted through the flagellar apparatus, binds epithelial cells and influences cell invasion. Molecular microbiology, 53(2), 541-553.

Stahl, M., \& Stintzi, A. (2011). Identification of essential genes in C. jejuni genome highlights hyper-variable plasticity regions. Functional \& integrative genomics, 11(2), 241-257.

Stewart, A. J., Mullen, W., \& Crozier, A. (2005). On-line high-performance liquid chromatography analysis of the antioxidant activity of phenolic compounds in green and black tea. Molecular nutrition \& food research, 49(1), 52-60.

Svensson, S. L., Frirdich, E., \& Gaynor, E. C. (2008). Survival strategies of Campylobacter jejuni: stress responses, the viable but nonculturable state, and biofilms. Campylobacter, 3rd ed. ASM Press, Washington, DC, 571-590.

Tadić, V. M., Dobrić, S., Marković, G. M., Đorđević, S. M., Arsić, I. A., Menković, N. R., \& Stević, T. (2008). Anti-inflammatory, gastroprotective, free-radical-scavenging, and 
antimicrobial activities of hawthorn berries ethanol extract. Journal of agricultural and food chemistry, 56(17), 7700-7709.

Tajbakhsh, S., Mohammadi, K., Deilami, I., Zandi, K., Fouladvand, M., Ramedani, E., \& Asayesh, G. (2008). Antibacterial activity of indium curcumin and indium diacetylcurcumin. African Journal of Biotechnology, 7(21).

Tajkarimi, M. M., S. A. Ibrahim, and D. O. Cliver. "Antimicrobial herb and spice compounds in food." Food control 21.9 (2010): 1199-1218.

Taylor, P. W., Hamilton-Miller, J. M., \& Stapleton, P. D. (2005). Antimicrobial properties of green tea catechins. Food science and technology bulletin, 2, 71.

Taylor, E. V., Herman, K. M., Ailes, E. C., Fitzgerald, C., Yoder, J. S., Mahon, B. E., \& Tauxe, R. V. (2013). Common source outbreaks of Campylobacter infection in the USA, 19972008. Epidemiology and infection, 141(05), 987-996.

Techathuvanan, C., Reyes, F., David, J. R., \& Davidson, P. M. (2014). Efficacy of Commercial Natural Antimicrobials Alone and in Combinations against Pathogenic and Spoilage Microorganisms. Journal of Food Protection, 77(2), 269-275.

Thanissery, R., and D. P. Smith. "Marinade with thyme and orange oils reduces Salmonella Enteritidis and Campylobacter coli on inoculated broiler breast fillets and whole wings." Poultry science 93.5 (2014): 1258-1262.

Tiwari, B. K., Valdramidis, V. P., O’Donnell, C. P., Muthukumarappan, K., Bourke, P., \& Cullen, P. J. (2009). Application of natural antimicrobials for food preservation. Journal of agricultural and food chemistry, 57(14), 5987-6000.

Townes, J. M. (2010). Reactive arthritis after enteric infections in the United States: the problem of definition. Clinical Infectious Diseases, 50(2), 247-254.

Van Spreeuwel, J. P., Duursma, G. C., Meijer, C. J., Bax, R., Rosekrans, P. C., \& Lindeman, J. (1985). Campylobacter colitis: histological immunohistochemical and ultrastructural findings. Gut, 26(9), 945-951.

Van Vuuren, S., \& Viljoen, A. (2011). Plant-based antimicrobial studies-methods and approaches to study the interaction between natural products. Planta Medica-Natural Products and MedicinalPlant Research, 77(11), 1168.

Veron, M., \& Chatelain, R. (1973). Taxonomic study of the genus Campylobacter Sebald and Véron and designation of the neotype strain for the type species, Campylobacter fetus (Smith and Taylor) Sebald and Véron. International Journal of Systematic Bacteriology, 23(2), 122-134. 
Vogel, H. A., \& Pelletier, J. (1815). Curcumin-biological and medicinal properties. J Pharma, 2, 50-50.

Wang, H., Provan, G. J., \& Helliwell, K. (2000). Tea flavonoids: their functions, utilisation and analysis. Trends in Food Science \& Technology, 11(4), 152-160.

Wang, Y., Lu, Z., Wu, H., \& Lv, F. (2009). Study on the antibiotic activity of microcapsule curcumin against foodborne pathogens. International journal of food microbiology, 136(1), 7174.

Wieczorek, K., \& Osek, J. (2013). Antimicrobial resistance mechanisms among Campylobacter. BioMed research international, 2013.

Witkowska, A. M., Hickey, D. K., Alonso-Gomez, M., \& Wilkinson, M. (2013). Evaluation of antimicrobial activities of commercial herb and spice extracts against selected food-borne bacteria. Journal of Food Research, 2(4), p37.

Whiley, H., van den Akker, B., Giglio, S., \& Bentham, R. (2013). The role of environmental reservoirs in human Campylobacteriosis. International journal of environmental research and public health, 10(11), 5886-5907.

WHO. 2011. Campylobacter. http://www.who.int/mediacentre/factsheets/fs255/en/. Accessed August 2014.

Wu, C. N., (2003). Safety and anti-inflammatory activity of curcumin: a component of tumeric (Curcuma longa). The Journal of Alternative \& Complementary Medicine, 9(1), 161-168.

Wu, J., Peng, W., Qin, R., \& Zhou, H. (2014). Crataegus pinnatifida: chemical constituents, pharmacology, and potential applications. Molecules, 19(2), 1685-1712.

Yam, T. S., Shah, S., \& Hamilton-Miller, J. M. T. (1997). Microbiological activity of whole and fractionated crude extracts of tea (Camellia sinensis), and of tea components. FEMS microbiology letters, 152(1), 169-174.

Yao, R., Burr, D. H., \& Guerry, P. (1997). CheY-mediated modulation of Campylobacter jejuni virulence. Molecular microbiology, 23(5), 1021-1031.

Yoda, Y., Hu, Z. Q., Zhao, W. H., \& Shimamura, T. (2004). Different susceptibilities of Staphylococcus and Gram-negative rods to epigallocatechin gallate. Journal of Infection and Chemotherapy, 10(1), 55-58.

Young, K. T., Davis, L. M., \& DiRita, V. J. (2007). Campylobacter jejuni: molecular biology and pathogenesis. Nature Reviews Microbiology, 5(9), 665-679. 
Zhao, H. C., \& Tian, B. F. (1996). China fruit-plant monograph, hawthorn flora. Zhongguo Lin Ye Press, Beijing, 14.

Zhou, G. H., Xu, X. L., \& Liu, Y. "Preservation technologies for fresh meat: A review”, Meat Science, (2010), 86, 119-128.

Zhou, Y., Bu, L., Guo, M., Zhou, C., Wang, Y., Chen, L., \& Liu, J. (2013). Comprehensive genomic characterization of Campylobacter genus reveals some underlying mechanisms for its genomic diversification. PloS one, 8(8), e70241.

Zilbauer, M., Dorrell, N., Wren, B. W., \& Bajaj-Elliott, M. (2008). Campylobacter jejunimediated disease pathogenesis: an update. Transactions of the Royal Society of Tropical Medicine and Hygiene, 102(2), 123-129.

Zivanovic, S., Chi, S., \& Draughon, A. F. (2005). Antimicrobial activity of chitosan films enriched with essential oils. Journal of Food Science, 70(1), M45-M51. 
CHAPTER 3

\section{ANTIBACTERIAL ACTIVITY OF COMMERCIALLY AVAILABLE PLANT EXTRACTS ON SELECTED CAMPYLOBACTER JEJUNI STRAINS}




\title{
ANTIBACTERIAL ACTIVITY OF COMMERCIALLY AVAILABLE PLANT EXTRACTS ON SELECTED CAMPYLOBACTER JEJUNI STRAINS
}

\author{
D.O. Sivasankaran ${ }^{1}$, G.S. Kumar-Phillips ${ }^{1}$, N.C. Rath ${ }^{1,2}$, J.Marcy ${ }^{1}$, M.F. Slavik ${ }^{1}$ \\ ${ }^{1}$ Poultry Science Department, University of Arkansas, Fayetteville, Arkansas 72701. \\ ${ }^{2}$ USDA/ARS
}

${ }^{1}$ To whom correspondence should be addressed:

Michael. F. Slavik, POSC O-310 1260 W.Maple St. University of Arkansas, Fayetteville, AR72701 (479) 5754387 Fax: (479) 5754202 mslavik@uark.edu 


\begin{abstract}
Campylobacter jejuni causes over 99\% of the foodborne infections associated with Campylobacter in the United States. This study involves evaluation of commercially available plant extracts of oregano, green tea, hawthorn and curcumin against four isolates of C. jejuni. Initial studies were carried out in broth cultures to determine the effectiveness of the extracts. Then, the study was carried out on chicken breast meat. Cell counts were determined at intervals of 0, 2, 6 and 24 hours and bacterial viability was determined using different concentrations of the above extracts. Both oregano and green tea extracts were found to be antibacterial in broth cultures that killed all bacteria at 24 hours. As marinades, the extracts were found to be effective only at high concentrations. No significant differences were found in the antibacterial effects of the extracts on different $C$. jejuni strains. These results demonstrate that commercially available plant extracts such as oregano and green tea have potential to reduce and/or eliminate C. jejuni in chicken meat.
\end{abstract}

KEYWORDS: C. jejuni, Green tea, Oregano, Hawthorn, Curcumin, Plant Extracts 


\section{INTRODUCTION}

Foodborne illnesses are a cause of concern for both developed and developing countries requiring food security to be carefully monitored by governments as populations grow and average life spans increase. In such an environment antimicrobials added to foods and used in food marinades have become important in reducing bacterial activity (Davidson et al., 2013). To reduce bacterial loads on meat is especially challenging because of the rich nutritional availability, pH and water activity level (Jayasena \& Jo, 2013).

Campylobacter spp. is one of the major causes of foodborne illnesses in the world. Although symptoms of this condition are usually not severe, the total annual cost as a result of these infections is millions of dollars in the United States. Investigations have revealed significant links between human Campylobacter jejuni infections and the consumption of undercooked poultry (Altekruse et al., 1999). Poultry products are an important component of the human diet and the safety of poultry products is very important (Venkitanarayanan et al., 2013). In an opinion expressed by the European Food Safety Authority (EFSA), the European Center for Disease Control and Prevention (ECDC), the European Medicines Agency (EMEA) and European Commissions Scientific Committee on Emerging and Newly Identified Health Risks (SCENIHR), the importance of Campylobacter and chicken meat production was highlighted (Možina et al., 2011).

Natural antimicrobials can be found in plant or animal sources with plant sources the more significant which can be used in the form of pure compounds or extracts. Phenolics, phenolic acids, quinones, flavonoids, thiosulfinates. glucosinolates and tannins that exist in these plant products are responsible for antibacterial properties of the plants (Witkowska et al., 2013; Hayek 
et al., 2013). These compounds are found in different parts of the plant from the leaves and fruit to the root, i.e., all parts of the plant and are responsible for their natural ability to protect against insects and harmful pathogens (Davidson et al., 2013). The major mechanism of action of essential oils has been explained by Burt, (2004) by its ability to significantly weaken the cytoplasmic membrane resulting in leakage of cell contents and bacterial cell destruction.

Oregano (Origanum vulgare L.) has components that have shown varying degrees of antimicrobial activity which is dependent on the species, geographical location, age and component of the plant from which the extract is separated (Burt, 2004). The major components along with their identified range of percentage were compiled by Jayasena \& Jo, (2013). Thymol and eugenol are the major components with inhibitory action against a wide range of bacteria with $p$-cymene being a minor component of oregano. In vitro model study using cecal contents, carvacol at $0.75 \%$ and thymol at $1 \%$ resulted in significant reduction of $C$. jejuni populations after 24 hours (Venkitnarayanan et al., 2013).

The antibacterial activity of tea against $C$. jejuni and $C$. coli has been reported with black and green tea extracts achieving total inhibition at 4 hours (Diker et al., 1991). There have been conflicting reports detailing the effectiveness of tea which could be because the researchers used different types of tea for experiments along with different sources and strengths of tea in the study (Miller 1995). Flavonoids are important secondary organic compounds (Rice-Evans et al., 1997) of which flavanols and flavonols are important subgroups found in tea (Wang et al., 2000). Important constituents of green tea are catechins (Wang et al., 2000) which have shown significant antibacterial activity and constitutes 15\% of the dry weight of green tea (Mabe et al., 1999) with epigallocatechin gallate (EGCg) being the major antimicrobial agent (Miller, 1995). Theaflavins and thearubigenes are other groups present in tea leaves (Gramza et al., 2006). An 
important study by Friedman et al., 2006, evaluated the antimicrobial activities of tea catechins against B.cereus and documented the ratio in antibacterial activity between the most active catechin and the least active catechin.

Hawthorn has been used for centuries as part of medicines across Europe and Asia as is referred to as the Crataegus species (Zhao and Tian, 1996). Hawthorn extracts are normally consumed as tea or tinctures (Benli et al., 2008). Hawthorn extract has shown antibacterial activity against Micrococcus flavus, Bacillus subtilis and Lysteria monocytogenes with no effect against Candida albicans (Tadić et al., 2008). In studies on the effect of Crataegus monogyna on C. jejuni, the extract did not totally inhibit the growth of the bacterium but less than $25 \%$ growth was observed and the results were consistent for both water and methanol extracts (Galgóczy et al., 2009).

Curcumin is responsible for the yellow color of turmeric and comprised of 94\% curcumin I, $6 \%$ of curcumin II and $0.3 \%$ of curcumin III (Chattopadhyay et al., 2004). Curcuma longa has shown antibacterial activity against E. coli, S. aureus, K. pneumoniae and S. epidermidis at low concentrations (Niamsa and Sittiwet, 2009). In studies, microcapsule curcumin had antibacterial effects comparable to free curcumin against S. aureus, B. subtilis, B. cereus, E. coli and $Y$. enterocolitica with S. aureus inhibition the highest and E. coli the lowest (Wang et al., 2009).

\section{MATERIALS AND METHODS}

\section{Bacterial strains and growth media:}

In this study, four different $C$. jejuni strains were used: one human strain (81176) and three poultry strains isolated from different stages of poultry processing such as a pre-chilled chicken carcass (PRCC), a post-chilled chicken carcass (POCC) and a retail chicken carcass (RECC). Media used for initial culturing of C. jejuni strains was Campylobacter Enrichment (CE) broth 
(Acumedia $^{\circledR}$ ). Frozen stock cultures of 81176, PRCC, POCC and RECC were passed twice onto Campylobacter blood agar plates and were then inoculated into CE broth which was incubated at $42^{\circ} \mathrm{C}$ under microaerophilic conditions $\left(5 \% \mathrm{O}_{2}, 10 \% \mathrm{CO}_{2}, 85 \% \mathrm{~N}_{2}\right)$ for 24 hours.

Campylobacter Enrichment Agar (CEA) supplemented with 5\% horse blood was used for plating the cultures after serial dilution.

\section{Plant extracts:}

The four plant extracts used in this study were green tea, oregano, hawthorn and curcumin. All were commercially purchased from gaia ${ }^{\circledR}$ herbs except for curcumin. Curcumin in powder form was purchased from Alfa Aesar ${ }^{\circledR}$. The constituents of the plants were extracted using either water or a combination of water and alcohol in a ratio to maximize constituent content ("Right+Right," 2014). The next step in the extraction process used 24 millibar pressure at $60^{\circ} \mathrm{C}$ to concentrate the extract via a closed loop system maintaining integrity of all components ("Low+Low," 2014).

\section{Green tea leaf extract:}

The organic green tea liquid herb extract was in water with $500 \mathrm{mg} / \mathrm{ml}$ herb equivalency. Oregano leaf extract:

The oregano leaf extract was from the herb Origanum vulgare with a 333mg/ml herb equivalency.

\section{Hawthorn extract:}

The extract purchased was of the hawthorn berry, flower and leaf of Crataegus spp with $667 \mathrm{mg} / \mathrm{ml}$ herb equivalency. 


\section{Curcumin extract:}

The extract has a total of 95\% curcuminoid content and was derived from turmeric rhizome.

These extracts were diluted in $1 \mathrm{X}$ phosphate buffered saline (PBS) to obtain concentrations of $0.25 \%, 0.5 \%$ and $1 \%$ of the purchased extracts for the broth culture studies as well as $1 \%, 5 \%$, $10 \%, 20 \%, 30 \%, 50 \%$ and $100 \%$ of the purchased extracts for chicken meat model studies.

\section{Preparation of plant extracts:}

\section{Broth culture study:}

A $0.25 \%$ of the purchased extract concentration was obtained by diluting $0.025 \mathrm{~mL}$ of the extract in $9.975 \mathrm{~mL}$ PBS while a $0.5 \%$ of the purchased extract concentration was obtained by diluting $0.05 \mathrm{~mL}$ of the extract in $9.95 \mathrm{~mL}$ PBS; a $1 \%$ of the purchased extract concentration was obtained by diluting $0.1 \mathrm{~mL}$ of the extract in $9.9 \mathrm{~mL}$ PBS.

In chicken meat model study, a total volume of $30 \mathrm{~mL}$ extract was prepared as follows:

- A $1 \%$ of the purchased extract concentration was obtained by diluting $0.3 \mathrm{~mL}$ of the extract in $29.7 \mathrm{~mL}$ of PBS.

- A $5 \%$ of the purchased extract concentration was obtained by diluting $1.5 \mathrm{~mL}$ of the extract in $28.5 \mathrm{~mL}$ of PBS.

- A $10 \%$ of the purchased extract concentration was obtained by diluting $3 \mathrm{~mL}$ of the extract in $27 \mathrm{~mL}$ of PBS.

- A $20 \%$ of the purchased extract concentration was obtained by diluting $6 \mathrm{~mL}$ of the extract in $24 \mathrm{~mL}$ of PBS. 
- A 30\% of the purchased extract concentration was obtained by diluting $9 \mathrm{ml}$ of the extract in $21 \mathrm{~mL}$ of PBS.

- A $50 \%$ of the purchased extract concentration was obtained by diluting $15 \mathrm{~mL}$ of the extract in $15 \mathrm{~mL}$ of PBS.

- A $100 \%$ of the purchased extract concentration was obtained by using $30 \mathrm{~mL}$ of the extract undiluted.

\section{Effect of plant extracts on C. jejuni strains in broth cultures:}

All the plant extracts green tea, oregano and hawthorn were tested at 3 different concentrations of $0.25 \%, 0.5 \%$ and $1 \%$ of the purchased extract concentration. The extracts were prepared in $1 \mathrm{X}$ phosphate buffered saline (PBS) solution. To each $1 \mathrm{~mL}$ of the extracts, $100 \mu \mathrm{L}$ of each of the $C$. jejuni strains was added.

A volume of $1.1 \mathrm{~mL}$ of each of the cultures was used as positive control. The treatment culture tubes along with the controls were incubated at $42^{\circ} \mathrm{C}$ under microaerophilic conditions. Samples were taken at time intervals of $0 \mathrm{~h}, 1 \mathrm{~h}, 2 \mathrm{~h}, 4 \mathrm{~h}$ and $24 \mathrm{~h}$ and subsequent serial dilutions were performed in $1 \mathrm{X}$ PBS from 1 to $7.100 \mu \mathrm{L}$ of each of the treated cultures were plated onto Campylobacter Enrichment Agar plates supplemented with 5\% horse blood. All these plates were then incubated at $42^{\circ} \mathrm{C}$ under microaerophilic conditions for 48 hours and viable C. jejuni colonies were counted using a colony counter. The results were recorded and expressed in terms of $\log \mathrm{CFU} / \mathrm{mL}$ vs time. The experiments were performed in triplicates.

\section{Meat model studies:}

\section{Preparation of marinade:}


Marinades used were prepared using one of the three plant extracts of oregano, green tea and hawthorn. Marinades of green tea and hawthorn extracts were used at concentrations of $50 \%$ and $100 \%$ of the purchased extract concentration whereas marinade with oregano was prepared at $30 \%$ and $50 \%$ of the purchased extract concentration. All the marinades were prepared on the same day of the experiment by diluting the extracts with $1 \mathrm{X}$ phosphate buffered saline solution (PBS).

\section{Preparation of inoculum}

Frozen stock cultures of 81176, PRCC, POCC and RECC were passed twice onto Campylobacter blood agar plates and were then inoculated into Campylobacter Enrichment (CE) broth which was incubated at $42^{\circ} \mathrm{C}$ under microaerophilic conditions $\left(5 \% \mathrm{O}_{2}, 10 \% \mathrm{CO}_{2}, 85 \%\right.$ $\mathrm{N}_{2}$ ) for 24 hours.

A chicken meat model was used in this study using uncooked boneless chicken breasts fillets purchased from a local supermarket in Fayetteville, Arkansas. The breast fillets were cut into approximately 1 inch square pieces using a sterile knife under a laminar flow hood to prevent external contamination. These meat pieces were placed in a sterile beaker and washed 10 times first with distilled water and then with sterile water twice. After thorough washing, these meat pieces were placed in sterile open petri plates under UV light (at $254 \mathrm{~nm}$ ) for 30 minutes on each side and then stored at $4^{\circ} \mathrm{C}$ for 24 hours in order to reduce bacterial counts (Murali et al., 2012).

\section{Effect of plant extracts on inoculated chicken meat:}

The chicken meat pieces were transferred into individual stomacher ${ }^{\circledR}$ bags after 24 hours. Individual pieces were inoculated on the surface with $100 \mu \mathrm{L}$ of each bacterial suspensions of C.jejuni, i.e., 81176, PRCC, POCC and RECC strains in their respective bags. For a negative 
control, one piece of chicken which was uninoculated was marinated with $5 \mathrm{~mL}$ PBS (1X). The bags containing the inoculated chicken pieces were held at room temperature for 30 minutes to allow bacterial attachment. A volume of $5 \mathrm{~mL}$ of each prepared marinade at the above mentioned concentrations were added to the individual bags containing the chicken pieces. The marinated chicken pieces were kept in the refrigerator at $4^{\circ} \mathrm{C}$ and samples were taken at $2 \mathrm{~h}, 6 \mathrm{~h}$ and $24 \mathrm{~h}$. Stomacher bags containing the chicken pieces were taken out at these time points and were stomached for 2 minutes using a Stomacher ${ }^{\circledR} 400$ Circulator to drive bacteria into suspension. Bacterial cell counts in suspension were then enumerated by serial dilution and plating onto CE agar plates.

\section{Measurement of antibacterial activity:}

All the plates were incubated at $42^{\circ} \mathrm{C}$ under microaerophilic conditions for 48 hours after which the plates were read using a colony counter and viable cell counts recorded.

\section{Statistical Analysis}

Both experiments to study the effect of plant extracts against $C$. jejuni in broth culture as well as on chicken meat were repeated three times to establish statistical significance. Statistical analysis was performed using JMP 11.0 provided by the University of Arkansas, Fayetteville.

\section{RESULTS}

The effectiveness of commercially available plant extracts was investigated in this study against four C. jejuni strains including 81176, PRCC, POCC and RECC. The plant extracts selected for the analysis included green tea, oregano, hawthorn and curcumin. The initial set of experiments on the four isolates was done in broth culture at three concentration levels of $0.25 \%, 0.5 \%$ and 
$1 \%$ of the purchased extract concentration. Of the four extracts, green tea (Figure 3.1 - Figure 3.4) and oregano (Figure 3.5 - Figure 3.8) showed 7-log reduction and killing all the bacteria within 24 hours of incubation at all three concentration levels. Hawthorn showed no significant $\log$ reduction $(\mathrm{P}>0.05)$ with respect to control after 24 hours of incubation for all concentrations and isolates tested (Fig 3.9 - Fig 3.12). Curcumin at the highest concentration of $1 \%$ of the purchased extract concentration produced a minimum of 2-log reduction from the control, at 24 hour time point for all isolates of C. jejuni (Fig 3.13 - Fig 3.16).

In order to narrow down the effective concentrations of the extracts in the meat model study, 81176 and PRCC isolates were selected to represent the human strain and poultry strain. Concentrations of $1 \%, 5 \%, 10 \%$ and $20 \%$ of the purchased extract concentration were tested at time points of 2 hour and 24 hour to narrow down the range of effective extract concentrations (Table 3.1). Based on these initial results, chicken breast pieces then were inoculated with the 81176, PRCC, POCC and RECC isolates and were marinated with 50\% and $100 \%$ of the purchased concentrations of green tea extract, $30 \%$ and $50 \%$ of the purchased concentrations of oregano extract and $50 \%$ and $100 \%$ of the purchased concentration of hawthorn extract. Marinades prepared using either $50 \%$ of the purchased hawthorn extract, $100 \%$ of the purchased hawthorn extract, $50 \%$ of the purchased green tea extract or $100 \%$ of the purchased green tea extract did not kill all the bacteria within 24 hours for all four strains of C.jejuni. Oregano at concentration $50 \%$ of the purchased extract concentration showed 6-log reduction of 81176 , PRCC, POCC and RECC C. jejuni strains. Oregano at 30\% of the purchased extract concentration showed 6-log reduction against POCC and RECC compared to 2-log reduction against 81176 and PRCC strains (Fig 3.17 - Fig 3.20).

\section{DISCUSSION}


The effect of tea extract on C. jejuni in broth was reported as killing all the bacteria in 4 hours (Diker, et al., 1991). No reference is given for the bacterial strains used or the concentration of the extract which makes it difficult to compare results. In our study, green tea was successful in killing all the C.jejuni in broth in 24 hours which is greater than reported by Murali et al., (2012) on 81176 and RECC strains where the bacteria were killed within 36 hours of incubation. In the previous work of Murali et al., (2012), tea extracts were prepared using the method of (Diker et al., 1991). The concentration of extract obtained by this method is dependent on the source and variety of the tea leaves. In our study, extracts were purchased commercially from gaia ${ }^{\circledR}$ herbs which state the extracts have "a consistent, measurable concentration of a recognized phytoconstituent” ("Beyond standardization," 2014) to account for the variability of plant product. Initial testing in the meat model, at the highest concentration used in broth study (1\% of the purchased extract concentration), did not show any reduction in viable counts which required testing at higher concentrations all the way up to full concentration of the commercial extract. At $100 \%$ of the purchased concentration of green tea in meat model, a 2- log reduction in bacteria was observed at the 2 hour time point and did not decrease any further till 24 hour time point. The growth inhibition of tea polyphenols against B.stearothermophilus (Sakanaka et al., 2000) shows a similar steady antibacterial activity at $20 \mathrm{hr}$ time point for different concentrations of tea polyphenols/ml in vitro.

Oregano extracts, in broth culture study, demonstrated a 7-log reduction in bacterial counts for all strains of C.jejuni after 24 hours. Thymol and carvacol, two major components of oregano have shown $<1 \mathrm{Log}$ CFU values at concentrations of $10,20 \& 30 \mathrm{mM}$ by 8 hours of incubation and maintained $<1$ Log CFU by 24 hours from 4.5 Log CFU values at time 0 hour (Kollannor $e t$ al., 2010). This trend matches the results observed in the $0.25 \%, 0.5 \%$ and $1.0 \%$ of the purchased 
concentrations of the extracts tested. When testing in the meat model, the minimum concentration of oregano that showed reduction in bacterial count was $30 \%$ of the purchased concentration in the POCC and RECC isolates of C. jejuni. The bacteria were completely killed using the $50 \%$ of the purchased concentration in all $C$. jejuni strains indicating that the $30 \%$ of the purchased concentration of oregano is very close to the minimum inhibitory concentration of the extract in the meat model. Testing carried out to determine the effect of oregano origanum oils on RM1221, RM1230, RM1274 \& RM1046 strains of C.jejuni revealed increased sensitivity to essential oils (Friedman et al., 2002). The results in the in vitro study by Friedman et al., 2002, do not show variation of oregano oil antibacterial activity between the different C.jejuni strains. This is very similar to the results observed in our broth culture study. In our meat model study differences were observed in the antibacterial action of oregano on POCC (post chilled) and RECC (retail chicken carcass) isolates as compared to 81176 (human strain) and PRCC (prechilled) isolates. One possible explanation is the effect of chilling on the C.jejuni pathogen after exposure to low temperatures affecting the antibacterial action of oregano on them. A difference in rate of death in certain strains of C.jejuni was observed after exposure of culture to $6^{\circ} \mathrm{C}$ for 24 hours (Hughes et al., 2010).

Hawthorn extract did not exhibit log reduction similar to that observed in green tea and oregano extracts in broth culture against all four isolates of C.jejuni through the 24 hours of incubation. In meat model tests the hawthorn extract at $100 \%$ of the purchased concentration exhibited a 1-log reduction at the 24 hour time point. This result is in agreement with experiments using extracts of Crataegus monogyna commonly known as hawthorn where less than 25\% growth inhibition was observed with C.jejuni (Galgóczy et al., 2009). Unfortunately no reference is made in the study to the concentration of the extract or the isolate of C.jejuni used. 
Curcumin experiments were conducted only in broth culture to see the effect of the extract at low concentrations. At the 24 hour time point a minimum of 2 log-reduction was observed for all strains of C.jejuni at $1 \%$ concentration. The broth culture studies of curcumin were primarily part of the study to determine suitable extracts to test on meat model. The initial tests in meat model indicated the requirement of higher concentrations for eliminating bacteria at 24 hour time point for all strains and the cost of curcumin was higher than other extracts which limited the range of testing.

There were major differences in concentrations of extracts required to inhibit the bacteria between broth medium tests and meat model tests. This has been recognized as a potential drawback of using plant extracts in the food (Davidson et al., 2013; Hayek et al., 2013; Škrinjar et al., 2009). This difference may be due to interaction of plant extracts with components present in food model such as high fat and protein content (Burt, 2004), lipids (Perumalla et al., 2011) and water activity. According to Hayek et al., 2013, pH levels in meat may influence the hydrophobic effect of extracts and in turn their antibacterial effect.

\section{CONCLUSIONS}

Future tests will involve isolating individual components of each of the extracts determining the dominant antibacterial component with minimal inhibitory concentrations (MIC). The higher concentration requirements of plant extracts in meat models can be resolved by determining combinations of lower concentration plant extracts that can inhibit bacterial growth and avoid undesirable sensory changes (Hayek et al., 2013). 


\section{FIGURE LEGEND}

Fig 3.1. Log CFU vs Time of green tea extract at 3 different concentrations against C.jejuni 81176. Green tea was effective at killing bacteria within 24 hours of incubation. There was a 7log decrease in growth in 24 hours for all 3 concentration levels $(\mathrm{P}<0.05)$.

Fig 3.2. Log CFU vs Time of green tea extract at 3 different concentrations against C.jejuni PRCC. For all 3 concentration levels, green tea showed a 7-log reduction from the control in 24 hours. Although green tea at $1 \%$ concentration showed a 1-log decrease in growth in 4 hours, it killed all the bacteria in 24 hours $(\mathrm{P}<0.05)$.

Fig 3.3. Log CFU vs Time of green tea extract at 3 different concentrations against C.jejuni POCC. Green tea showed a 7- $\log$ reduction from the control in 24 hours $(\mathrm{P}<0.05)$. There was no significant difference in the action of $0.25 \%$ and $0.5 \%$ concentrations against the isolate.

Fig 3.4. Log CFU vs Time of green tea extract at 3 different concentrations against C.jejuni RECC. All three concentrations of green tea showed a 7-log reduction from the control in 24 hours $(\mathrm{P}<0.05)$. Green tea at $1 \%$ showed a 1 -log reduction in 4 hours, but there was a steady decline in count after that.

Fig 3.5. Log CFU vs Time of oregano extract at 3 different concentrations against C.jejuni 81176. Oregano was effective at killing bacteria within 24 hours, showing a 7- log reduction $(\mathrm{P}<0.05)$. Although oregano $1 \%$ showed a 1 - $\log$ reduction in 4 hours, there was a steep decline in growth after that.

Fig 3.6. Log CFU vs Time of oregano extract at 3 different concentrations against C.jejuni PRCC. All concentrations of oregano were effective in killing bacteria within 24 hours ( $\mathrm{P}<$ 0.05).

Fig 3.7. Log CFU vs Time of oregano extract at 3 different concentrations against C.jejuni POCC. For all 3 concentrations of oregano, there was an 8- log decrease $(\mathrm{P}<0.05)$ killing all the bacteria in 24 hours. Oregano $1 \%$ showed a 1 - log decrease in 4 hours with a steady decline after that.

Fig 3.8. Log CFU vs Time of oregano extract at 3 different concentrations against C.jejuni RECC. Oregano was found to be effective in killing bacteria within 24 hours of incubation $(\mathrm{P}<0.05)$. There was a 1- log decrease for oregano $1 \%$ in 4 hours of incubation.

Fig 3.9. Log CFU vs Time of hawthorn extract at 3 different concentrations against $C$.jejuni 81176. All the 3 concentrations did not show significant difference in their action against the isolate for all time points. Also, hawthorn at all concentrations failed to kill the bacteria within 24 hours of incubation. 
Fig 3.10. . Log CFU vs Time of hawthorn extract at 3 different concentrations against C.jejuni PRCC. Hawthorn 1\% showed more than 1- log reduction in growth at 24 hours.

Fig 3.11. Log CFU vs Time of hawthorn extract at 3 different concentrations against C.jejuni POCC. Hawthorn 1\% showed a 1- log difference in 24 hours. There was no significant difference observed between the concentrations at 24 hour time point.

Fig 3.12. Log CFU vs Time of hawthorn extract at 3 different concentrations against C.jejuni RECC. Although a slight decrease was seen from the control in 24 hours for all the three concentrations, there was no significant difference in its action between the concentrations against the isolate.

Fig 3.13. Log CFU vs Time of curcumin extract at 3 different concentrations against C.jejuni 81176. Curcumin 1\% showed more than 2- log reduction in 24 hours whereas $0.25 \%$ and $0.5 \%$ showed less than 1- log reduction with no significant difference in its action between the two concentrations.

Fig 3.14. Log CFU vs Time of curcumin extract at 3 different concentrations against C.jejuni PRCC. Curcumin 1\% was found to be effective among the three concentrations and showed a 3$\log$ reduction in 24 hours of incubation whereas $0.25 \%$ and $0.5 \%$ concentrations showed a 2 log decrease in growth.

Fig 3.15. Log CFU vs Time of curcumin extract at 3 different concentrations against C.jejuni POCC. Curcumin 1\% showed a 2 - log reduction in 24 hours of incubation.

Fig 3.16. Log CFU vs Time of curcumin extract at 3 different concentrations against C.jejuni RECC. Curcumin 1\% showed a 3- log decrease in 24 hours of incubation. Curcumin $0.25 \%$ and $0.5 \%$ concentrations showed more than 2 - log reduction, in 24 hours.

Fig 3.17. Log CFU vs Time of oregano, green tea and hawthorn extract marinated on chicken breast pieces at 2 different concentration levels against C.jejuni 81176. Oregano at 50\% succeeded in killing all bacteria within 2 hours of incubation resulting in a 6- log reduction (P $<0.05$ ) whereas oregano 30\% showed a 2 - log decrease in 24 hours. Green tea 100\% showed 2$\log$ reduction whereas green tea 50\% and hawthorn 100\% showed a 1 - log reduction in 2 hours of incubation.

Fig 3.18. Log CFU vs Time of oregano, green tea and hawthorn extract on chicken breast pieces at 2 different concentration levels against C.jejuni PRCC. Oregano at 50\% was the most effective of the extracts which succeeded in killing all bacteria within 2 hours of incubation $(\mathrm{P}<0.05)$.

Fig 3.19. Log CFU vs Time of oregano, green tea and hawthorn extract on chicken breast pieces at 2 different concentrations against C.jejuni POCC. Oregano at 30\% and 50\% succeeded in killing all bacteria within 6 hours of incubation $(\mathrm{P}<0.05)$. 
Fig 3.20. Log CFU vs Time of oregano, green tea and hawthorn extract on chicken breast pieces at 2 different concentrations against C.jejuni RECC. Oregano at 30\% and 50\% succeeded in killing all bacteria within 6 hours of incubation $(\mathrm{P}<0.05)$. 


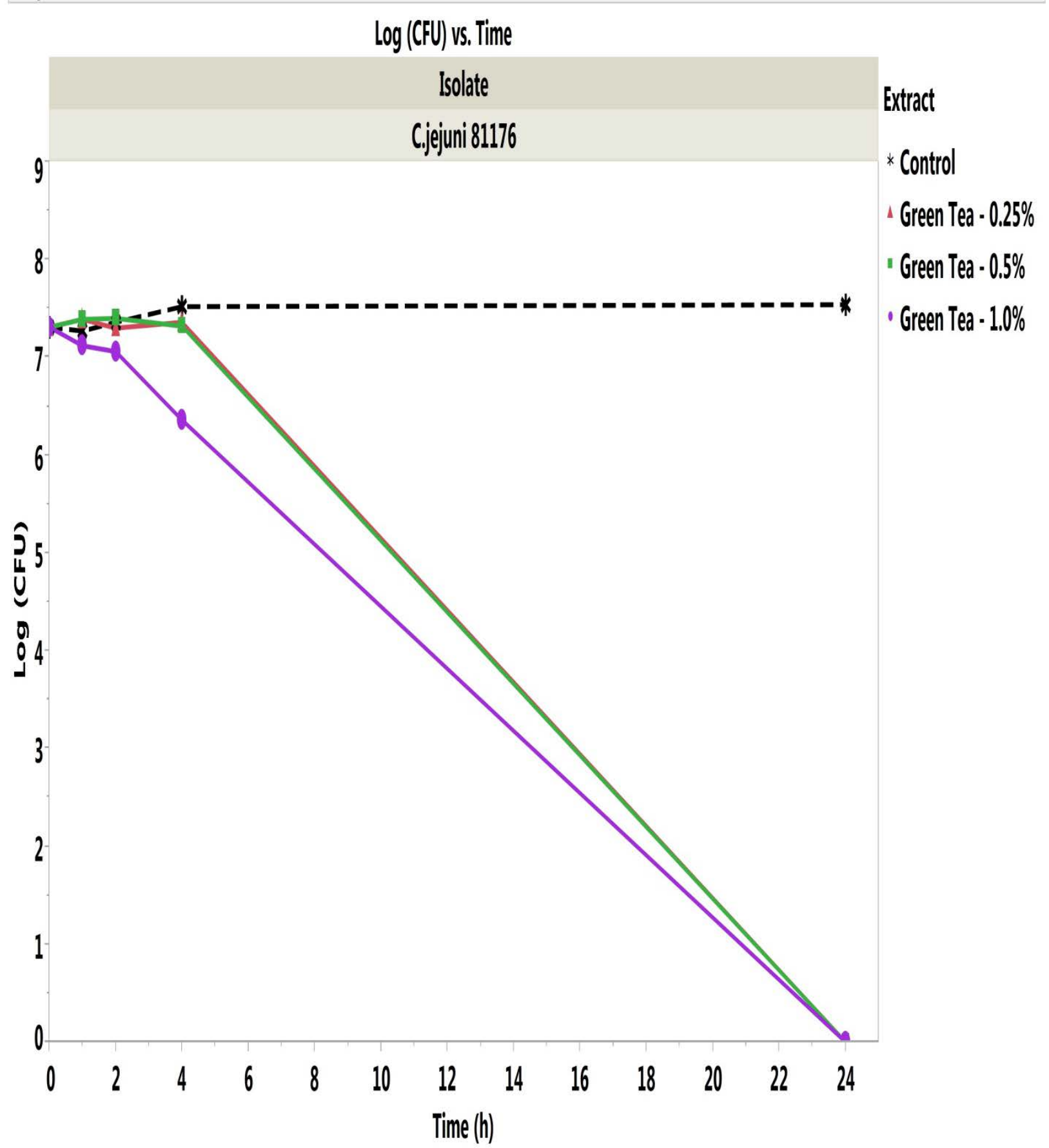

Fig 3.1. Log CFU vs Time of green tea extract at 3 different concentrations against $C$.jejuni 81176. Green tea was effective at killing bacteria within 24 hours of incubation. There was a 7log decrease in growth in 24 hours for all 3 concentration levels $(\mathrm{P}<0.05)$. 


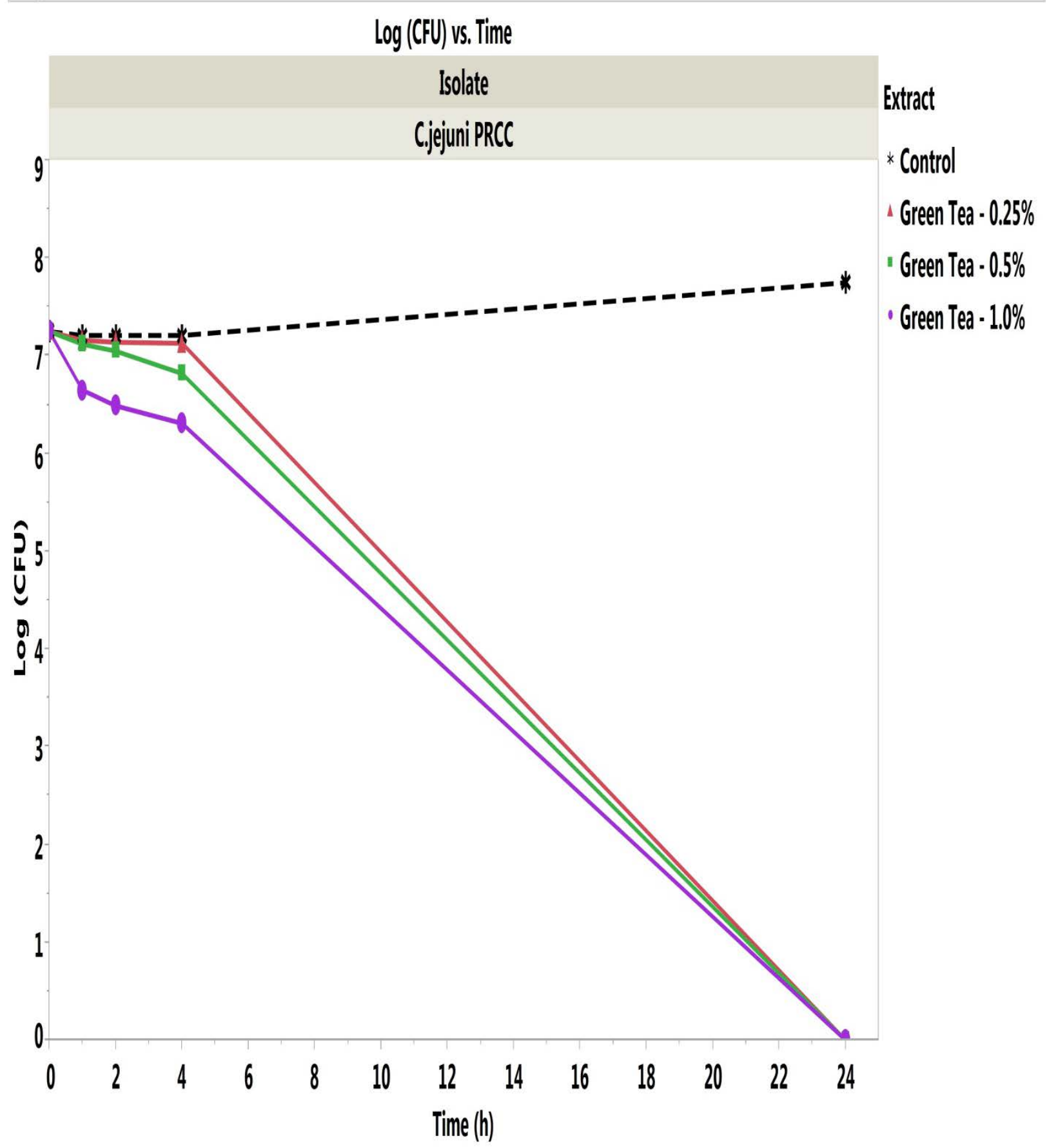

Fig 3.2. Log CFU vs Time of green tea extract at 3 different concentrations against $C$.jejuni PRCC. For all 3 concentration levels, green tea showed a 7-log reduction from the control in 24 hours. Although green tea at $1 \%$ concentration showed a 1-log decrease in growth in 4 hours, it killed all the bacteria in 24 hours $(\mathrm{P}<0.05)$. 


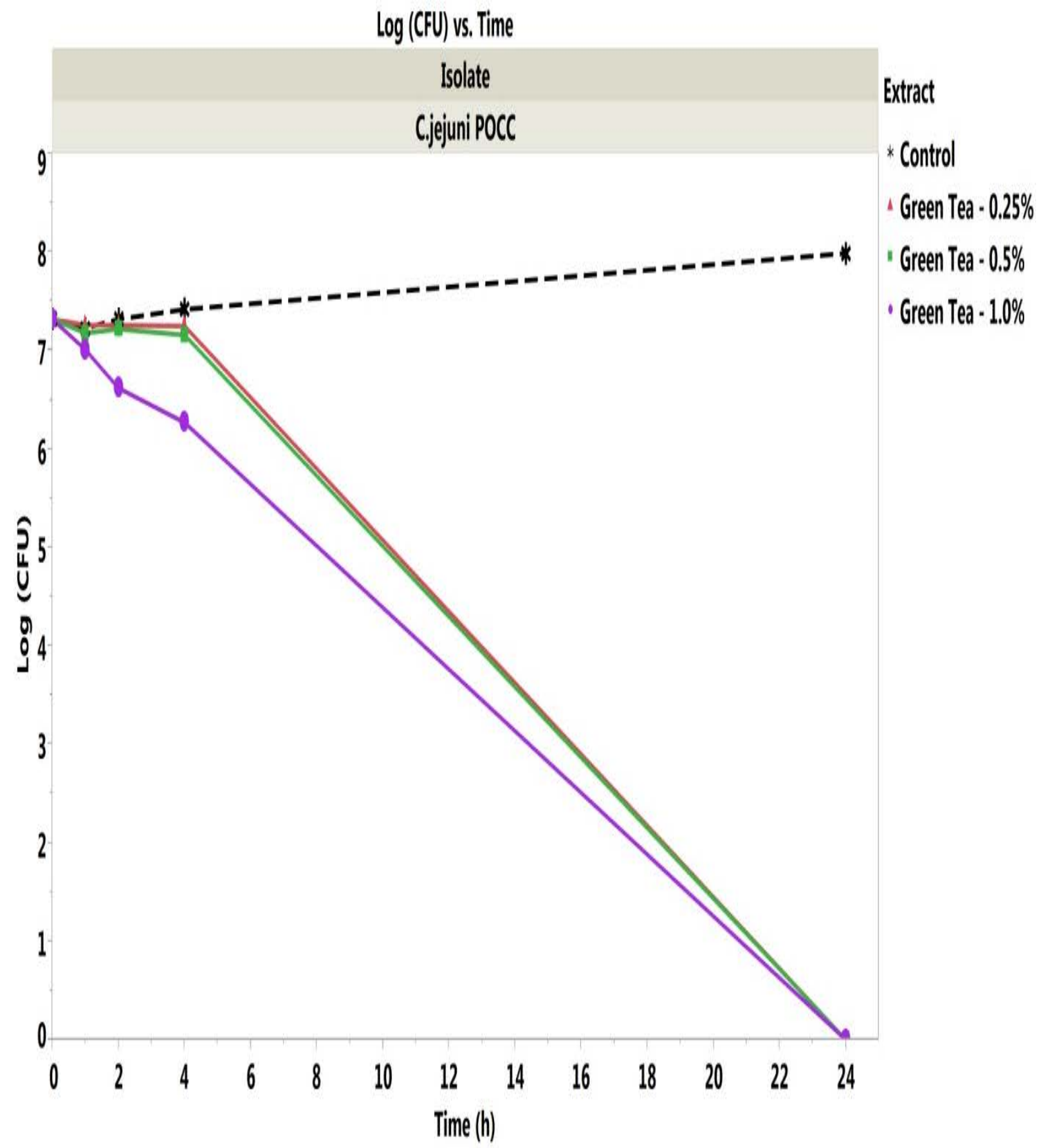

Fig 3.3. Log CFU vs Time of green tea extract at 3 different concentrations against C.jejuni POCC. Green tea showed a 7- log reduction from the control in 24 hours $(\mathrm{P}<0.05)$. There was no significant difference in the action of $0.25 \%$ and $0.5 \%$ concentrations against the isolate. 


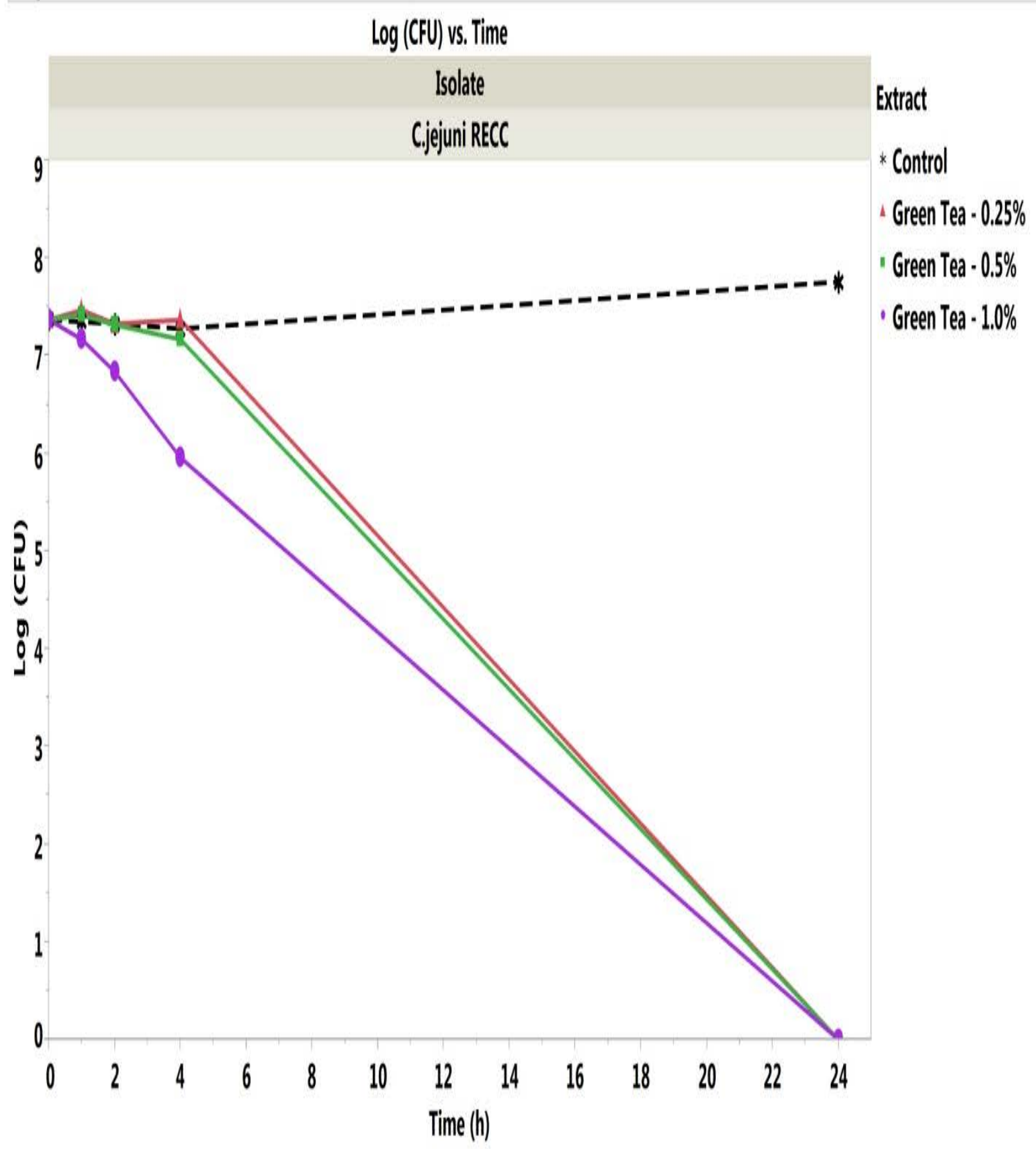

Fig 3.4. Log CFU vs Time of green tea extract at 3 different concentrations against $C$.jejuni RECC. All 3 concentration of green tea showed a 7-log reduction from the control in 24 hours. Green tea $1 \%$ showed a 1-log reduction in 4 hours, but there was a steady decline in count after that $(\mathrm{P}<0.05)$. 


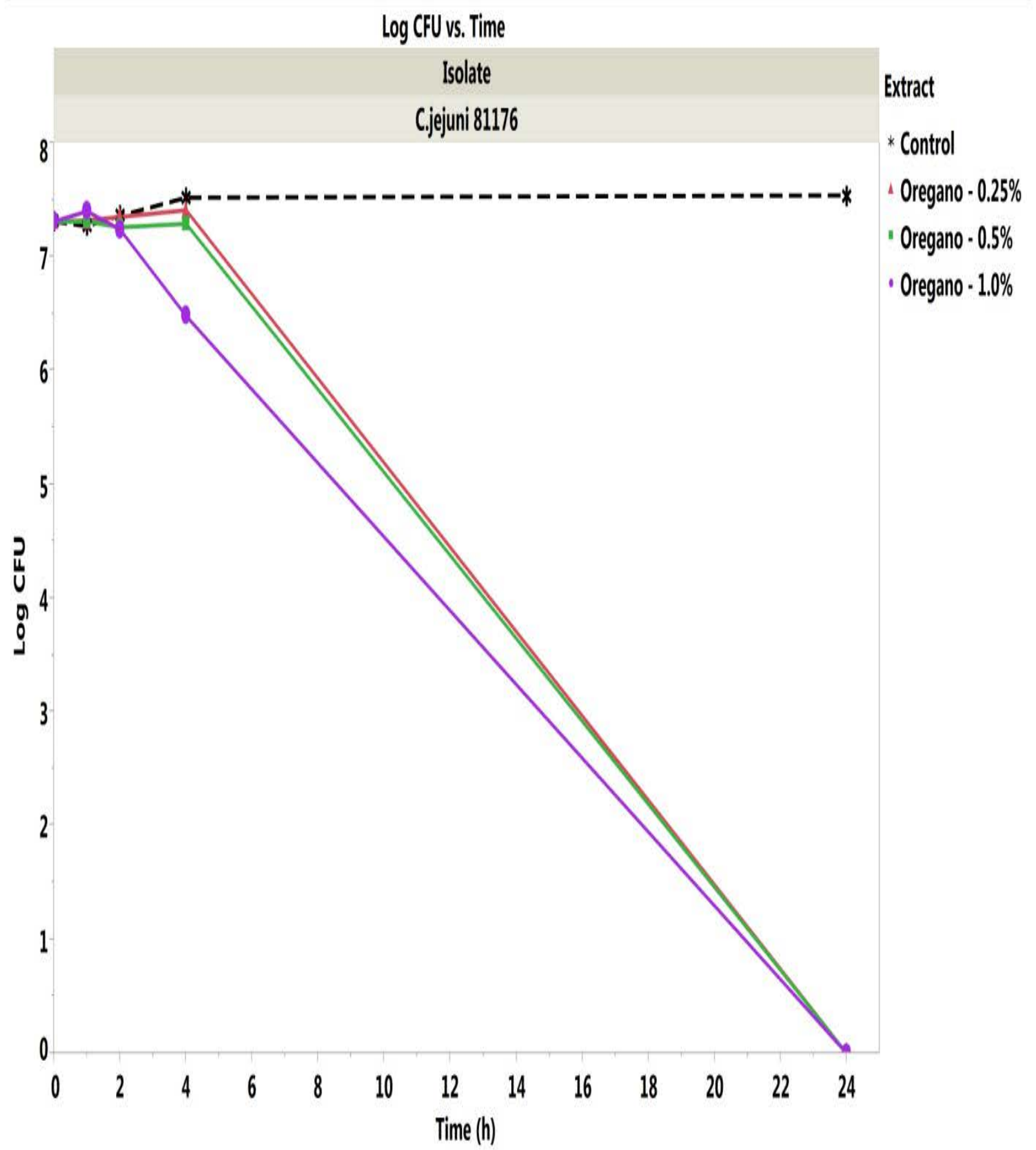

Fig 3.5. Log CFU vs Time of oregano extract at 3 different concentrations against C.jejuni 81176. Oregano was effective at killing bacteria within 24 hours, showing a 7- log reduction $(\mathrm{P}<0.05)$. Although oregano 1\% showed a 1- log reduction in 4 hours, there was a steep decline in growth after that $(\mathrm{P}<0.05)$. 


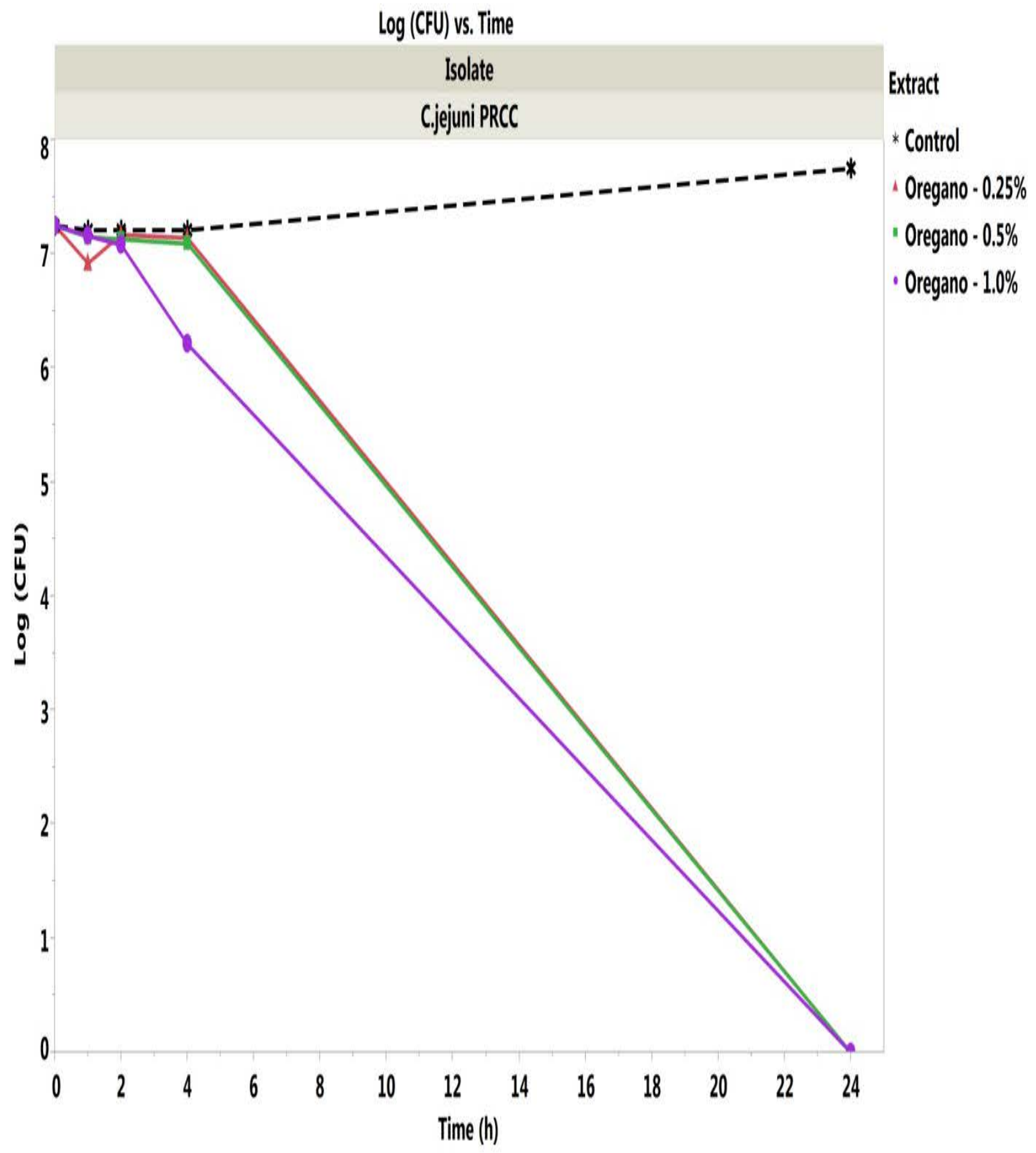

Fig 3.6. Log CFU vs Time of oregano extract at 3 different concentrations against $C$.jejuni PRCC. All concentrations of oregano were effective in killing bacteria within 24 hours ( $\mathrm{P}<$ 0.05). 


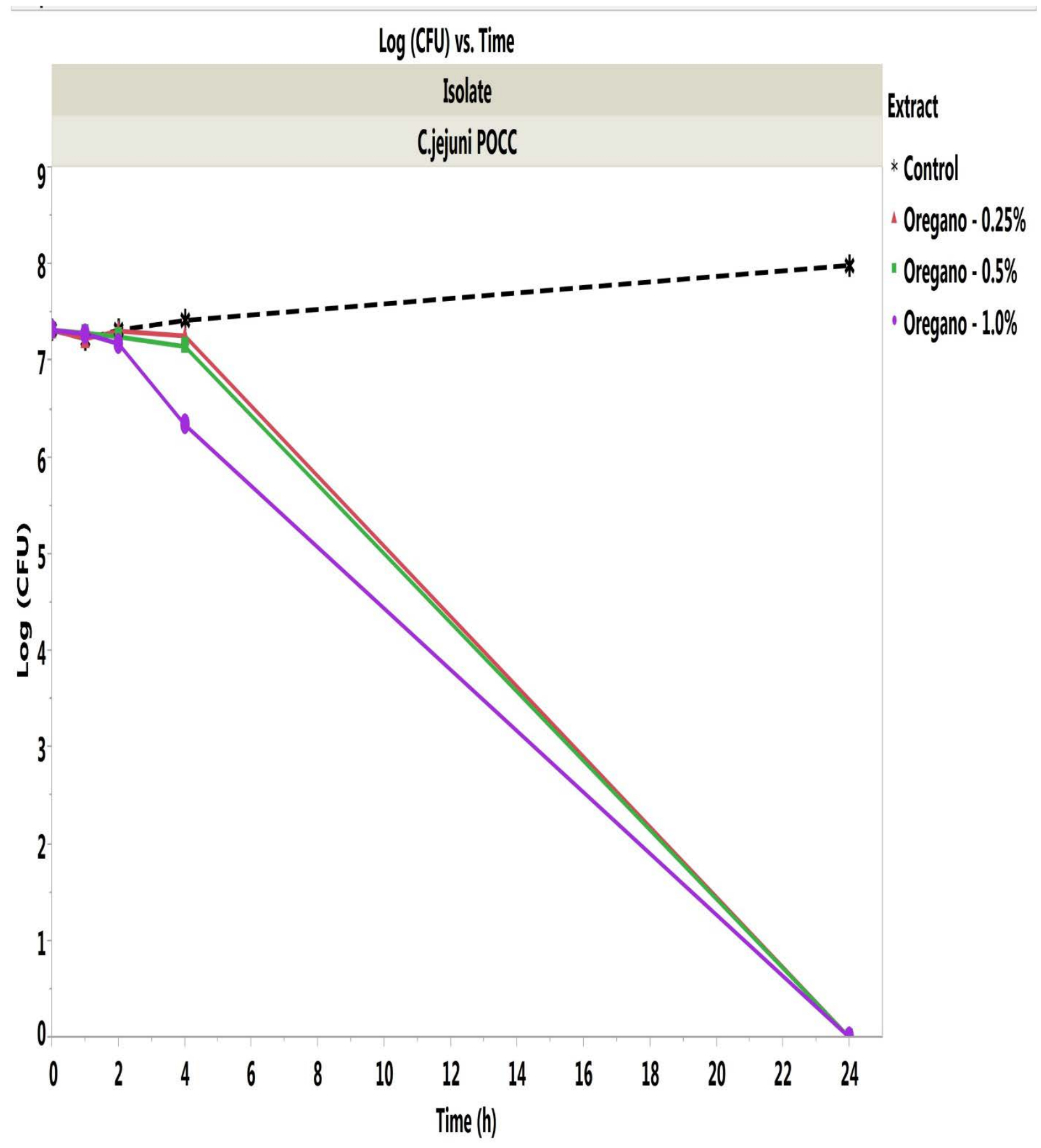

Fig 3.7. Log CFU vs Time of oregano extract at 3 different concentrations against C.jejuni POCC. For all 3 concentrations of oregano, there was an 8- log decrease $(\mathrm{P}<0.05)$ killing all the bacteria in 24 hours. Oregano 1\% showed a 1- log decrease in 4 hours with a steady decline after that. 


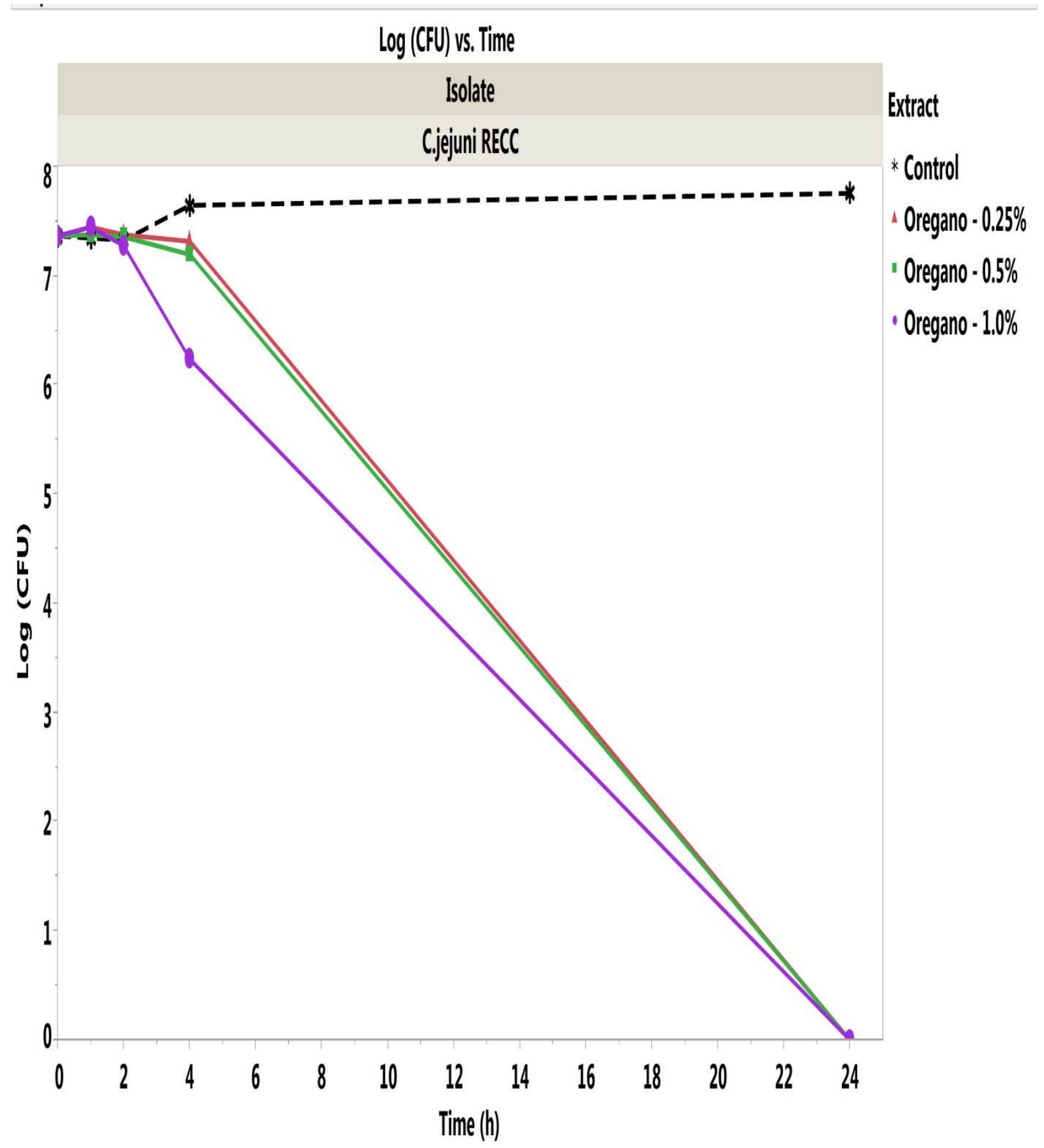

Fig 3.8. Log CFU vs Time of oregano extract at 3 different concentrations against C.jejuni RECC. Oregano was found to be effective in killing bacteria within 24 hours of incubation $(\mathrm{P}<0.05)$. There was a 1- $\log$ decrease for oregano $1 \%$ in 4 hours of incubation. 


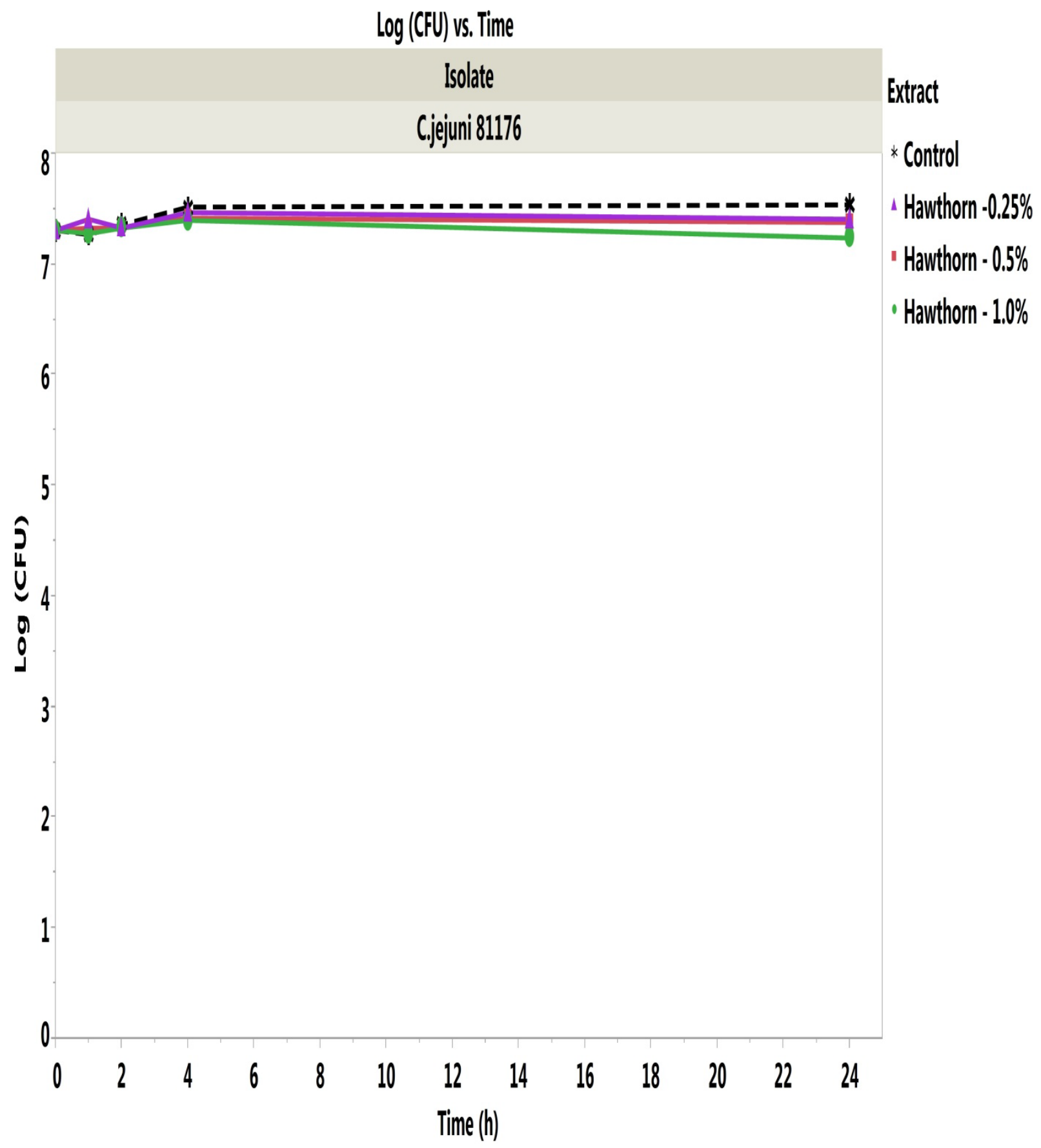

Fig 3.9. Log CFU vs Time of hawthorn extract at 3 different concentrations against C.jejuni 81176. All the 3 concentrations did not show significant difference in their action against the isolate for all time points. Also, hawthorn at all concentrations failed to kill the bacteria within 24 hours of incubation. 


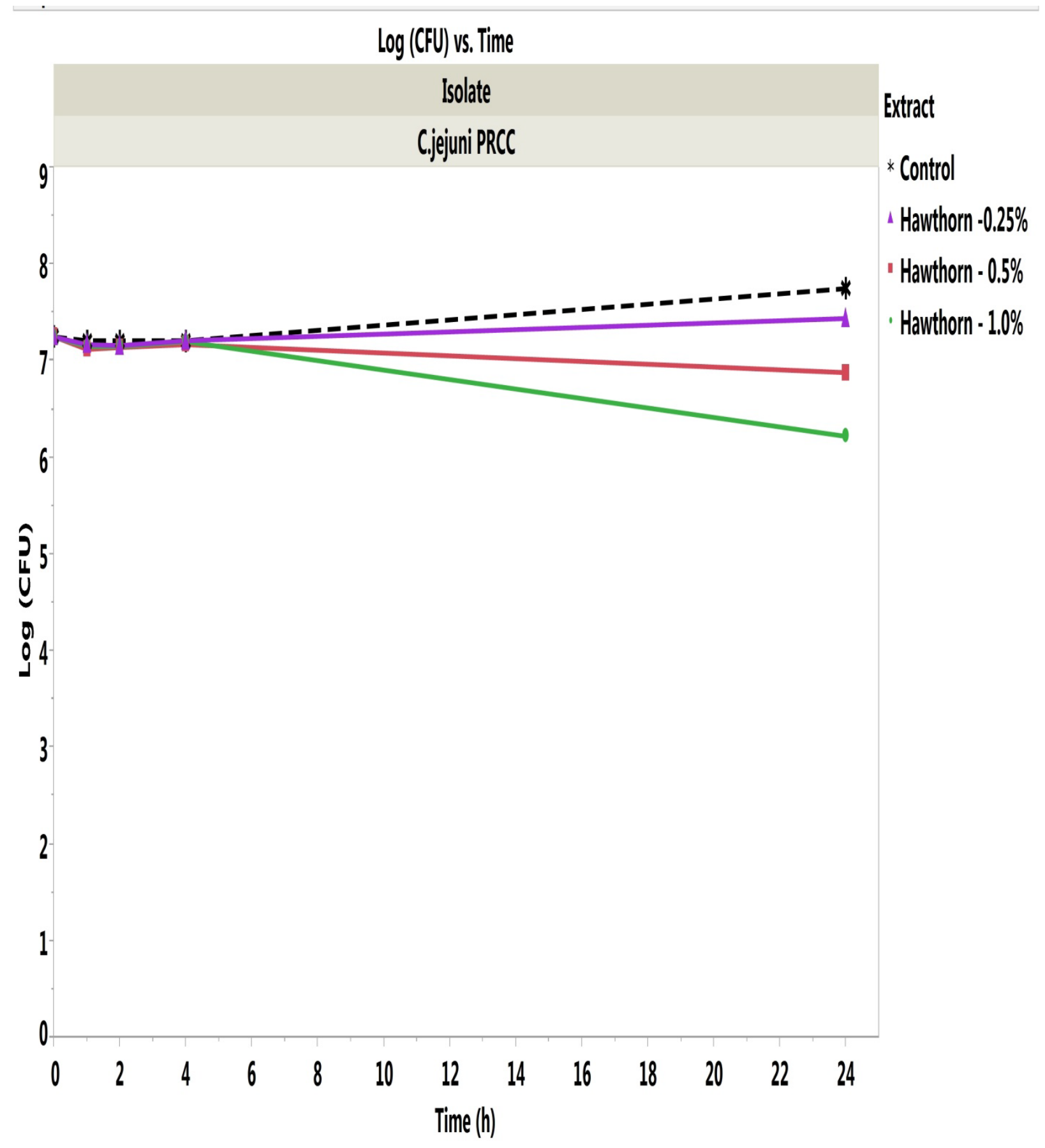

Fig 3.10. . Log CFU vs Time of hawthorn extract at 3 different concentrations against C.jejuni PRCC. Hawthorn 1\% showed more than 1- log reduction in growth at 24 hours. 


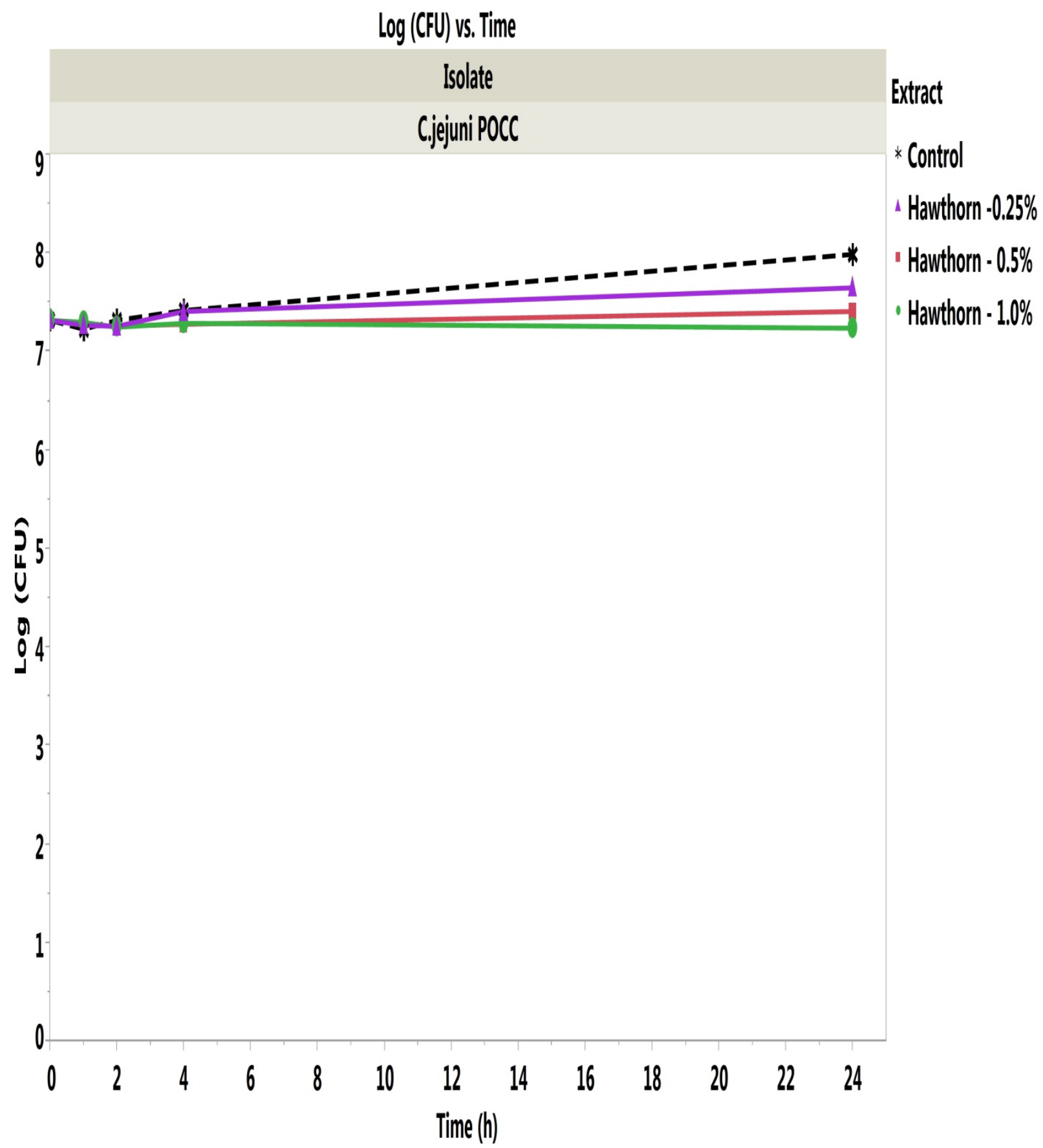

Fig 3.11. Log CFU vs Time of hawthorn extract at 3 different concentrations against C.jejuni POCC. Hawthorn 1\% showed a 1- log difference in 24 hours. There was no significant difference observed between the concentrations at 24 hour time point. 


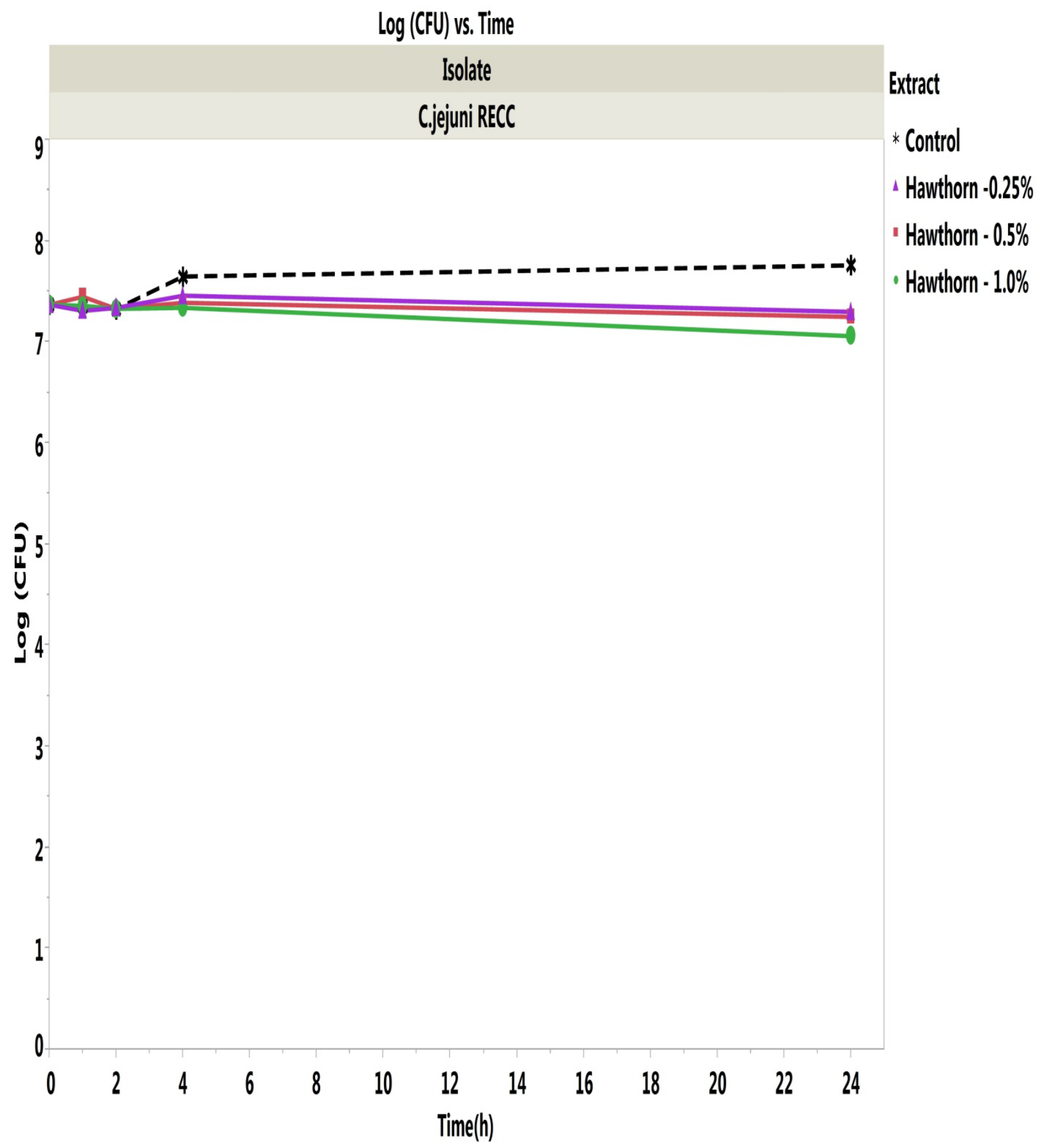

Fig 3.12. Log CFU vs Time of hawthorn extract at 3 different concentrations against $C$.jejuni RECC. Although a slight decrease was seen from the control in 24 hours for all the three concentrations, there was no significant difference in its action between the concentrations against the isolate. 


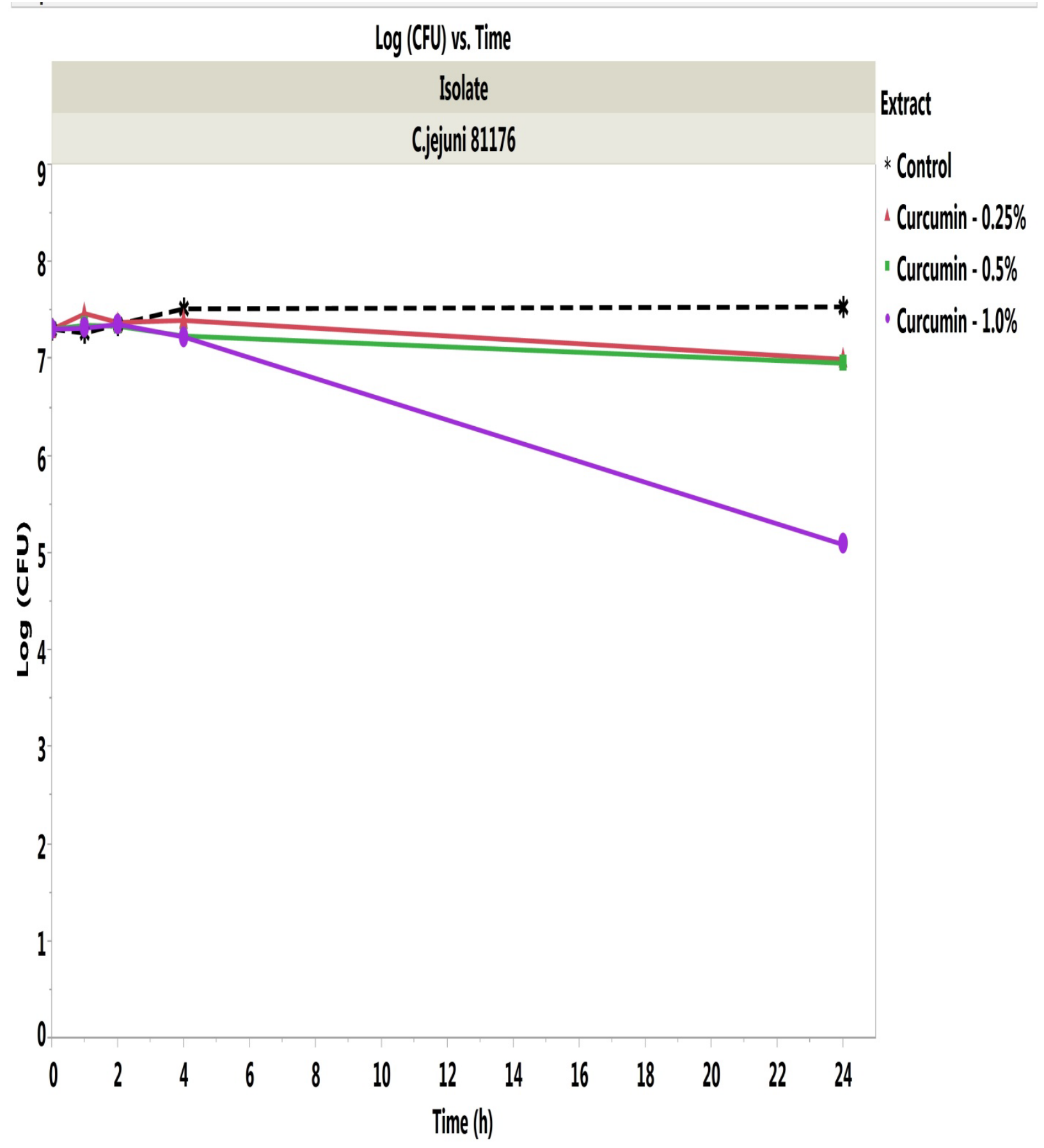

Fig 3.13. Log CFU vs Time of curcumin extract at 3 different concentrations against C.jejuni 81176. Curcumin $1 \%$ showed more than 2 - log reduction in 24 hours whereas $0.25 \%$ and $0.5 \%$ showed less than 1- log reduction with no significant difference in its action between the two concentrations. 


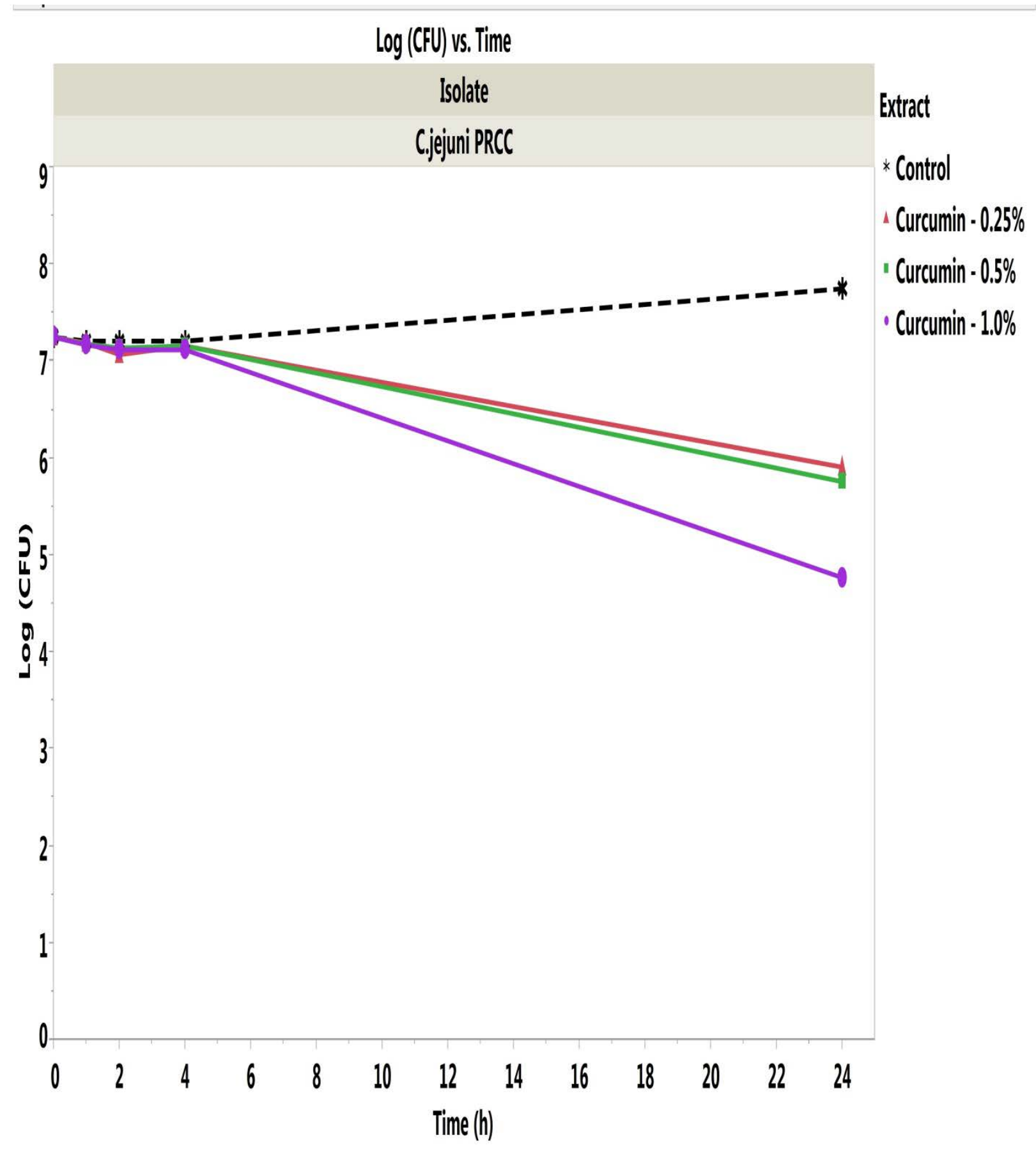

Fig 3.14. Log CFU vs Time of curcumin extract at 3 different concentrations against C.jejuni PRCC. Curcumin 1\% was found to be effective among the three concentrations and showed a 3log reduction in 24 hours of incubation whereas $0.25 \%$ and $0.5 \%$ concentrations showed a 2 log decrease in growth. 


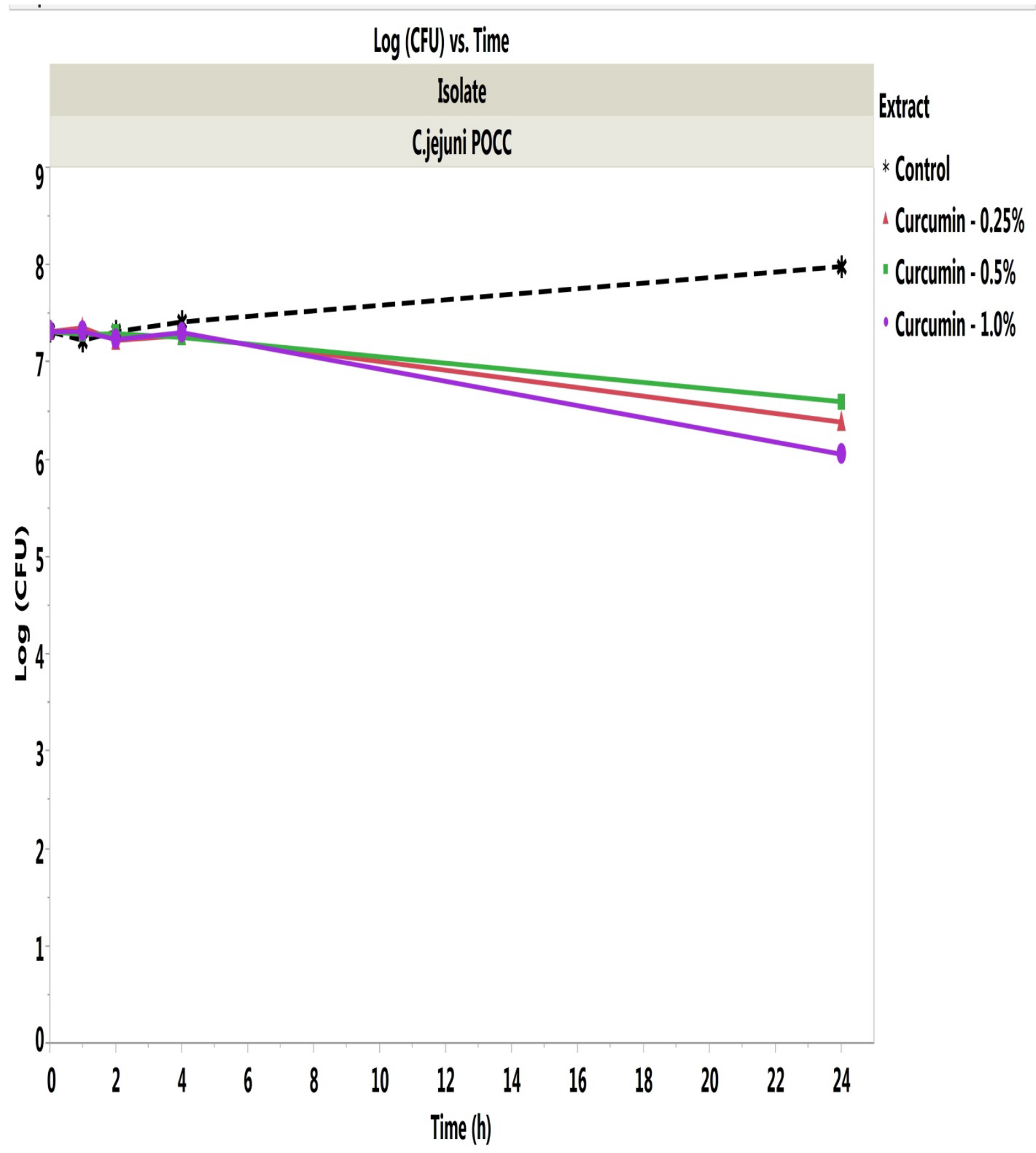

Fig 3.15. Log CFU vs Time of curcumin extract at 3 different concentrations against C.jejuni POCC. Curcumin 1\% showed a 2- log reduction in 24 hours of incubation. 


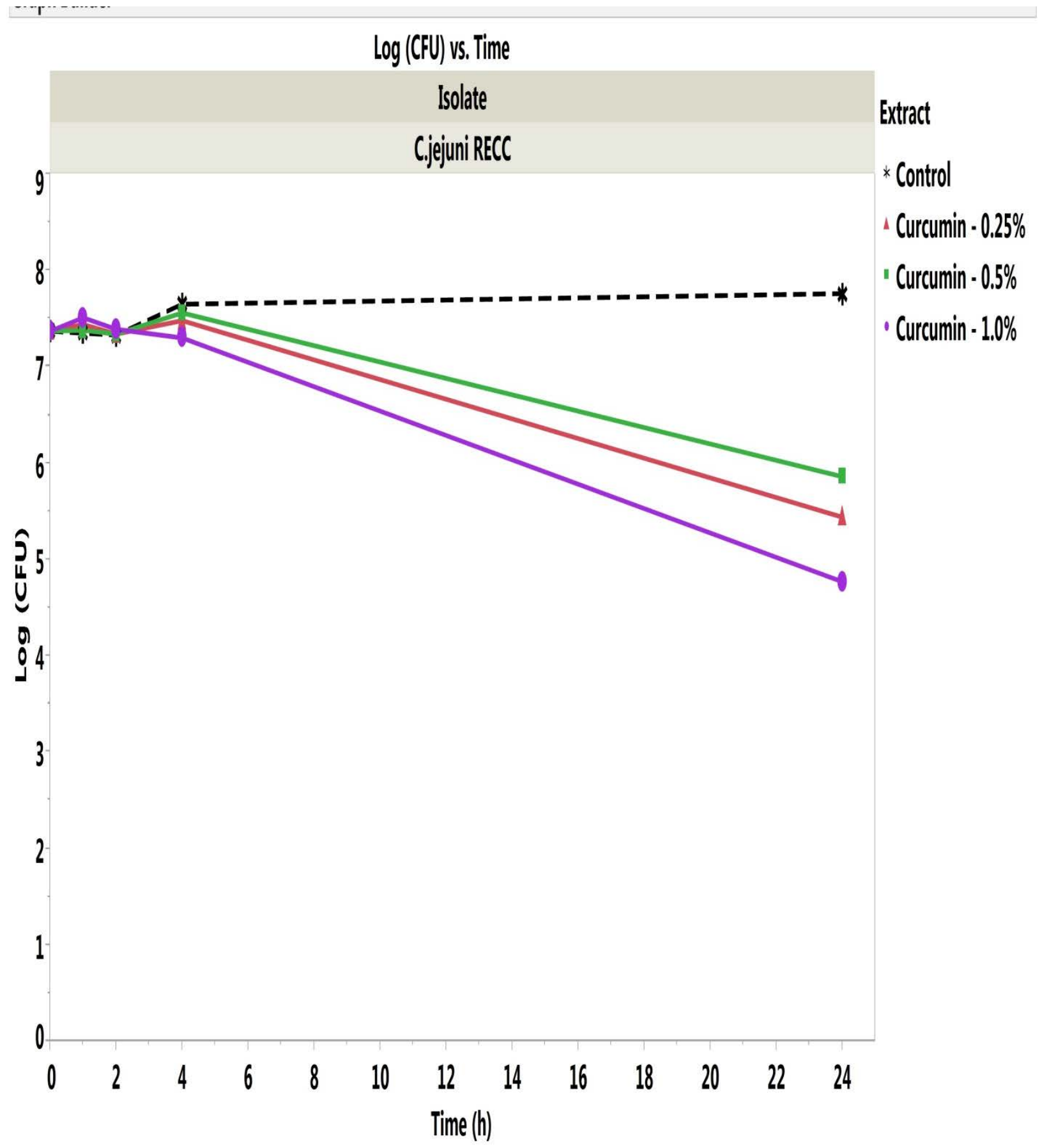

Fig 3.16. Log CFU vs Time of curcumin extract at 3 different concentrations against C.jejuni RECC. Curcumin 1\% showed a 3- log decrease in 24 hours of incubation. Curcumin $0.25 \%$ and $0.5 \%$ concentrations showed more than 2 - log reduction, in 24 hours. 


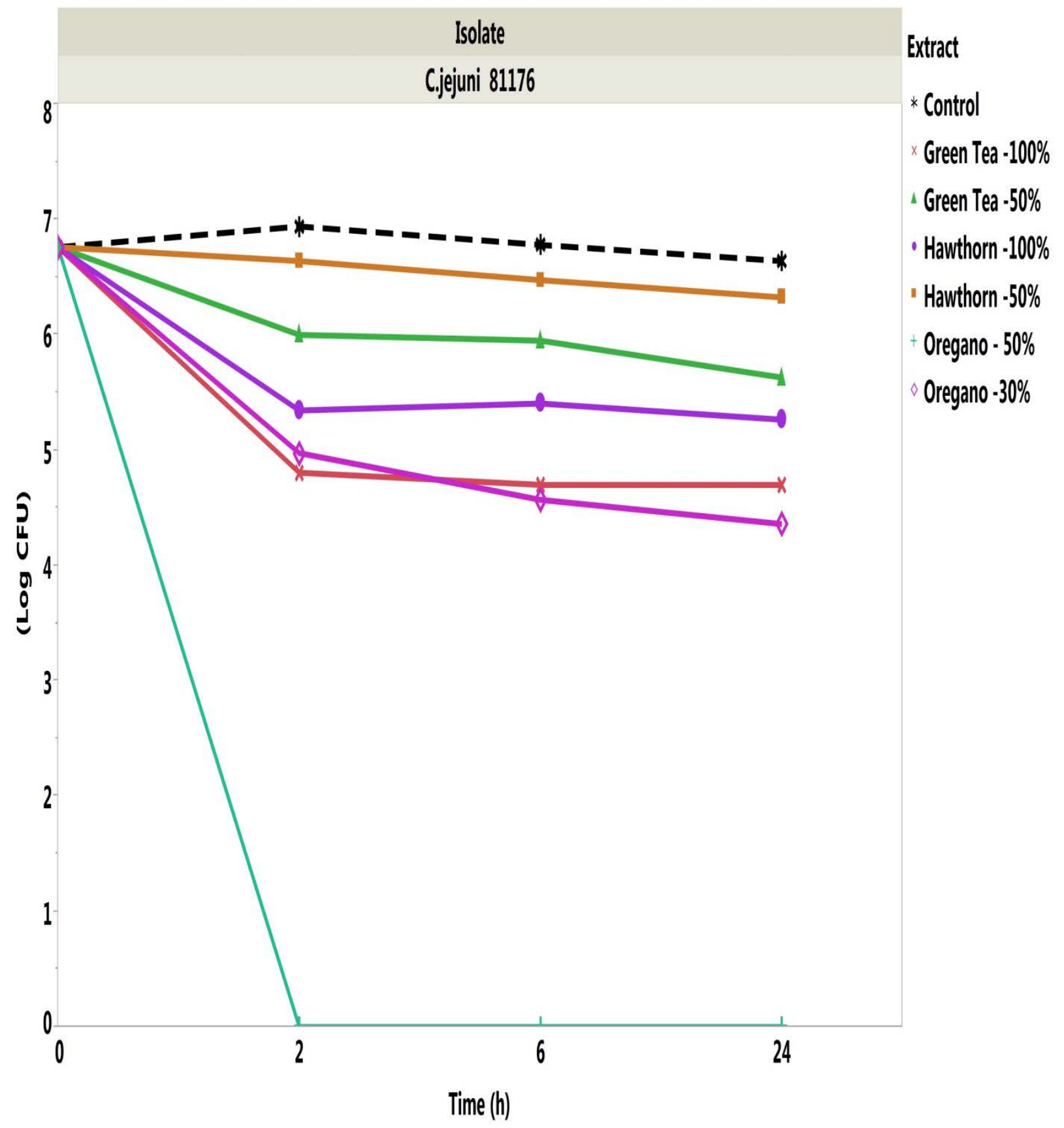

Fig 3.17. Log CFU vs Time of oregano, green tea and hawthorn extract marinated on chicken breast pieces at 2 different concentration levels against C.jejuni 81176. Oregano at 50\% succeeded in killing all bacteria within 2 hours of incubation resulting in a 6- log reduction ( $\mathrm{P}$ $<0.05$ ) whereas oregano $30 \%$ showed a 2 - log decrease in 24 hours. Green tea $100 \%$ showed 2$\log$ reduction whereas green tea $50 \%$ and hawthorn $100 \%$ showed a 1 - log reduction in 2 hours of incubation. 


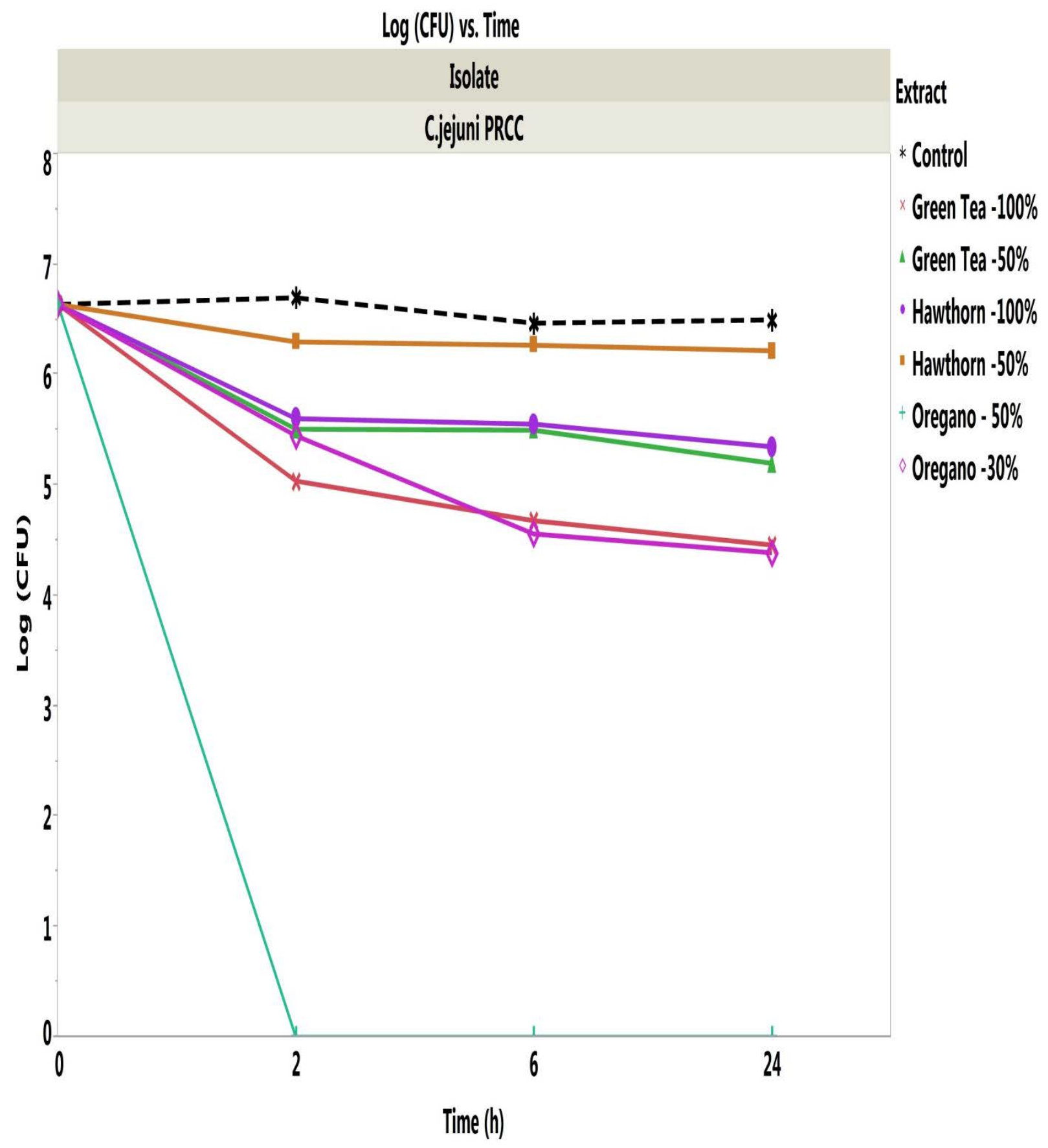

Fig 3.18. Log CFU vs Time of oregano, green tea and hawthorn extract on chicken breast pieces at 2 different concentration levels against C.jejuni PRCC. Oregano at 50\% was the most effective of the extracts which succeeded in killing all bacteria within 2 hours of incubation $(\mathrm{P}<0.05)$. 


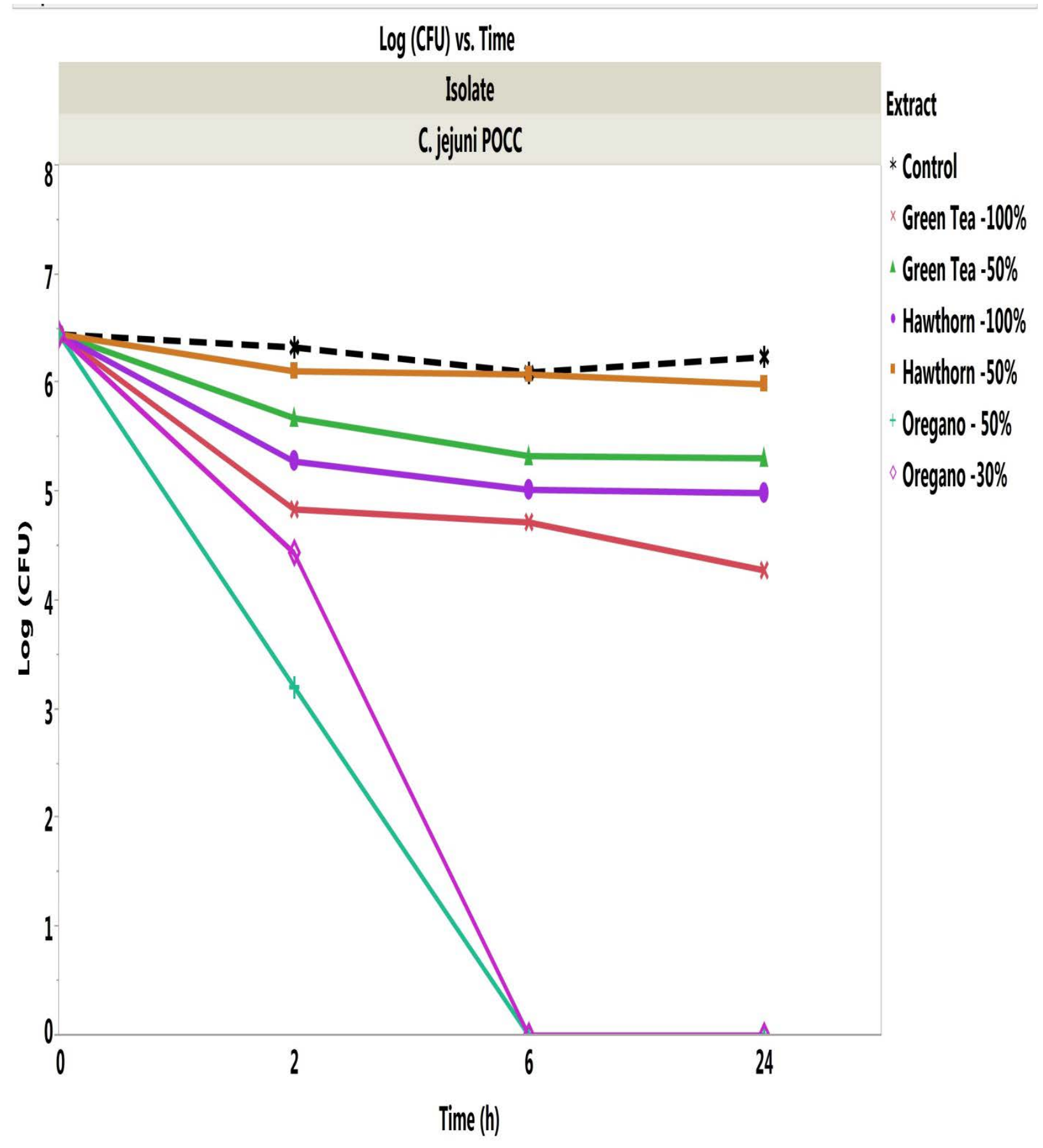

Fig 3.19. Log CFU vs Time of oregano, green tea and hawthorn extract on chicken breast pieces at 2 different concentrations against C.jejuni POCC. Oregano at 30\% and 50\% succeeded in killing all bacteria within 6 hours of incubation $(\mathrm{P}<0.05)$. 


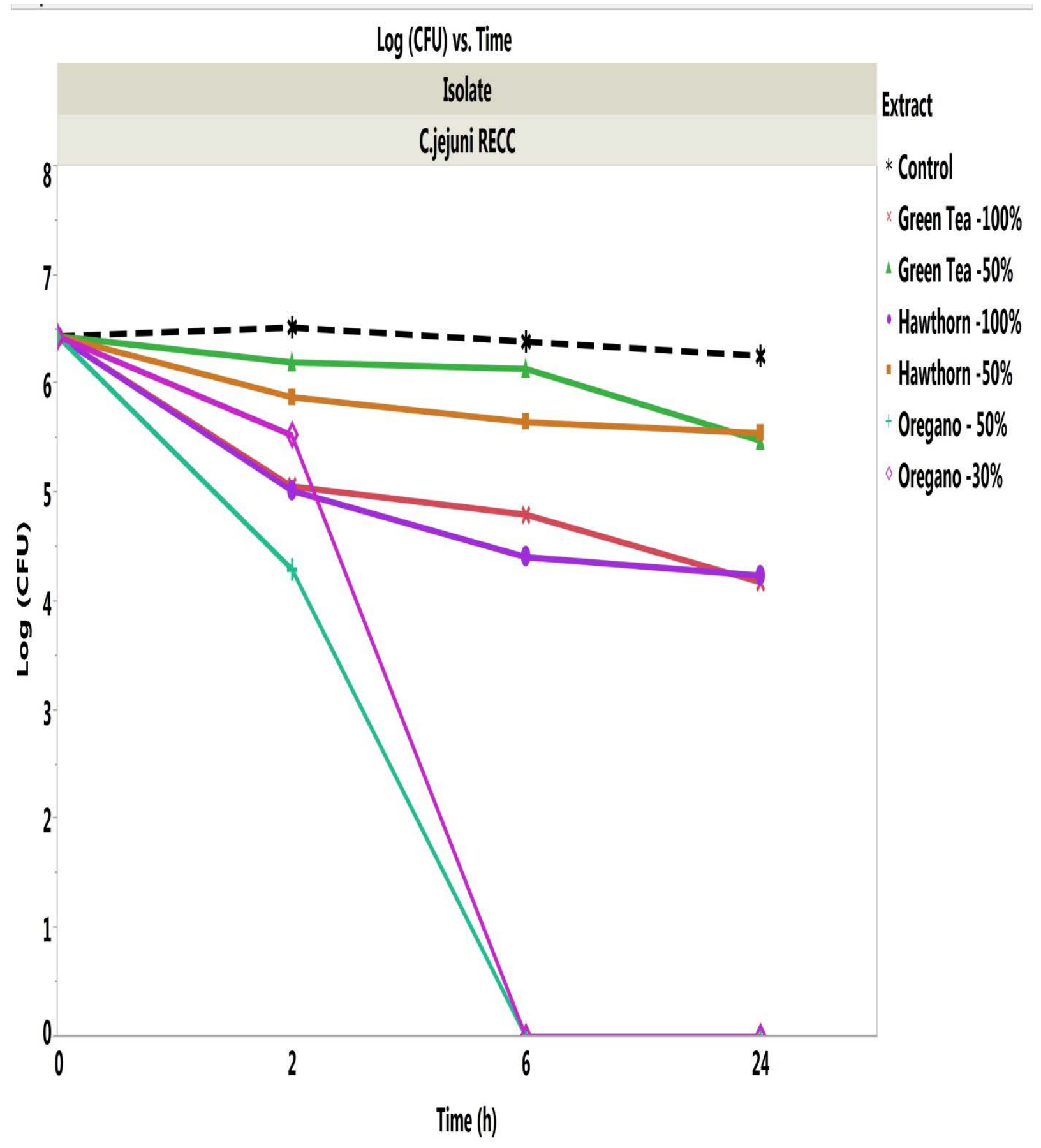

Fig 3.20. Log CFU vs Time of oregano, green tea and hawthorn extract on chicken breast pieces at 2 different concentrations against C.jejuni RECC. Oregano at 30\% and 50\% succeeded in killing all bacteria within 6 hours of incubation $(\mathrm{P}<0.05)$. 
Table 3.1. Log CFU at $2 \mathrm{hr} / 24 \mathrm{hr}$ time point for Oregano and Green Tea to determine concentrations that reduced bacteria over a 2 hour period in chicken breast fillet compared to in vitro studies. The maximum concentration that effectively killed bacteria within 24 hours in all strains tested was the starting point for meat model study.

\begin{tabular}{|c|c|c|c|c|}
\hline \multirow{2}{*}{$\begin{array}{l}\text { PLANT } \\
\text { EXTRACTS }\end{array}$} & \multicolumn{2}{|c|}{ C.jejuni 81176 - Log CFU } & \multicolumn{2}{|c|}{ C.jejuni PRCC - Log CFU } \\
\hline & 2 hour & 24 hour & 2 hour & 24 hour \\
\hline Control & 7 & 7 & 7 & 7 \\
\hline Green Tea - 1\% & 6 & 5 & 6 & 6 \\
\hline Green Tea - 5\% & 7 & 7 & 7 & 7 \\
\hline $\begin{array}{l}\text { Green Tea - } \\
10 \%\end{array}$ & 7 & 7 & 7 & 7 \\
\hline $\begin{array}{l}\text { Green Tea - } \\
20 \%\end{array}$ & 7 & 7 & 7 & 7 \\
\hline Oregano - $1 \%$ & 6 & 5 & 6 & 5 \\
\hline Oregano - $5 \%$ & 7 & 7 & 7 & 7 \\
\hline Oregano - $10 \%$ & 7 & 7 & 7 & 7 \\
\hline Oregano - 20\% & 7 & 7 & 6 & 7 \\
\hline
\end{tabular}




\section{REFERENCES}

Altekruse, S. F., Stern, N. J., Fields, P. I., \& Swerdlow, D. L. (1999). Campylobacter jejuni--an emerging foodborne pathogen. Emerging infectious diseases, 5(1), 28.

Benli, M., Yiğit, N., Geven, F., Güney, K., \& Bingöl, Ü. (2008). Antimicrobial activity of endemic Crataegus tanacetifolia (Lam.) Pers and observation of the inhibition effect on bacterial cells. Cell biochemistry and function, 26(8), 844-851.

Beyond Standardization. (2014). Retrieved September 27, 2014, from http://www.gaiaherbs.com/pages/process_step/11/Beyond-Standardization

Burt, Sara. "Essential oils: their antibacterial properties and potential applications in foods-a review." International journal of food microbiology 94.3 (2004): 223-253.

Chattopadhyay, I., Biswas, K., Bandyopadhyay, U., \& Banerjee, R. K. (2004). Turmeric and curcumin: Biological actions and medicinal applications. Current science, 87(1), 44-53.

Davidson, P. M., Critzer, F. J., \& Taylor, T. M. (2013). Naturally occurring antimicrobials for minimally processed foods. Annual review of food science and technology, 4, 163-190.

Diker, K. S., Akan, M., Hascelik, G., \& Yurdakök, M. (1991). The bactericidal activity of tea against Campylobacter jejuni and Campylobacter coli. Letters in Applied microbiology, 12(2), 34-35.

Friedman, M., Henika, P. R., \& Mandrell, R. E. (2002). Bactericidal activities of plant essential oils and some of their isolated constituents against Campylobacter jejuni, Escherichia coli, Listeria monocytogenes, and Salmonella enterica. Journal of Food Protection, 65(10), 15451560.

Friedman, M., Henika, P. R., Levin, C. E., Mandrell, R. E., \& Kozukue, N. (2006). Antimicrobial activities of tea catechins and theaflavins and tea extracts against Bacillus cereus. Journal of Food Protection, 69(2), 354-361.

Galgóczy, L., Hevér, T., Orosz, L., Krisch, J., Vágvölgyi, C., Tölgyesi, M., \& Papp, T. (2009). Growth inhibition effect of fruit juices and pomace extracts on the enteric pathogens Campylobacter jejuni and -Salmonella ser. Typhimurium.The Internet Journal of Microbiology, 7.

Gramza, A., Khokhar, S., Yoko, S., Gliszczynska-Swiglo, A., Hes, M., \& Korczak, J. (2006). Antioxidant activity of tea extracts in lipids and correlation with polyphenol content. European journal of lipid science and technology,108(4), 351-362. 
Hamilton-Miller, J. M. (1995). Antimicrobial properties of tea (Camellia sinensis L.). Antimicrobial agents and chemotherapy, 39(11), 2375.

Hayek, S. A., Gyawali, R., \& Ibrahim, S. A. (2013). Antimicrobial Natural Products.

Hughes, R. A., Cogan, T., \& Humphrey, T. (2010). Exposure of Campylobacter jejuni to $6^{\circ}$ C: Effects on Heat Resistance and Electron Transport Activity. Journal of Food Protection, 73(4), 729-733.

Jayasena, D.D. and Jo, C., “Essential oils as potential antimicrobial agents in meat and meat products: A Review”, Trends in Food Science and Technology, 34(2) December 2013, Pages 96108.

Kollannor, J. A., Darre, M. J., Donoghue, A. M., Donoghue, D. J., \& Venkitanarayanan, K. (2010). Antibacterial effect of trans-cinnamaldehyde, eugenol, carvacrol, and thymol on Salmonella Enteritidis and Campylobacter jejuni in chicken cecal contents in vitro. Journal of Applied Poultry Research, 19, 237-244.

Low+Low Method. (2014). Retrieved September 27, 2014, from

http://www.gaiaherbs.com/pages/process_step/6/Low-Low-Method

Mabe, K., Yamada, M., Oguni, I., \& Takahashi, T. (1999). In vitro and in vivo activities of tea catechins against Helicobacter pylori. Antimicrobial agents and chemotherapy, 43(7), 17881791.

Možina, S. S., Kurinčič, M., Klančnik, A., \& Mavri, A. (2011). Campylobacter and its multiresistance in the food chain. Trends in Food Science \& Technology, 22(2), 91-98.

Murali, N., Kumar-Phillips, G. S., Rath, N. C., Marcy, J., \& Slavik, M. F. (2012). Effect of marinating chicken meat with lemon, green tea and turmeric against food borne bacterial pathogens. International Journal of Poultry Science, 11(5), 326-332.

Niamsa, N., \& Sittiwet, C. (2009). Antimicrobial activity of Curcuma longa aqueous extract. Journal of Pharmacology and Toxicology, 4(4), 173-177.

Perumalla, A. V. S., \& Hettiarachchy, N. S. (2011). Green tea and grape seed extracts-Potential applications in food safety and quality. Food Research International, 44(4), 827-839.

Rice-Evans, C., Miller, N., \& Paganga, G. (1997). Antioxidant properties of phenolic compounds. Trends in plant science, 2(4), 152-159.

Right+Right Method. (2014). Retrieved September 27, 2014, from http://www.gaiaherbs.com/pages/process_step/5/Right-Right-Method 
Sakanaka, S., Juneja, L. R., \& Taniguchi, M. (2000). Antimicrobial effects of green tea polyphenols on thermophilic spore-forming bacteria. Journal of bioscience and bioengineering, 90(1), 81-85.

Škrinjar, M. M., \& Nemet, N. T. (2009). Antimicrobial effects of spices and herbs essential oils. Acta periodica technologica, (40), 195-209.

Tadić, V. M., Dobrić, S., Marković, G. M., Đorđević, S. M., Arsić, I. A., Menković, N. R., \& Stević, T. (2008). Anti-inflammatory, gastroprotective, free-radical-scavenging, and antimicrobial activities of hawthorn berries ethanol extract. Journal of agricultural and food chemistry, 56(17), 7700-7709.

Venkitanarayanan, K., Kollanoor-Johny, A., Darre, M. J., Donoghue, A. M., \& Donoghue, D. J. (2013). Use of plant-derived antimicrobials for improving the safety of poultry products. Poultry science, 92(2), 493-501.

Wang, H., Provan, G. J., \& Helliwell, K. (2000). Tea flavonoids: their functions, utilisation and analysis. Trends in Food Science \& Technology, 11(4), 152-160.

Wang, Y., Lu, Z., Wu, H., \& Lv, F. (2009). Study on the antibiotic activity of microcapsule curcumin against foodborne pathogens. International journal of food microbiology, 136(1), 7174 .

Witkowska, A. M., Hickey, D. K., Alonso-Gomez, M., \& Wilkinson, M. (2013). Evaluation of antimicrobial activities of commercial herb and spice extracts against selected food-borne bacteria. Journal of Food Research, 2(4), p37.

Zhao, H. C., \& Tian, B. F. (1996). China fruit-plant monograph, hawthorn flora. Zhongguo Lin Ye Press, Beijing, 14. 
CHAPTER 4

CONCLUSION 
The overall aim of this study was to determine the antibacterial activity of commercially available plant extracts on selected strains of $C$. jejuni. The study involved testing these extracts against the strains of bacteria initially in broth culture and then in chicken meat model. It was found that higher concentrations were required to kill the bacteria in meat as compared to broth study. Future studies would involve isolating individual components of each of the extracts determining the dominant antibacterial component with minimal inhibitory concentrations. Combinations of plant extracts have to be explored to resolve the problem of high concentration required to inhibit $C$. jejuni strains in meat. 
APPENDIX A1

EFFECT OF CURCUMIN MARINADE IN MEAT 


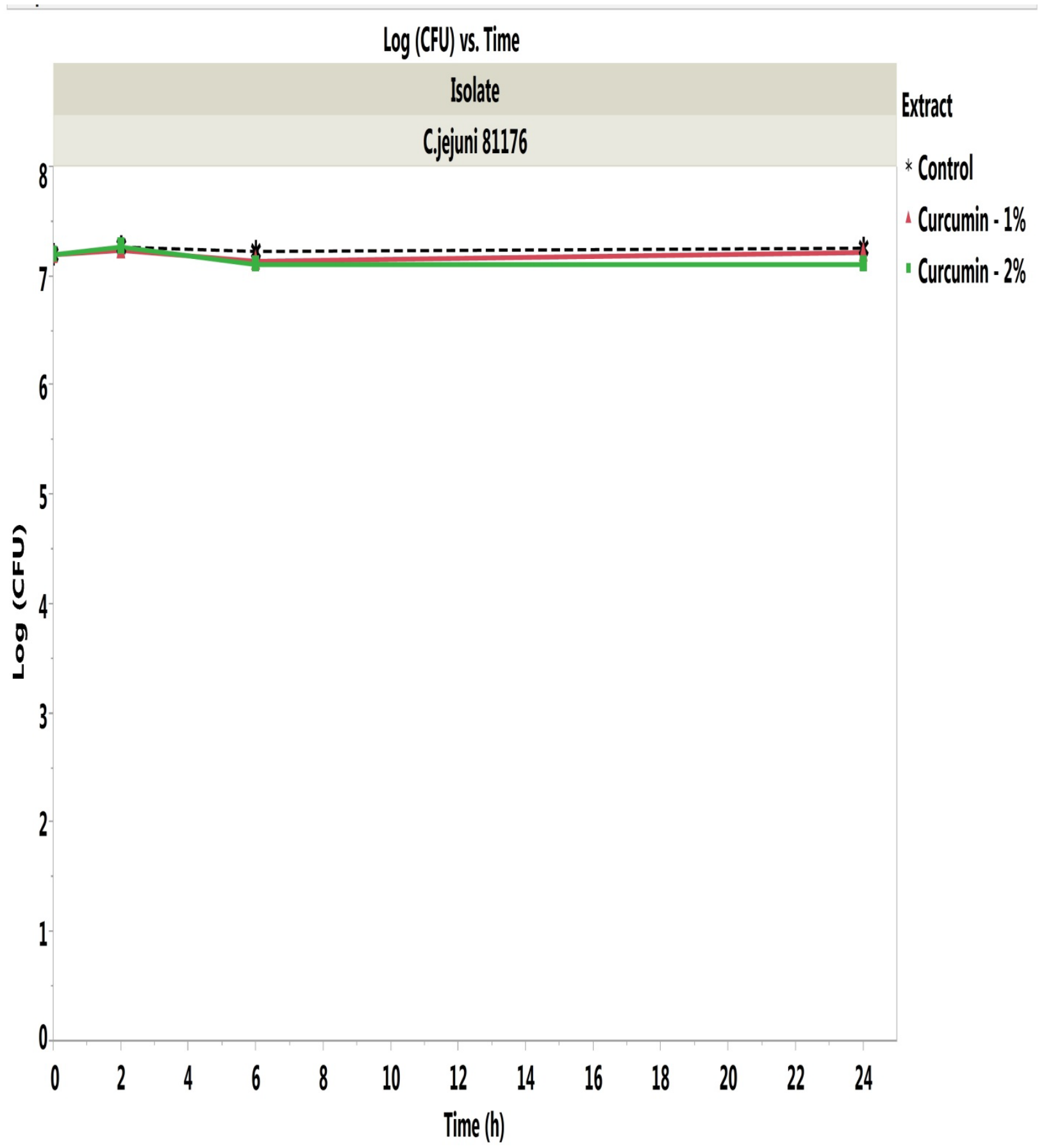

Figure A1.1. Log CFU vs Time of curcumin at 2 different concentrations against C.jejuni 81176. Curcumin was not effective at reducing or killing the bacteria within 24 hours. 


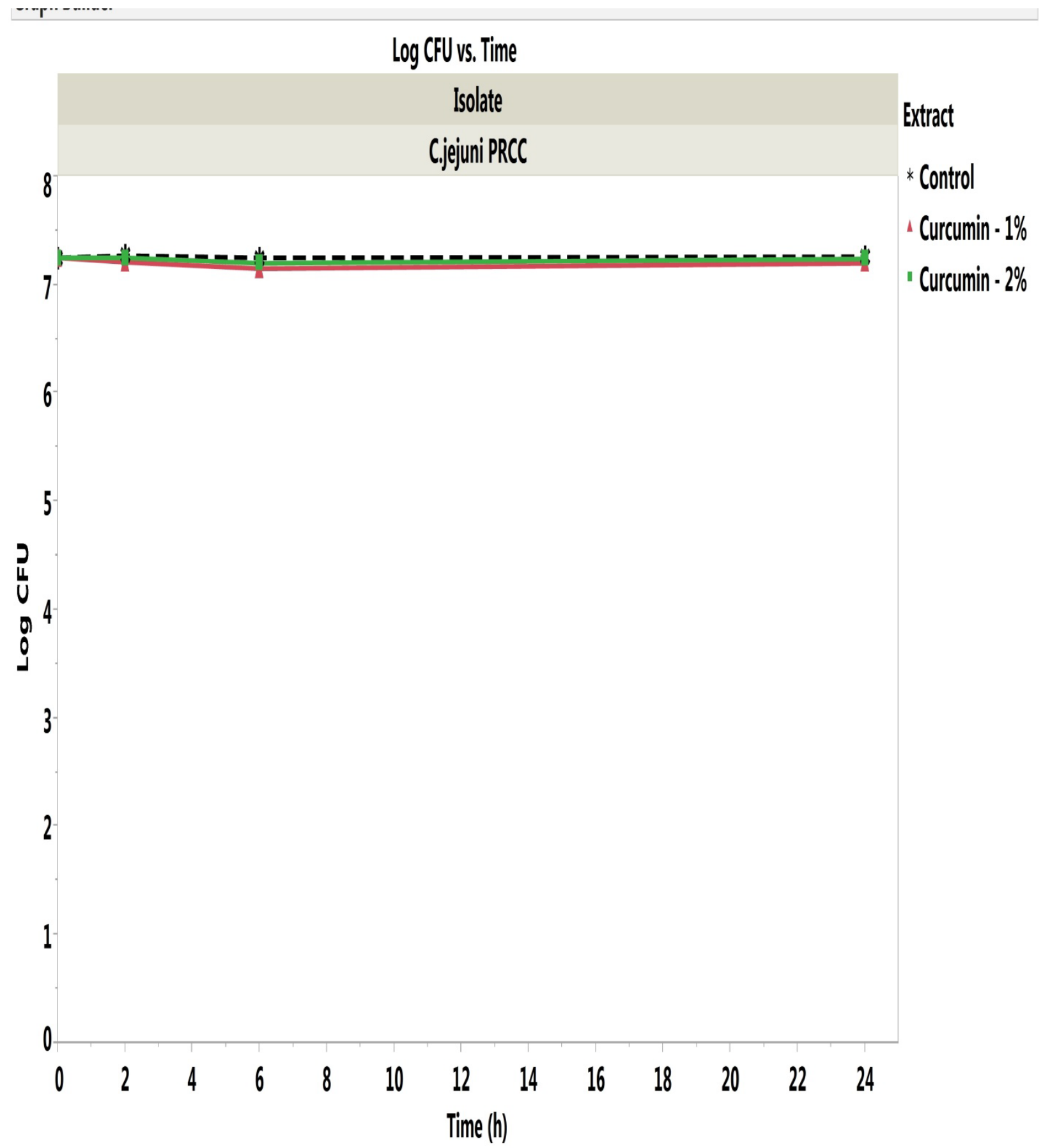

Figure A1.2. Log CFU vs Time of curcumin at 2 different concentrations against C.jejuni PRCC. Curcumin was not effective at reducing or killing the bacteria within 24 hours. 


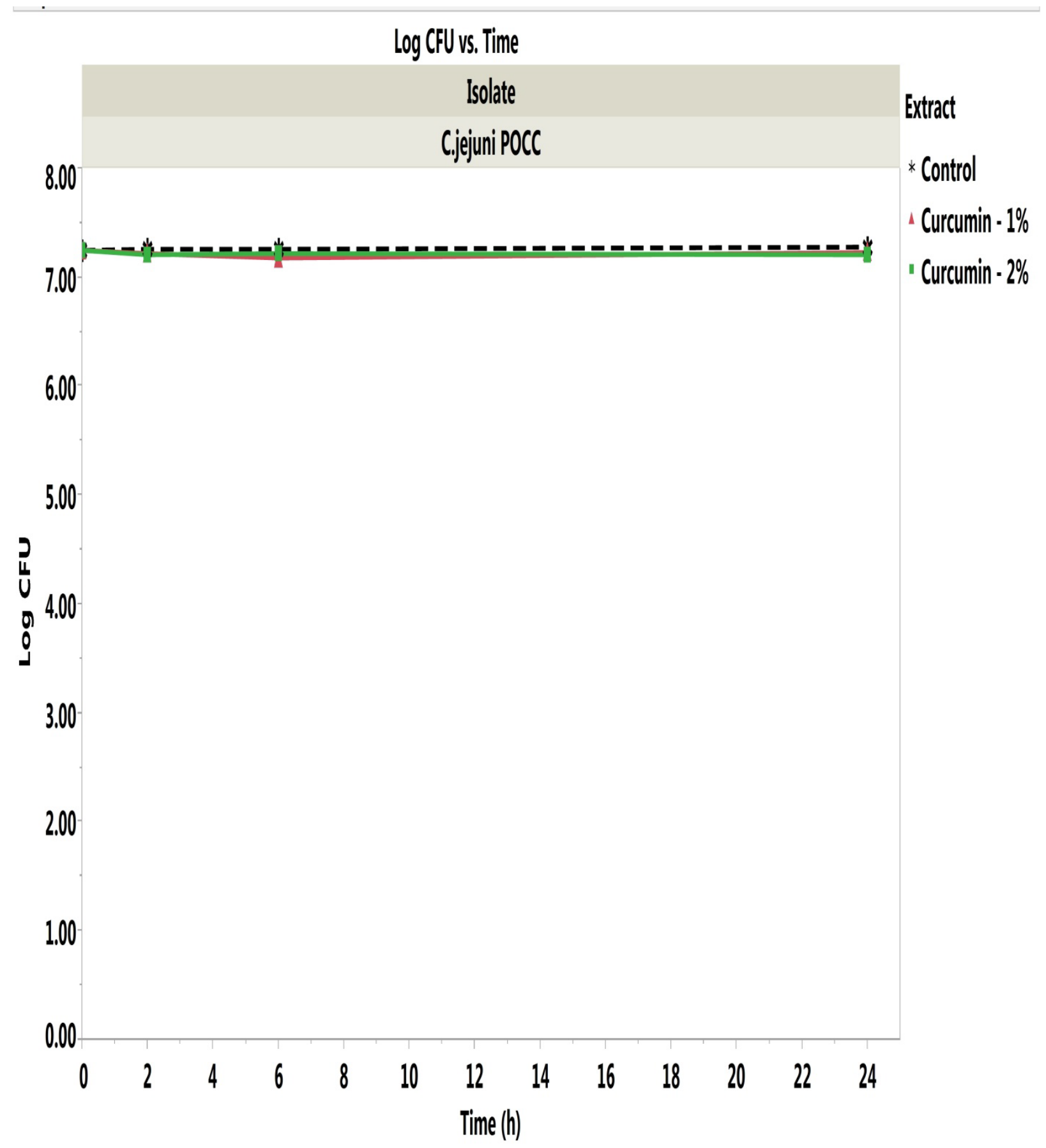

Figure A1.3. Log CFU vs Time of curcumin at 2 different concentrations against C.jejuni POCC. Curcumin was not effective at reducing or killing the bacteria within 24 hours. 


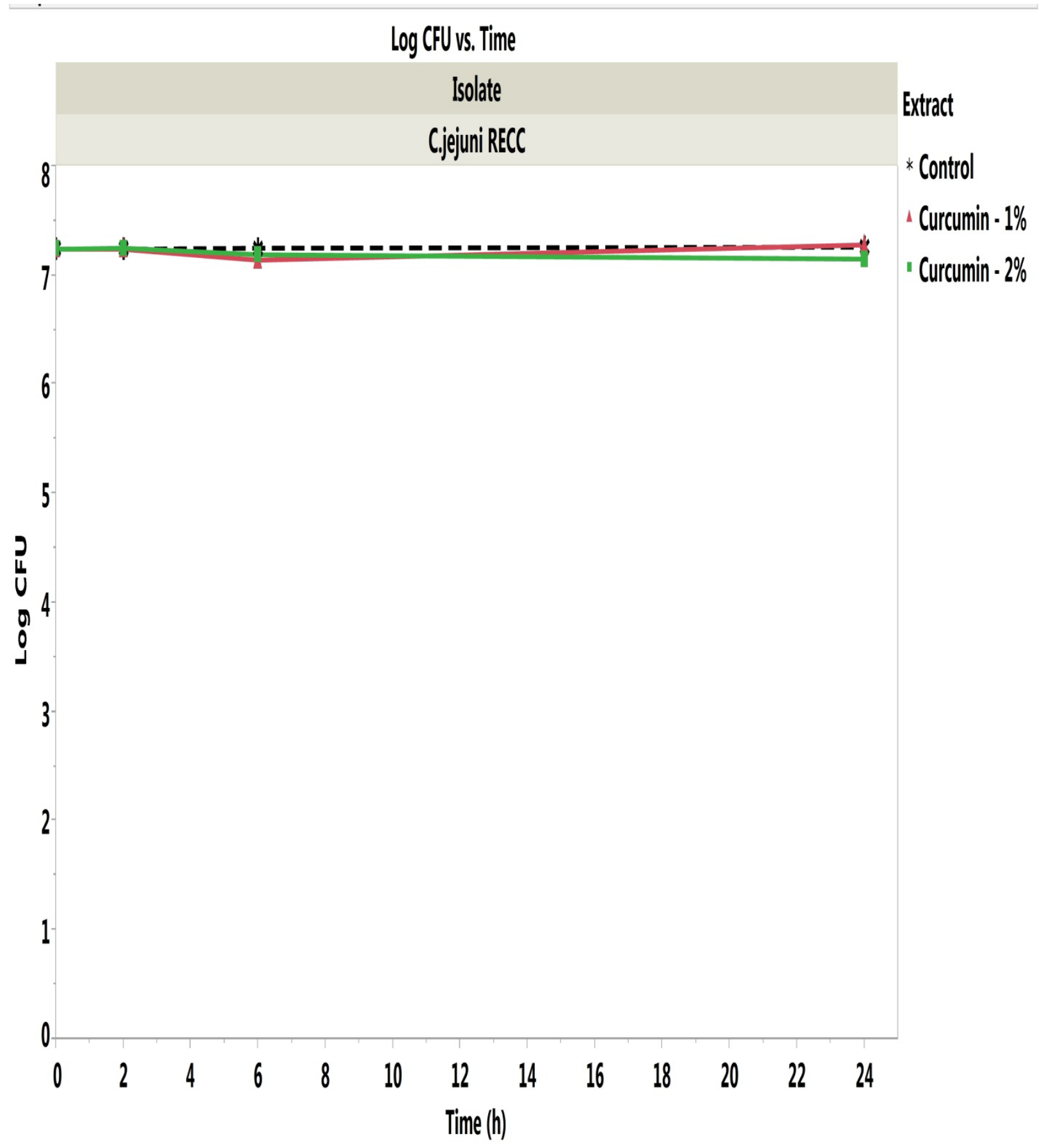

Figure A1.4. Log CFU vs Time of curcumin at 2 different concentrations against C.jejuni RECC. Curcumin was not effective at reducing or killing the bacteria within 24 hours. 
APPENDIX A2

COMMERCIALLY AVAILABLE EXTARCTS PRODUCTION PROCESS 


\section{INTRODUCTION}

The plant extracts are extracted from the different parts of the plants using various methods and are purified to meet high standards required of commercial products.

\section{METHODS}

\section{Right + Right Method* [2]}

If constituents are water soluble the extracts are extracted by dissolving in water otherwise hydroethanolic extraction processes are used. If fat soluble constituents are required to be captured a supercritical extraction technique is used.

\section{Low + Low method* [1]}

Once the bioactive constituents of the herbs have been extracted, the extracts are then highly concentrated with low + low method-low temperature in combination with low atmospheric pressure - to protect the fragile, subtle vital forces of each plant.

Preserving the full chemical makeup requires a slow, careful concentration technique involving low temperature and low atmospheric pressure.

The low + low method of concentration uses a low atmospheric pressure of 24 millibars (versus the Earth's standard sea level pressure of 1,013.25 millibars) that allows the water and alcohol to evaporate slowly (much more slowly than other conventional concentration methods), while a low temperature of $60^{\circ} \mathrm{C}\left(140^{\circ} \mathrm{F}\right.$, nearly $75^{\circ}$ below water's boiling point of $\left.212^{\circ} \mathrm{F} / 100^{\circ} \mathrm{C}\right)$ prevents any volatile, subtle, natural compounds from being damaged. As it evaporates, the 
organic grain alcohol is recaptured and purified, creating a closed-loop system in which no alcohol evaporates into the environment.

\section{EXTRACTS}

\section{Oregano Leaf Extract}

- $333 \mathrm{mg} / \mathrm{ml}$ herb equivalency

- Extraction method is Right+ Right

\section{Green Tea Leaf Extract}

- $500 \mathrm{mg} / \mathrm{ml}$ herb equivalency

- Extraction method is Right+ Right

- Low + Low Concentration method

\section{Hawthorn berry, flower and leaf}

- $667 \mathrm{mg} / \mathrm{ml}$ herb equivalency

- Extraction method is Right+ Right

- Low + Low Concentration method

\section{Curcumin}

- $95 \%$ total curcuminoid content from turmeric rhizome 


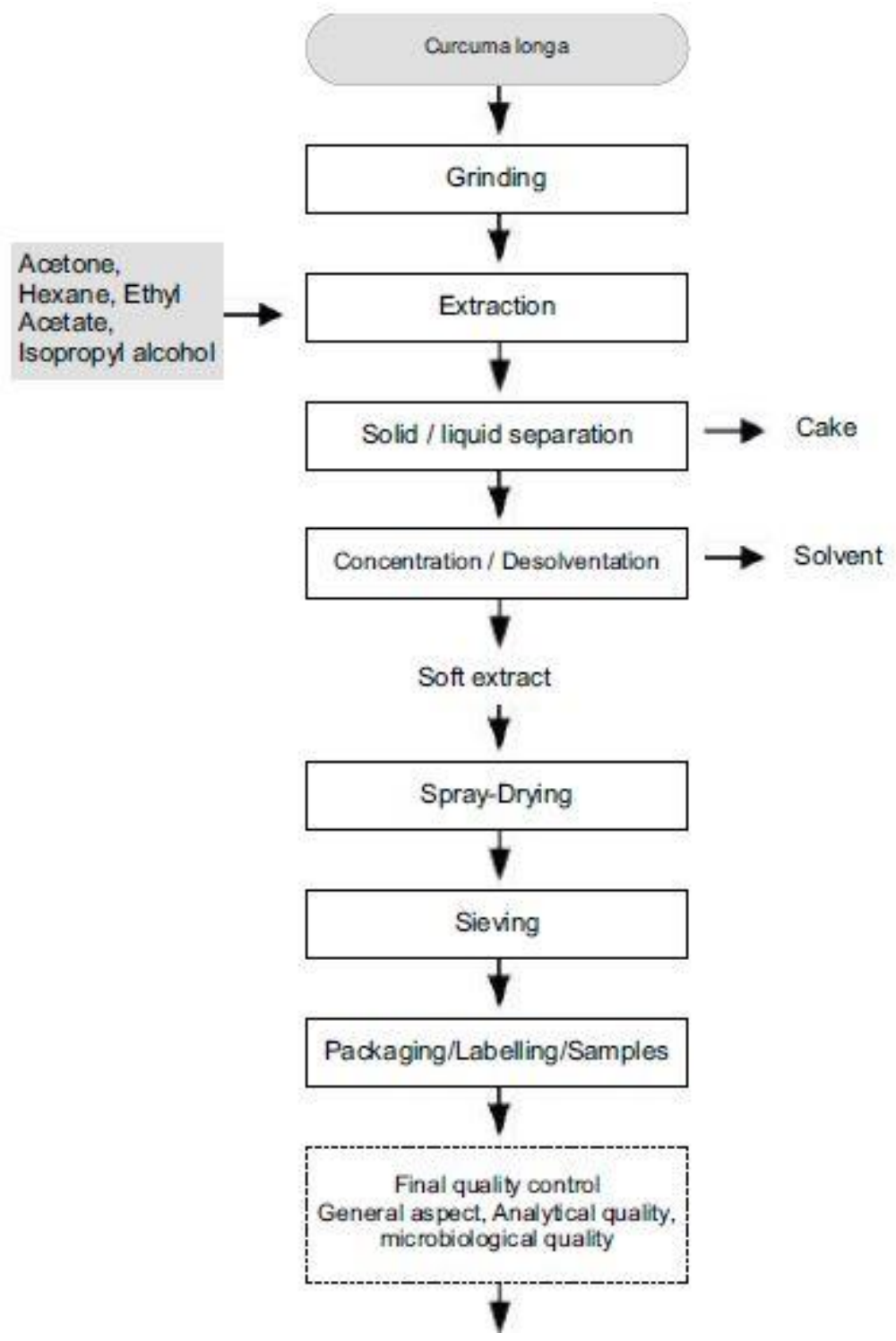

Figure A2.1 Curcumin commercial extraction process** (Source: G.Harris, personal communication, April 16, 2014) 


\section{REFERNCES}

1. Low + Low Method. Retrieved August 31, 2014, from http://www.gaiaherbs.com/pages/process_step/6/Low-Low-Method

2. Right + Right Method. Retrieved August 31, 2014, from http://www.gaiaherbs.com//pages/process_step/5/RightRight-Method 